UNIVERSIDADE DE SÃO PAULO

FACULDADE DE MEDICINA DE RIBEIRÃO PRETO

DEPARTAMENTO DE PUERICULTURA E PEDIATRIA

LETÍCIA FERRO LEAL

"Via Wnt/ $\beta$-catenina em

tumores adrenocorticais pediátricos"

Ribeirão Preto 


\section{LETÍCIA FERRO LEAL}

\section{"Via Wnt/ $\beta$-catenina em tumores adrenocorticais pediátricos"}

Dissertação apresentada à Faculdade de Medicina de Ribeirão Preto da Universidade de São Paulo para a obtenção do título de Mestre em Ciências Médicas.

Área de concentração: Saúde da criança e do adolescente

Opção: Investigação em Saúde da Criança e do Adolescente

Orientador:

Prof. Dr. Sonir Roberto Rauber Antonini

Ribeirão Preto 
Autorizo a reprodução e divulgação total ou parcial deste trabalho, por qualquer meio convencional ou eletrônico, para fins de estudo e pesquisa, desde que citada a fonte.

\section{Catalogação da Publicação}

Preparada pela Biblioteca do Serviço de Biblioteca e Documentação

Faculdade de Medicina de Ribeirão Preto

Universidade de São Paulo

Leal, Letícia Ferro

Via Wnt/ $\beta$-catenina em tumores adrenocorticais pediátricos. Ribeirão Preto, 2011.

117 p. : il. ; $30 \mathrm{~cm}$

Dissertação de Mestrado, apresentada à Faculdade de Medicina de Ribeirão Preto/USP. Área de concentração: Saúde da Criança e do Adolescente.

Orientador: Antonini, Sonir.

1. Tumorigênese Adrenocortical. 2. Expressão Gênica.

3. Genes CTNNB1 e TP53. 4. Via Wnt/ $\beta$-catenina 
Nome: Leal, Letícia Ferro

Título: Via Wnt/ $\beta$-catenina em tumores adrenocorticais pediátricos

Dissertação apresentada à Faculdade de Medicina de Ribeirão Preto da Universidade de São Paulo para a obtenção do título de Mestre em Ciências Médicas.

Área de concentração: Saúde da criança e do adolescente

Opção: Investigação em Saúde da Criança e do Adolescente

\section{Aprovado em:}

\section{Banca Examinadora}

Prof. Dr.

Instituição:

Julgamento: Assinatura:

Prof. Dr. Instituição:

Julgamento: Assinatura:

Prof. Dr. Instituição:

Julgamento: Assinatura: 
"Os sonhos transformam a vida numa grande aventura. Eles não determinam o lugar aonde você vai chegar, mas produzem a força necessária para arrancá-lo do lugar em que você está." 
Dedicatória 
A meus pais, João Batista e Sandra, pais exemplares, por me apoiarem em todas as etapas da vida. 
Agradecimentos 
A meus pais, Sandra e João Batista, que sempre me deram suporte para tudo e que nunca me deixaram desistir, mesmo quando a vontade de voltar para casa era maior que a vontade de continuar, que me fizeram acreditar que vale a pena lutar por um sonho, mesmo sabendo da incerteza de realizá-lo. Acima de tudo, me mostraram que a fé é capaz de mover montanhas.

Ao meu irmão Glauco, por nunca me negar nada, por ter o melhor coração que pude conhecer e por me fazer sentir orgulho de ser sua irmã.

Ao meu orientador, que acreditou em mim, mesmo sem me conhecer e que continuou acreditando depois de conhecer. Por ter perdido tantas manhãs e tardes me ensinando o que eu já deveria saber, por ter tido, sempre, muita paciência. E, principalmente, por ter me feito crescer, como pessoa e como profissional.

Aos meus avós, Aparecida e Edgar, por torcerem sempre por mim, por darem coragem e me fazerem acreditar que sou capaz de alcançar tudo que quero.

Ao meu namorado, Luis Henrique, por saber me dividir com o trabalho, por compartilhar minhas conquistas como se fossem dele e por ter sido paciente sempre que o cansaço e a preocupação me deixavam dominar.

Aos que me ensinaram a dar os primeiros passos na biologia molecular Fernando, Fábio e Wendy. Em especial à Wendy, por ter sido muito mais que uma colega de trabalho, uma amiga, que sempre me encorajou e me estimulou nas horas em que era difícil continuar.

À Aniette Espiñeira, por ter sido um grande exemplo de força e determinação e por me fazer ter a certeza de que valeria a pena optar por fazer pós-graduação.

À Lidiane Soares Silos, minha amiga-irmã, que tanto me deu força, que enxugou minhas lágrimas, por sempre estar do meu lado e por me ter feito rir quando a única vontade era de chorar.

Aos meus amigos de pós-graduação e laboratório Ana Cláudia, Débora, Fernanda, Roberta, Carol, Silvia, Bia, Rogério, Leonardo, Renata, Leandro e Jucá, que fizeram do ambiente de trabalho um ambiente agradável e prazeroso de estar.

À Sabrina Paulo, por ter se tornado muito mais que uma amiga ou uma colega de trabalho, por cuidar de mim, pelas consultorias sobre quaisquer assuntos e por sido, por muitas vezes, "minha mãe" ou "mermã". 
À Lívia Mermejo, pela contribuição inestimável para este trabalho e, muito mais que isso, por ser minha amiga e minha médica, pelos conselhos quando precisei e pelos cuidados quando foram necessários.

Às minhas amigas de muitos anos, Cinthia, Marina, Paula, Luana e Bruna que mesmo de longe sempre estiveram tão perto.

Às amigas de pós-graduação Maria Lúcia, Patrícia e Camila por terem me dado o privilégio de trabalhar com elas durante nosso curso de pós-graduação no Departamento de Pediatria e por terem me proporcionado momentos tão agradáveis.

À Profa. Dra. Leandra Ramalho, por ser sempre tão solícita e por ter sido uma colaboradora de fundamental importância.

À Profa. Dra. Margaret de Castro, meu exemplo de dedicação, inteligência, sensatez e profissionalismo, por ter sido minha segunda orientadora e por me fazer acreditar que tudo sempre daria certo.

Ao Prof. Dr. Ayrton Moreira, pelo exemplo de vida e dedicação, pelos inúmeros ensinamentos, pelo apoio e incentivo em todos os momentos que envolveram desafios.

Ao Prof. Dr. Carlos Scrideli, pela parceria neste trabalho e por me ter me dado a honra de tê-lo em minha banca.

À Dra. Paula Elias, pelos esclarecimentos sobre diversos assuntos e pela paz que transmite a todos ao seu redor.

À equipe do Centro Infantil Boldrini, pela grande parceria neste trabalho.

Aos meus amigos do laboratório de Endocrinologia - Metabologia por terem me recebido tão bem quando cheguei ao Hospital das Clínicas, ainda na faculdade, em especial a Sebastião e Milena, que abriram as portas para que eu pudesse estagiar no laboratório e que me ensinaram muito mais que técnicas, me ensinaram lições que levarei por toda minha vida.

Aos meus amigos do laboratório de Endocrinologia - Imunoensaios José Roberto, Adriana e Mara, ótimos professores, por tanto terem me ensinado e por terem colocado em meu caminho o meu orientador, Prof. Dr. Sonir Antonini.

Às secretárias do Departamento de Puericultura e Pediatria, em especial à Sandra e Ana Lúcia, secretárias do programa de pós-graduação, por todo suporte que precisei durante o período de pós-graduação.

À CAPES, pelo apoio financeiro em todos estes meses de pós-graduação. 
A todos que, de alguma forma, contribuíram direta ou indiretamente para este trabalho.

Finalmente, e talvez o agradecimento mais importante, a Deus, por nunca ter me abandonado, por ser meu conforto nas horas mais difíceis e por ter colocado todas essas pessoas em minha vida. 
Resumo 
Leal LF. Via Wnt/ß-catenina em tumores adrenocorticais pediátricos. 2011. 117 f. Dissertação (Mestrado) - Faculdade de Medicina de Ribeirão Preto, Universidade de São Paulo, Ribeirão Preto, 2011.

Introdução: Em crianças das regiões Sul e Sudeste do Brasil há uma incidência elevada de tumores adrenocorticais (TAC). Anormalidades da $\beta$-catenina tem sido encontradas em TAC em adultos e sugerem a ativação da via Wnt/ $\beta$-catenina nestes tumores. No entanto, não há estudos avaliando o papel desta via em casuísticas de TAC pediátricos. Objetivos: Avaliar o papel da via Wnt/ $\beta$-catenina e mutações do gene $C T N N B 1$ na tumorigênese adrenocortical pediátrica. Indivíduos, Material e Métodos: Foram avaliados 62 pacientes pediátricos com TAC oriundos de dois centros de referência. Controles: córtex adrenal de indivíduos jovens com morte acidental. Avaliou-se a presença de mutação nos genes TP53 e CTNNB1. A expressão de genes da via Wnt (CTNNB1, o ligante WNT4, os inibidores SFRP1, DKK3 e AXIN1, o fator de transcrição TCF7 e os genes-alvo MYC e WISP2) foi avaliada por qPCR, utilizando-se o método de $2^{-\Delta \Delta \mathrm{Ct}}$. Adicionalmente, a expressão de proteínas da via Wnt/ß-catenina e P53 foi avaliada por imunoistoquímica. Avaliou-se a relação entre possíveis anormalidades moleculares com o fenótipo clínico e o desfecho. Resultados: A sobrevida geral foi maior em pacientes menores que 5 anos de idade $(\mathrm{p}<0.0001)$ e em pacientes com estágios tumorais menos avançados $(\mathrm{p}<0.0001)$. A mutação P53 p.R337H foi encontrada em $87 \%$ dos pacientes e não se associou com características clinicopatológicas ou desfecho. Mutações do gene CTNNB1 foram encontradas em 4/62 (6\%) TAC, todos carreadores da mutação P53 p.R337H. Houve associação entre óbito e presença de mutações do gene $C T N N B 1(\mathrm{p}=0,02)$. Acúmulo difuso da $\beta$-catenina foi observado em $71 \%$ dos TAC, a maioria sem mutações do CTNNB1. Comparados a adrenais normais, os TAC apresentaram aumento da expressão do RNAm de $C T N N B 1(\mathrm{p}=0.008)$ e diminuição da expressão de genes inibidores da via Wnt: DKK3 ( $<<0.0001), S F R P 1(\mathrm{p}=0.05)$ e AXIN1 ( $\mathrm{p}=0.04)$. Com relação aos genes-alvo da via Wnt/ $\beta$-catenina, TAC apresentaram expressão aumentada de WISP2 e baixa expressão de MYC. Maior sobrevida geral foi associada à expressão baixa de SFRP1 ( $\mathrm{p}=0.01)$, WNT4 $(\mathrm{p}=0.004)$ e $T C F 7(\mathrm{p}<0.01)$. Conclusões: Em TAC pediátricos, mutações somáticas ativadoras do gene $C T N N B 1$ são pouco freqüentes e parecem estar associadas à maior ocorrência de óbito. Mesmo na ausência de mutações do gene $C T N N B 1$, estes tumores apresentaram acúmulo de $\beta$-catenina e do gene-alvo WISP2 e expressão reduzida de inibidores da via Wnt (DKK3, SFRP1 e AXIN1). Estes dados demonstram evidências de anormalidades na via Wnt/ $\beta$-catenina em TAC pediátricos, mesmo na ausência de mutações do gene CTNNB1. É provável que outros eventos genéticos afetando a via $\mathrm{Wnt} / \beta$-catenina estejam envolvidos na tumorigênese adrenocortical pediátrica.

Palavras-chave: tumorigênese adrenocortical, expressão gênica, genes $C T N N B 1$ e TP53, Via Wnt- $\beta$ catenina. 
Abstract 
Leal LF. Wnt/ $\beta$-catenin signaling pathway in childhood adrenocortical tumors. 2011. $117 \mathrm{f}$. Dissertação (Mestrado) - Faculdade de Medicina de Ribeirão Preto, Universidade de São Paulo, Ribeirão Preto, 2011.

Context: $C T N N B 1$ mutations and activation of $\mathrm{Wnt} / \beta$-catenin pathway are frequent in adult adrenocortical tumors (ACTs) but data on childhood ACTs are lacking. Objective: To investigate Wnt/ $\beta$-catenin pathway abnormalities and CTNNB1 mutations in childhood ACTs. Patients and Methods: Clinicopathological findings and outcome of 62 childhood ACTs patients were analyzed regarding to $C T N N B 1 / \beta$-catenin mutations and to the expression of Wnt-related genes $(C T N N B 1$, a Wnt ligand: WNT4, Wnt inhibitors: $S F R P 1, D K K 3$ and $A X I N 1$, a transcription factor: TCF7, and target genes: MYC and WISP2) by qPCR and immunohistochemistry. Results: Overall survival (OS) was higher in patients younger than 5 years $(\mathrm{p}<0.0001)$ and associated with less advanced tumoral stage $(\mathrm{p}<0.0001)$. The p.R337H P53 mutation, found in $87 \%$ of the patients, was not associated with clinicopathological findings or outcome. CTNNB1 activating mutations were found in only 4/62 ACTs (6\%), all of them harboring TP53 mutation. There was association between the presence of CTNNB1 mutation and death $(\mathrm{p}=0.02)$. Diffuse $\beta$-catenin accumulation was found in $71 \%$ of ACTs, most of them without CTNNB1 mutation. CTNNB1 mutated ACTs presented weak/moderate $\beta$-catenin accumulation. Compared to normal adrenals, ACTs presented increased expression of CTNNB1 $(\mathrm{p}=0.008)$ and underexpression of Wnt inhibitor genes: DKK3 $(\mathrm{p}<0.0001)$, SFRP1 $(\mathrm{p}=0.05)$ and AXIN1 ( $\mathrm{p}=0.04)$. With regards to $\mathrm{Wnt} / \beta$-catenin target genes, ACTs presented lower expression of $M Y C$ but increased expression of WISP2. Higher overall survival was associated with underexpression of SFRP1 $(\mathrm{p}=0.01)$, WNT4 $(\mathrm{p}=0.004)$ and TCF7 $(\mathrm{p}<0.01)$. Conclusions: In childhood ACTs, CTNNB1 mutations are rare and appear to be associated with poor prognosis. Regardless of CTNNB1 mutations, these tumors presented reduced expression of Wnt inhibitor genes (DKK3, SFRP1 and AXIN1) and increased expression of $C T N N B 1$ and a target gene, WISP2. Thus, besides CTNNB1 mutations, additional genetic events affecting the Wnt/ $\beta$-catenin pathway may be involved in childhood adrenocortical tumorigenesis.

Key-words: adrenocortical tumorigenesis, gene expression, $C T N N B 1$ and TP53 genes, Wnt/ $\beta$-catenin signaling pathway. 
Siglas e Abreviaturas 
AAC: $\quad$ adenomas adrenocorticais

ACTB: $\quad$ beta actina

ACTH: $\quad$ Hormônio adrenocorticotrófico

AIMAH: $\quad$ Hiperplasia adrenal macronodular independente de ACTH

AMPc-PKA: $\quad$ Cyclin Adenosine MonoPhosphate-Protein Kinase A

APC: $\quad$ adenomatous polyposis coli

CAC: $\quad$ carcinomas adrenocorticais

cDNA: DNA complementar

CEMEL: $\quad$ Centro de Medicina Legal

CK1: $\quad$ casein kinase 1

COG: $\quad$ Children's Oncology Group

$\mathrm{Ct}: \quad$ cycle threshold

CTNNB 1: $\quad$ catenin (cadherin-associated protein), beta 1

DHEA-S: $\quad$ sulfato de di-hidro-epiandrosterona

DKK: $\quad$ Dickkopf

DNA: $\quad$ ácido desoxirribonucleico

DVL1: $\quad$ Dishevelled

EGFR: $\quad$ Epidermal growth factor receptor

GSK3: $\quad$ glycogen synthase kinase 3

GUSB: $\quad$ beta glucuronidase

H19: $\quad$ Imprinted maternally expressed transcript

HCFMRP-USP: Hospital das Clínicas da Faculdade de Medicina de Ribeirão Preto da Universidade de São Paulo

IGF: Insulin like factor

IGF1: $\quad$ Insulin like factor 1 (gene)

IGF1R: $\quad$ Insulin like factor 1 (gene)

IGF-1R: $\quad$ Insulin like factor receptor 1

IGF2: $\quad$ Insulin like factor 2 (gene)

IGF-I: $\quad$ Insulin like factor 1 (hormônio)

IHQ: $\quad$ imunoistoquímica

IPACTR: $\quad$ The International Pediatric Adrenocortical Tumor Registry

LFS: $\quad$ síndrome de Li-Fraumeni 
LOH: $\quad$ loss of heterozygosity

LRP: $\quad$ low density lipoprotein receptor-related protein

miRNA: microRNA

mRNA: $\quad$ RNA mensageiro

mTOR: mechanistic target of rapamycin (serine/threonine kinase)

MYC: $\quad$ v-myc myelocytomatosis viral oncogene homolog

NR5A2: $\quad$ nuclear receptor subfamily 5, group A, member 2

p21cip1: $\quad C D K N 1 A$, cyclin-dependent kinase inhibitor $1 A$

p57kip2: $\quad$ CDKN1C, cyclin-dependent kinase inhibitor $1 C$

P53: $\quad$ Tumor protein 53 (proteína)

PCR: $\quad$ reação de polimerase em cadeia

PCRq: $\quad$ reação de polimerase em cadeia quantitativa

PKA: $\quad$ Proteína Quinase A

PPNAD: $\quad$ Primary Pigmented Nodular Adrenocortical Disease

PRKARIA: protein kinase, cAMP-dependent, regulatory, type I, alpha

RNA: ácido ribonucléico

RT-PCR: $\quad$ reverse transcription PCR

SF1: $\quad$ Steroidogenic factor 1

SFRP1: $\quad$ secreted Frizzled-related protein 1

TAC: $\quad$ tumores adrenocorticais

TBP: $\quad$ TATA Box binding protein

TCF7: $\quad$ transcription factor 7 (T-cell specific, HMG box)

TP53: $\quad$ Tumor protein $p 53$ (gene)

WIF1: $\quad$ WNT inhibitory factor 1

WISP2: $\quad$ WNT1 inducible signaling pathway protein 2

Wnt: Wingless-type

$\beta$-Trcp: $\quad$ beta-transducin repeat containing

$\Delta \mathrm{Rn}: \quad$ variação de fluorescência 
Lista de Figuras 
Figura 1. Morfologia do córtex adrenal normal adulto

Figura 2. Morfologia do córtex adrenal normal fetal

Figura 3 (a-b). Sinalização da Via Wnt//-catenina

Figura 4. Distribuição dos TAC de acordo com o perfil de secreção hormonal

Figura 5. Sobrevida geral em pacientes com TAC de acordo com o estágio tumoral ao diagnóstico (Classificação de Sandrini)

Figura 6 (a-b). Mutação P53 p.R337H no DNA genômico (a) e no DNA tumoral (b) de paciente com TAC

Figura 7. Sobrevida em pacientes com TAC de acordo com a presença da mutação P53 p.R337H

Figura 8 (a-d). Seqüenciamento do cDNA do gene $C T N N B 1$, demonstrando as mutações identificadas em 4 TAC pediátricos

Figura 9 (a-e). Expressão do RNAm de CTNNB1 em TAC pediátricos e controles, de acordo com o estágio tumoral, de acordo com o padrão de secreção hormonal e em relação à presença da mutação $\mathrm{P} 53$ p.R337H e à presença de mutações no gene CTNNB1....

Figura 10 (a-e). Expressão do RNAm de $D K K 3$ em TAC pediátricos e controles, de acordo com o estágio tumoral, de acordo com o padrão de secreção hormonal e em relação à presença da mutação $\mathrm{P} 53$ p.R337H e à presença de mutações no gene $C T N N B 1$.

Figura 11 (a-e). Expressão do RNAm de SFRPI em TAC pediátricos e controles, de acordo com o estágio tumoral, padrão de secreção hormonal, em relação à presença da mutação $\mathrm{P} 53$ p.R337H, em relação à presença de mutações no gene CTNNB1

Figura 11 (f). Expressão do RNAm de $S F R P 1$ em TAC pediátricos em relação à sobrevida

Figura 12 (a-e). Expressão do RNAm de AXIN1 em TAC pediátricos e controles, de acordo com o estágio tumoral, de acordo com o padrão de secreção hormonal e em relação à presença da mutação $\mathrm{P} 53$ p.R337H e à presença de mutações no gene CTNNB1

Figura 13 (a-e). Expressão do RNAm de $M Y C$ em TAC pediátricos e controles, de acordo com o estágio tumoral, de acordo com o padrão de secreção hormonal e em relação à presença da mutação P53 p.R337H e à presença de mutações no gene CTNNB1

Figura 14 (a-f). Expressão do RNAm de TCF7 em TAC pediátricos e controles, de acordo com o estágio tumoral, padrão de secreção hormonal, em relação à presença da mutação P53 p.R337H, em relação à presença de mutações no gene CTNNB1 e sobrevida ... 62 
Figura 15 (a-e). Expressão do RNAm de WNT4 em TAC pediátricos e controles, de acordo com o estágio tumoral, padrão de secreção hormonal, em relação à presença da mutação P53 p.R337H, em relação à presença de mutações no gene CTNNB1

Figura 15 (f). Expressão do RNAm de WNT4 em TAC pediátricos em relação à sobrevida . 64

Figura 16 (a-e). Expressão do RNAm de TP53 em TAC pediátricos e controles, de acordo com o estágio tumoral, de acordo com o padrão de secreção hormonal e em relação à presença da mutação p.P53 R337H e à presença de mutações no gene CTNNB1

Figura 17 (a-e). Expressão do RNAm de $A P C$ em TAC pediátricos e controles, de acordo com o estágio tumoral, de acordo com o padrão de secreção hormonal e em relação à presença da mutação p.P53 R337H e à presença de mutações no gene CTNNB1

Figura 18 (a-e). Expressão do RNAm de WISP2 em TAC pediátricos e controles, de acordo com o estágio tumoral, de acordo com o padrão de secreção hormonal e em relação à presença da mutação p.P53 R337H e à presença de mutações no gene CTNNB1

Figura 19 (a-d). Correlação entre a expressão do RNAm de TP53 e alguns componentes da via Wnt/ $\beta$-catenina em TAC pediátricos

Figura 20. Imunoistoquímica para $\beta$-Catenina em TAC pediátrico e tecido adrenal normal adjacente

Figura 21. Imunoistoquímica para P53 em TAC pediátricos e tecido adrenal normal adjacente

Figura 22. Imunoistoquímica para DKK3 em TAC pediátrico e tecido adrenal normal adjacente

Figura 23. Imunoistoquímica para $\mathrm{MYC}$ em $\mathrm{TAC}$ pediátrico e tecido adrenal normal adjacente

Figura 24. Imunoistoquímica para WISP2 em TAC pediátrico e tecido adrenal normal adjacente

Figura 25. Estágio tumoral e desfecho em parte dos TAC de acordo com anormalidades de $\beta$-catenina e P53 
Lista de Tabelas 
Tabela 1. Estadiamento dos TAC de acordo com os critérios de Macfarlane modificado por Sullivan e critérios de Sandrini

Tabela 2. Oligonucleotídeos utilizados no sequenciamento do exon 10 do gene TP53...... 46

Tabela 3. Oligonucleotídeos utilizados no sequenciamento da região codificadora do CTNNB1

Tabela 4. Genes da via Wnt- $\beta /$ catenina e respectiva identificação dos ensaios utilizandos para realização das qPCR

Tabela 5. Desfecho clínico dos 62 pacientes portadores de TAC analisados de acordo estadiamento tumoral

Tabela 6. Características dos pacientes com TAC com mutações no gene CTNNB1 55 
Sumário 
1. Introdução

Embriologia, Histologia e Fisiologia da Córtex Adrenal ....................................................2

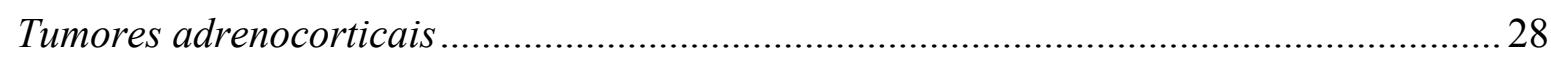

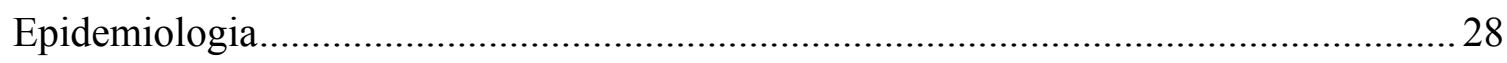

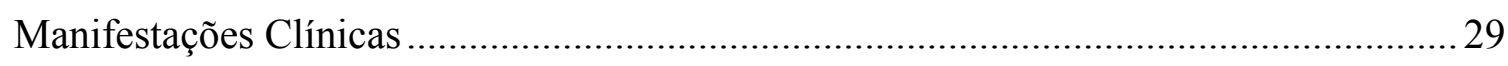

Classificação e Estadiamento Tumoral............................................................................. 30

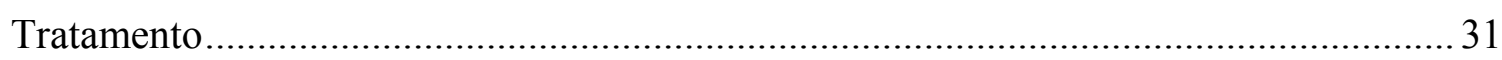

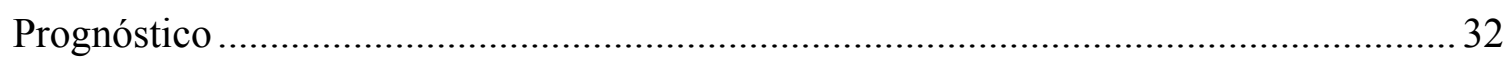

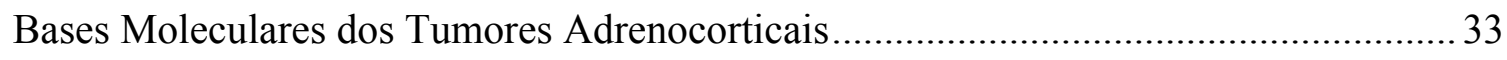

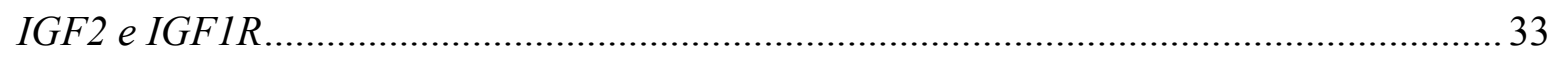

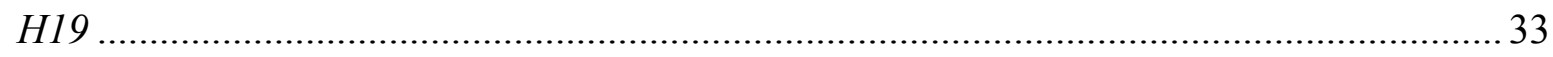

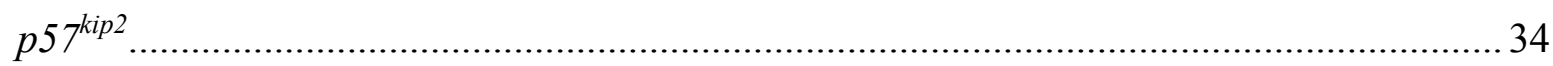

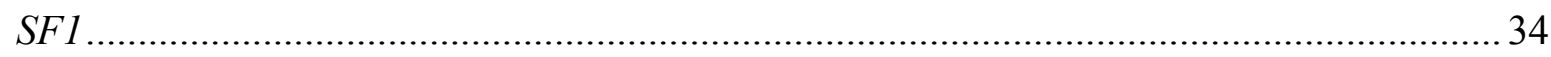

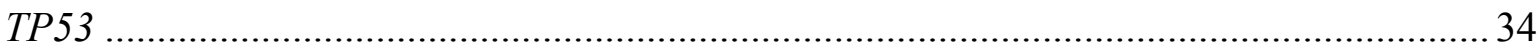

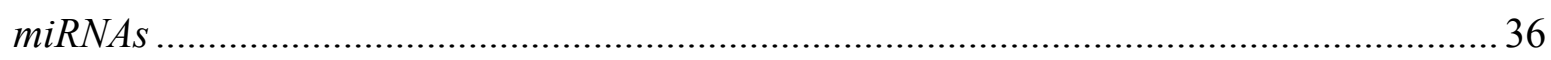

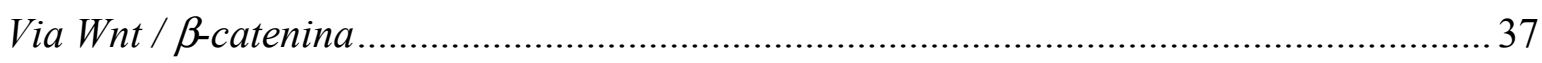

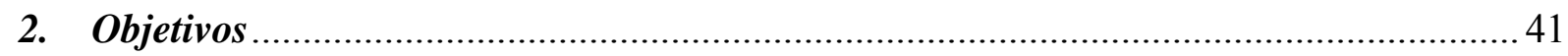

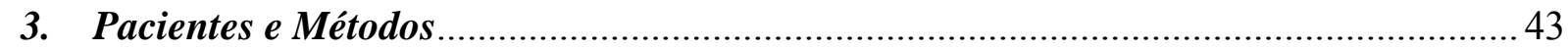

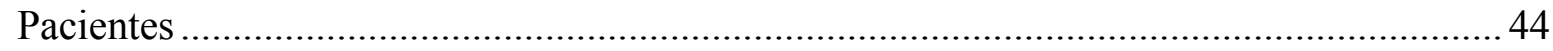

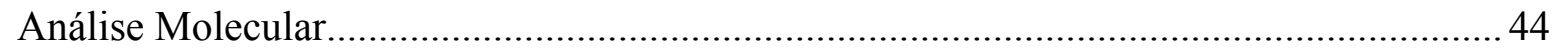

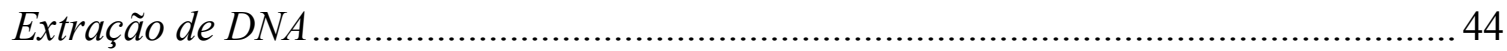

Avaliação de Mutação nos genes TP53 e CTNNB1 …………………………………........ 46

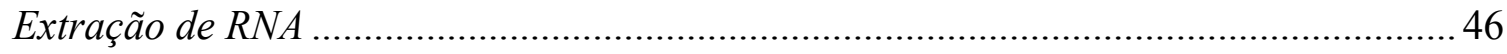

$q P C R$

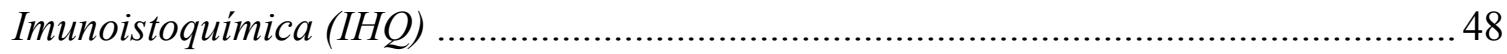

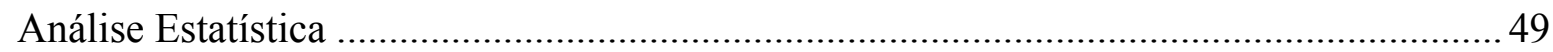

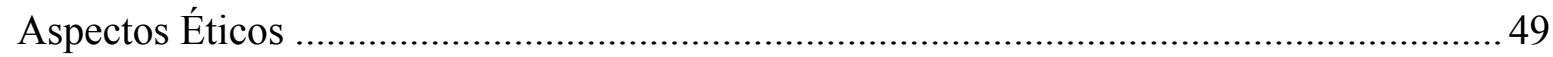

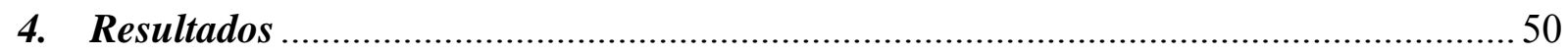

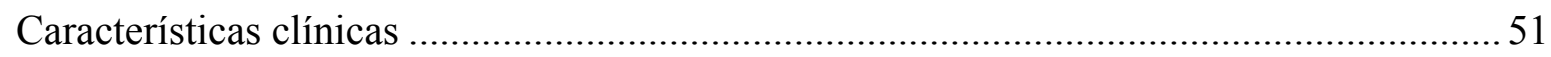

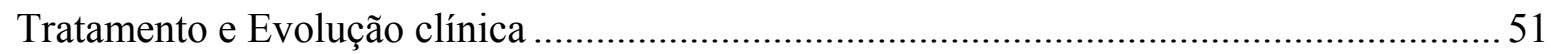

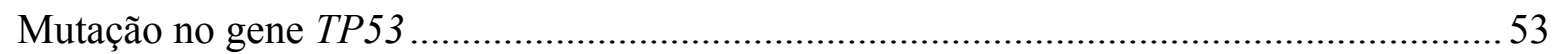

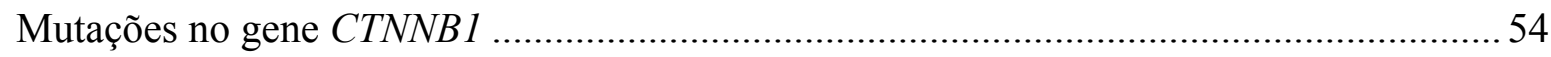




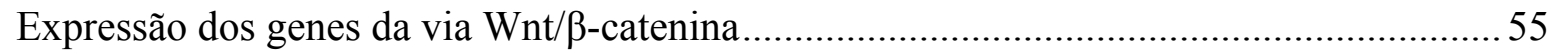

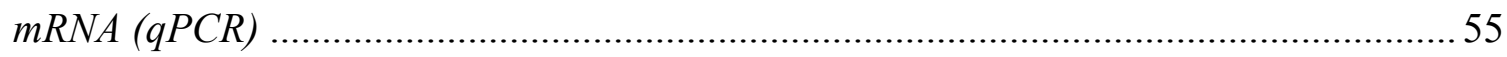

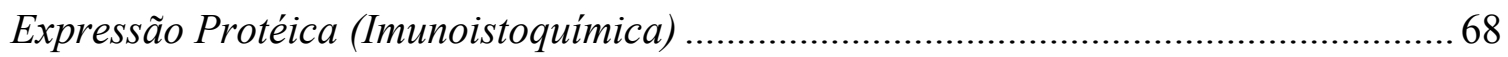

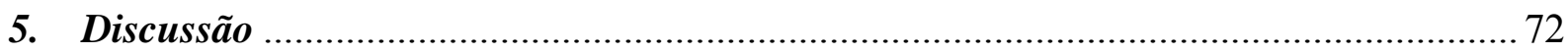

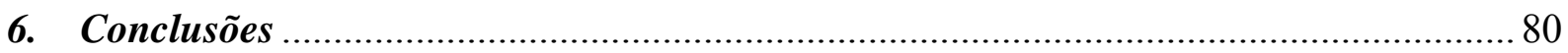

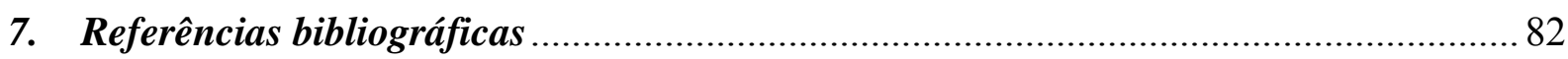

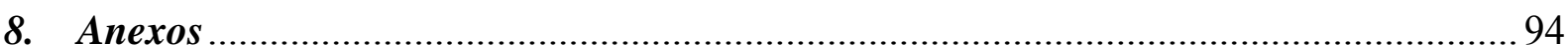

Anexo A. Características clinicas, patológicas, moleculares e desfecho dos pacientes .......95

Anexo B. Características histopatológicas de Weiss dos TAC provenientes do HCRP-

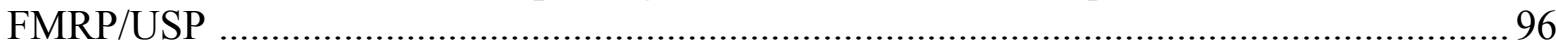

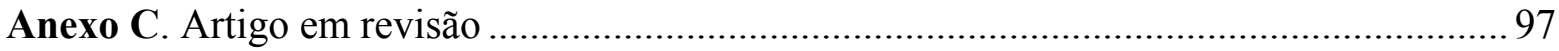


1. Introdução 


\section{Embriologia, Histologia e Fisiologia da Córtex Adrenal}

As glândulas adrenais ou supra-renais são órgãos endócrinos que produzem hormônios esteróides e catecolaminas, responsáveis por diversas funções fisiológicas vitais. Esta glândula é dividida em medula, responsável pela liberação dos hormônios epinefrina e noraepinefrina e córtex, responsável pela secreção de mineralocorticóides, glicocorticóides e andrógenos (Figura 1) [1,2].

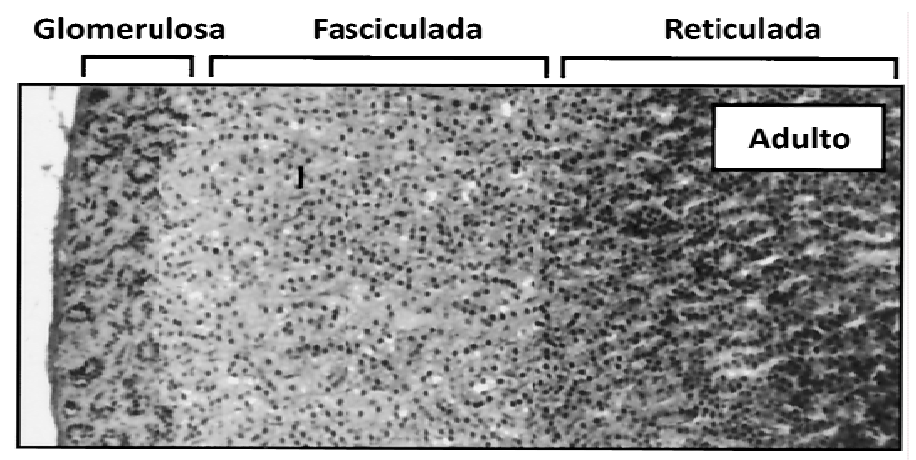

Figura 1. Morfologia do córtex adrenal normal adulto, envidenciando 3 zonas distintas: glomerulosa, fasciculada e reticulada. Adaptado de Mesiano \& Jaffe. 1997.

O córtex adrenal possui origem mesodérmica e, na espécie humana, já pode ser identificado na quarta semana de gestação como um espessamento do epitélio celômico entre a prega urogenital primitiva e mesentério dorsal. Em geral, a porção do epitélio celômico medial aos mesonefros produz as células destinadas ao córtex adrenal e as células da porção ventral aos mesonefros produzem as células destinadas às gônadas. Na quinta semana de gestação, as células primitivas começam a migrar e formam cordões, que se condensam para formar o "blastema adrenal", a primeira manifestação reconhecível da glândula adrenal [2].

No segundo mês de gestação, o córtex adrenal já é identificado como órgão distinto. Nesta fase, é composto por uma zona fetal e uma zona definitiva. O córtex fetal exibe um crescimento intenso entre a $10^{\mathrm{a}}$ e $15^{\mathrm{a}}$ semana de gestação, chegando a ocupar 80 a $90 \%$ de todo o córtex adrenal (Figura 2). Esta zona fetal tem uma intensa atividade esteroidogênica, sendo composto por células características, derivadas de áreas vizinhas ao epitélio celômico e morfologicamente idênticas às células que originam as gônadas, que secretam principalmente sulfato de di-hidro-epiandrosterona (DHEA-S).

Após o nascimento, a zona fetal sofre apoptose e desaparece após alguns meses de vida $[2,3]$. O tempo de involução da zona fetal ainda permanece controverso e não se sabe se 
esta involução é determinada na gestação ou após o nascimento [4]. Acredita-se que a adrenal diminui e atinge seu tamanho habitual nas primeiras duas semanas após o nascimento [5]. Nos três primeiros anos de vida ocorre o desenvolvimento do córtex adrenal adulto, que corresponde a $90 \%$ do peso da glândula [6].

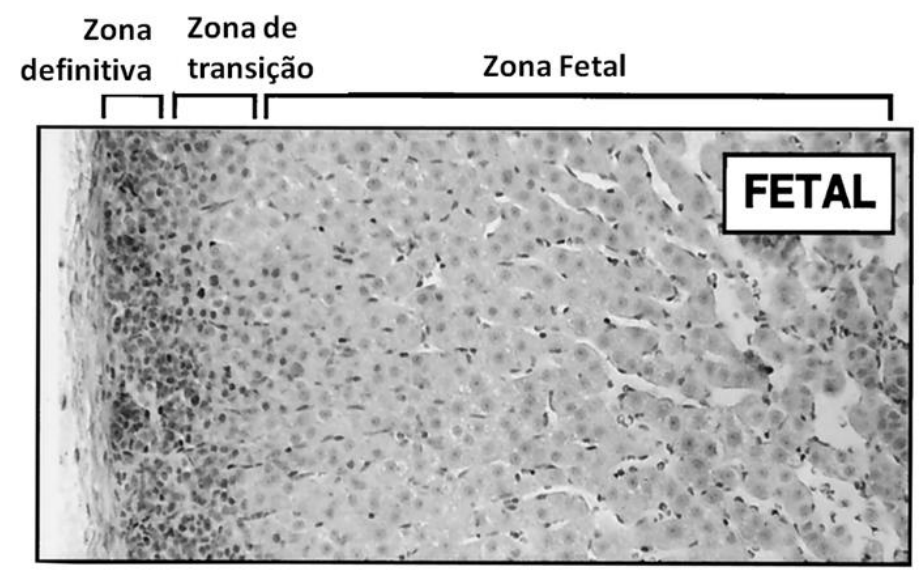

Figura 2. Morfologia do córtex adrenal normal fetal (meados da gestação). O córtex fetal é composto por 2 zonas diferentes: definitiva (mais externa) e a maior, fetal (mais interna). A zona de transição compreende a borda externa da zona fetal e forma um compartimento funcionalmente distinto entre a zona fetal e a zona definitiva. Adaptado de Mesiano \& Jaffe, 1997.

\section{Tumores adrenocorticais}

Tumores adrenocorticais benignos ou malignos podem ocorrer em ambos os sexos e em qualquer faixa etária. A grande maioria dos tumores é de tamanho pequeno e comportamento benigno. Por outro lado, carcinomas adrenocorticais (CAC) são raros, agressivos e apresentam prognóstico desfavorável [7-10].

\section{Epidemiologia}

Tumores adrenocorticais benignos são relativamente comuns em humanos e, em autópsias, a prevalência de adenomas ou hiperplasia adrenal chega a 7,3\% [11]. CAC, por sua vez, são raros e correspondem a aproximadamente $0,02 \%$ de todos os cânceres notificados ao redor do mundo [12].

A incidência dos tumores adrenocorticais (TAC) apresenta pico bimodal, sendo mais comuns nos primeiros 5 anos de vida e entre a $4^{\text {a }}$ e $5^{\text {a }}$ décadas de vida. Em todas as faixas etárias estes tumores são mais freqüentes no sexo feminino [12-14]. 
Em crianças, TAC constituem aproximadamente $0,2 \%$ de todos os tumores malignos, entretanto sua incidência varia de acordo com a região geográfica, sendo dez a quinze vezes mais elevada no Sul e Sudeste do Brasil, onde ocorrem aproximadamente 3,4 casos por milhão de crianças menores de 14 anos por ano. Em Los Angeles (Estados Unidos) e em Hong Kong (China) esse número cai para 0,4 e 0,1 casos por milhão de crianças por ano, respectivamente $[15,16]$. A razão da incidência mais elevada no Brasil ainda não é totalmente conhecida, porém a presença de uma única mutação germinativa no gene TP53 encontrada na maioria das crianças afetadas parece estar associada a este risco elevado [17, 18].

Um registro de tumores para coletar informações sobre tumores adrenocorticais ao redor de todo o mundo foi criado, o Registro International de Tumor Adrenocortical Pediátrico ou The International Pediatric Adrenocortical Tumor Registry (IPACTR). Os dados do registro podem ser utilizados para se ter uma visão global da doença, seu tratamento, desfecho e fatores de risco e para futuros estudos. Além disso, pode também ajudar na racionalização e uniformização do tratamento. Os dados dos estudos do IPACTR juntamente com os dados do COG (Children's Oncology Group) também visam fornecer informações importantes sobre a biologia dos TAC. Além disso, em função do fato de a maioria dos TAC secretarem hormônios, os dados do IPACTR poderão ajudar a descobrir os efeitos em longo prazo da exposição precoce a estes hormônios no crescimento e desenvolvimento da criança $[19,20]$.

\section{Manifestações Clínicas}

A suspeita diagnóstica geralmente ocorre em função de o paciente apresentar uma síndrome clínica decorrente do excesso hormonal e, eventualmente, massa abdominal palpável. Em adultos, a síndrome mais comumente associada é a Síndrome de Cushing, decorrente do hipercortisolismo. [14, 21, 22]. Em pacientes mais idosos, a maioria dos TAC tende a ser não funcionais.

A maioria dos TAC em crianças e adolescentes é funcional, apresentando-se, tipicamente, com sinais e sintomas de produção excessiva de andrógenos (Virilização) ou de cortisol (Síndrome de Cushing) ou ambos (Misto). O distúrbio hormonal mais comum em crianças é o excesso de andrógenos, seguido por tumores mistos. Diferente de adultos, o excesso de cortisol isolado é pouco comum em pacientes pediátricos [22]. 
Raramente TAC apresentam secreção de estrógeno ou aldosterona. Outras manifestações incomuns dos TAC incluem hipoglicemia, resistência insulínica não relacionada à secreção de glicocorticóides e policitemia [23].

\section{Classificação e Estadiamento Tumoral}

Em TAC pediátricos, a distinção entre adenomas e carcinomas é difícil, pois os critérios morfológicos nem sempre permitem uma classificação histopatológica satisfatória. $\mathrm{O}$ tamanho, o peso e a atividade mitótica do tumor são os critérios mais usados para discriminação entre adenomas e carcinomas [24].

O sistema de estadiamento tumoral mais utilizada internacionalmente para a classificação dos TAC pediátricos é a Escala de Macfarlane modificado por Sullivan (Tabela 1) $[25,26]$. Em função da grande experiência no seguimento em longo prazo de pacientes pediátricos com TAC, o grupo paranaense liderado pelo Professor Rômulo Sandrini propôs um classificação mais específica para o estadiamento de crianças com TAC. Esta escala, conhecida como "Escala de Sandrini modificada" tem sido utilizada no Brasil e reconhecida internacionalmente (Tabela 1) [16].

Tabela 1. Estadiamento dos TAC de acordo com os critérios de Macfarlane modificado por Sullivan e critérios de Sandrini

\begin{tabular}{|c|c|c|}
\hline $\begin{array}{l}\text { Estágio } \\
\text { tumoral }\end{array}$ & Macfarlane modificado por Sullivan & Sandrini \\
\hline $\mathbf{I}$ & Tumor restrito à adrenal e menor que $5 \mathrm{~cm}$ & $\begin{array}{l}\text { Tumor totalmente ressecável cirurgicamente, }<200 \mathrm{~cm}^{3} \text {, } \\
\text { ausência de metástase e concentrações hormonais } \\
\text { normais após a cirurgia }\end{array}$ \\
\hline II & Tumor restrito à adrenal e maior que $5 \mathrm{~cm}$ & $\begin{array}{l}\text { Tumor residual microscópico, }>200 \mathrm{~cm}^{3} \text {, rompimento da } \\
\text { cápsula e disseminação do tumor durante a cirurgia ou } \\
\text { persistência de concentrações hormonais elevadas após a } \\
\text { cirurgia }\end{array}$ \\
\hline III & Invasão local & Massa residual ou tumor inoperável \\
\hline IV & Metástases à distância & Metástases à distância \\
\hline
\end{tabular}

A classicação histopatológica proposta por Weiss e cols. é amplamente utilizada para classificar os tumores adrenocorticais, segundo os critérios baseados em 9 escores: alto índice mitótico, mitoses atípicas, alta atividade nuclear, baixa porcentagem de células limpas, necrose, arquitetura difusa do tumor, invasão capsular, invasão sinusoidal e invasão venosa. 
Considera-se malignos aqueles tumores cuja soma dos escores for maior que 3 [27]. No entanto, esta classificação foi eficaz para a predição de pobre prognóstico somente em TAC em adultos. Em crianças, o estadiamento tumoral foi mais confiável para a predição de prognóstico [28].

\section{Tratamento}

A cirurgia é o único tratamento efetivo conhecido para TAC e a ressecção completa do tumor é a única terapêutica que pode curar ou prolongar a sobrevida de forma significante, particularmente se a doença for detectada em estágios iniciais (I e II). A utilização da cirurgia laparoscópica para a ressecção dos TAC é controversa. De acordo com revisão recente, este procedimento pode ser utilizado, em pacientes adultos, para remoção de TAC pequenos e possivelmente benignos (estágios I e II). Devido ao risco de ruptura da cápsula, fragmentação tumoral e dificuldades técnicas para retirar completamente o tumor com margens livres, o emprego desta técnica deve ser restrito a estes casos específicos [29]. Entretanto, em TAC pediátricos, a cirurgia por laparotomia é a via de escolha, contra-indicando-se o uso de cirurgia laparóspica neste pacientes [30]. Esta conduta tem sido a empregada no HCFMRPUSP.

A abordagem transabdominal ou toracoabdominal é recomendada para os tumores suspeitos de malignidade. Carcinomas aderentes ou invadindo estruturas adjacentes requerem excisão em bloco de rim, baço, hepatectomia ou pancreatectomia parcial, sendo que linfadenectomia deve também ser considerada. A reoperação deve ser considerada em caso de recorrência local e metástases isoladas. Os pacientes aparentemente curados cirurgicamente requerem acompanhamento rigoroso e contínuo [7, 20].

O mitotane (o-p'DDD), um agente adrenotóxico, é considerado a principal droga com resultados mais satisfatórios e menores taxas de recorrência [31]. Foi demonstrado, em estudo prévio com adultos, que $75 \%$ dos pacientes submetidos ao tratamento com mitotane tiveram a secreção hormonal controlada e aproximadamente $8 \%$ tiveram regressão do tumor. No entanto, mostrou-se ineficiente em prolongar a sobrevida dos pacientes com carcinomas de estágios III e IV [7, 32]. Além do tratamento monoterápico com mitotane, em 2003, uma conferência internacional sobre o manejo de CAC determinou que pacientes com doença metastática avançada podem se beneficiar de quimioterapia combinada, composta por etoposídeo, doxorrubicina e cisplatina ou com estreptozotocina [33, 34]. Se o mitotane 
sozinho não for capaz de controlar o excesso hormonal, drogas que interfiram na função adrenal, como o cetoconazol, metirapona, etomidato ou mifepristona ou antagonistas do receptor glicorticóide (RU486), podem ser empregadas [29, 35].

Nos últimos anos, alguns ensaios clínicos com terapia direcionada ao sistema IGF vêm sendo desenvolvidos em pacientes com TAC [36], baseado nos achados de diversos estudos que demonstraram que a hiper regulação da via IGF é um dos principais eventos no desenvolvimento de CAC [37-40]. Foi demonstrado em linhagens celulares de CAC que antagonistas do receptor de IGF-I (IGF-1R) causam significante inibição do crescimento dose-dependente e que, quando empregados em conjunto com o mitotane, inibem ainda mais o crescimento celular [41]. O estudo envolvendo terapia direcionada ao sistema IGF já está em fase III e os pacientes portadores de CAC já foram recrutados para o uso do inibidor oral de pequenas moléculas do IGF-1R (NCI Trial No. NCT00924989). Este estudo tem final previsto para 2013 e esclarecerá se este tipo de terapia é factível e eficaz para este tipo de tumor [36].

O conhecimento de outros defeitos genéticos e anormalidades em vias de sinalização, tal como a via Wnt, envolvidos na patogênese dos TAC também podem ser aplicados em ensaios clínicos como novos alvos terapêuticos para desenvolver novas terapias e abrir perspectivas de intervenção terapêutica.

\section{Prognóstico}

Muitos dos pacientes acometidos têm prognóstico desfavorável e há poucas alternativas de tratamento farmacológico $[42,43]$. Os carcinomas podem apresentar-se com doença regional e/ou metástases à distância que, usualmente, acometem fígado, pulmões, rins e ossos [14]. Pacientes com doença residual após a cirurgia apresentam prognóstico desfavorável, sendo a ressecção completa do tumor o fator prognóstico mais importante.

De modo geral, o prognóstico em pacientes pediátricos com TAC é melhor que em pacientes adultos. A idade ao diagnóstico menor que três anos, tamanho do tumor abaixo de $200 \mathrm{~cm}^{3}$, tumor produtor exclusivamente de andrógenos e doença no estágio I são fatores de bom prognóstico [16]. É possível que idade mais avançada ao diagnóstico e a ocorrência de tumor secretor de cortisol ou aldosterona contribuam para um prognóstico desfavorável em adultos. Por outro lado, a presença de tumores secretores de andrógenos pode estar associada a um desfecho mais favorável [44]. 


\section{Bases Moleculares dos Tumores Adrenocorticais}

Embora o processo de tumorigênese adrenal ainda não esteja completamente esclarecido, nos últimos 15 anos, diversos estudos importantes ajudaram a elucidar parcialmente os fenômenos moleculares envolvidos na tumorigênese adrenocortical [17, 18, 45-48].

Os TAC estão associados à expressão aumentada do fator de crescimento semelhante à insulina do tipo 2 (IGF2) [37, 39, 46, 49], à expressão elevada de membros da família de receptores de fator de crescimento epidérmico (EGFR), ao aumento do número de cópias e expressão aumentada do Fator Esteroidogênico $1(S F 1)[48,50]$ e a mutações do gene TP53 $[17,18]$. Outros marcadores moleculares como $H 19$ e $p 57^{k i p 2}$, ambos localizados no cromossomo 11p15.5, mesmo locus do IGF2, também parecem estar envolvidos na patogênese dos TAC [51].

\section{IGF2 e IGF1R}

O sistema IGF tem um papel importante no desenvolvimento e crescimento fisiológico da glândula adrenal [39]. O IGF2 exerce efeitos mitogênicos através da interação com o receptor de IGF-I (IGF-1R) e a expressão aumentada do IGF2/IGF1R pode desencadear uma série de eventos moleculares que podem levar à malignidade [40]. A participação do IGF1R na tumorigênese adrenocortical adulta e pediátrica não está bem esclarecida, porém a expressão aumentada do $I G F 2$ tem sido encontrada na maioria dos TAC esporádicos [37, 46].

\section{H19}

A expressão de $H 19$ é elevada na adrenal fetal humana e diminui cerca de $50 \%$ na adrenal adulta. A expressão deste gene é dependente de ACTH e sua regulação parece estar relacionada à via AMPc-PKA (Cyclic Adenosine Mono Phosphate-Protein Kinase A). A expressão de $H 19$ é significativamente reduzida em CAC tanto não funcionantes como funcionantes, especialmente nos tumores secretores de cortisol e aldosterona [52]. 
O produto do gene $C D K N 1 C$, ou p57 $7^{\text {kip2 }}$, um membro da família quinase p21CIP1 ciclina-dependente, parece regular proliferação celular, saída do ciclo celular e manutenção das células diferenciadas. O produto deste gene é encontrado em altos níveis na maioria dos tecidos humanos normais. Há também a perda de atividade do produto gênico de $\mathrm{p} 57^{\mathrm{kip} 2} \mathrm{em}$ TAC virilizantes, tanto adenomas e carcinomas, sugerindo que este gene tem um papel fundamental na manutenção normal da diferenciação e função adrenocortical [52, 53].

\section{SF1}

O gene NR5A2 codifica o fator esteroidogênico 1 (SF1), que tem papel essencial na regulação do desenvolvimento da adrenal e gônadas. O número de cópias deste gene está aumentado na maioria dos TAC pediátricos analisados por Figueiredo e cols. [54] e a análise por meio de Western blot demonstrou uma expressão aumentada da proteína SF1 [48]. Além disso, em adultos, tumores não esteroidogênicos não expressaram a proteína SF1 [55]. O aumento da expressão de $N R 5 A 2$ e o aumento no número de cópias deste gene parecem ser mais comuns em TAC de crianças que em adultos [50]. Nenhuma correlação foi encontrada entre o aumento da expressão de $S F 1$ e variaveis histológicas e/ou manifestação clínica da doença em crianças [48]. No entanto, em pacientes adultos, a forte expressão de SF1 correlacionou-se com pior prognóstico [55].

\section{TP53}

O gene TP53 (OMIM: 191170) codifica uma importante proteína supressora tumoral, a P53, capaz de interromper o ciclo celular e induzir apoptose quando há dano ao DNA. Este é um dos mecanismos moleculares mais importantes na defesa contra alterações genéticas que possam desencadear tumores. A função da P53 é comparada à função de "guardião" da proliferação celular em circunstâncias que fogem da normalidade. Portanto, a perda da atividade da P53 pode promover ou facilitar o desenvolvimento do câncer [56].

Mutações neste gene são encontradas em diversos tipos de tumores, como câncer de pulmão [57], carcinoma do plexo coróide e osteosarcoma [58], tumores colorretais [59], câncer de mama [60], entre outros, inclusive TAC [17, 61, 62]. 
Mutações do gene TP53 em TAC foram descritas em pacientes em diferentes lugares do mundo, tanto em adultos como em crianças. Trabalho recente envolvendo um grupo de pacientes adultos com TAC mostrou que parte dos pacientes eram portadores de diferentes mutações no gene TP53 (p.L188WfsX2; p.E346X; p.C176F; p.R342P; p.A129del; p.R283C; p.E343X; p.R342P; p.K132N) [63]. Estudos de casos envolvendo pacientes pediátricos com TAC também identificaram diferentes mutações neste gene, como as mutações IVS10-2 A>G [61], p.V143A [64], p.R175AfsX6 [65], p.T220C, sendo esta última, encontrada em uma criança com tumor adrenocortical associado à síndrome de Li-Fraumeni (LFS) [66].

A síndrome de Li-Fraumeni é uma síndrome que apresenta herança autossômica dominante e predispõe a diversos tumores incluindo sarcoma ósseo e de tecidos moles, câncer de mama, tumor cerebral, carcinoma adrenocortical e leucemia. Esta síndrome familiar parece estar associada principalmente a mutações germinativas no gene TP53 [67, 68]. Diversas mutações neste gene, incluindo as mutações p.R342X, p.R342P e p.R337G também foram encontradas em crianças com TAC associado à síndrome de Li-Fraumeni [69].

Uma mutação germinativa do gene TP53 (p.R337H) encontrada em pacientes das regiões Sul e Sudeste do Brasil parece estar associada à incidência elevada deste tipo de tumor nestas regiões $[17,18]$. A análise de haplótipos deste mutante demonstrou que a probabilidade desta mutação ocorrer independentemente é muito pequena, demonstrando um possível efeito fundador [70]. Resultados de estudo recente demonstraram que as famílias brasileiras carreando este alelo mutante habitam locais ao longo da principal rota utilizada pelos comerciantes portugueses nos séculos XVIII e XIX. Adicionalmente, o achado desta mutação em um indivíduo português sem laços com o Brasil reforça a tese da origem portuguesa desta mutação comum no Brasil [70].

A mutação P53 p.R337H encontra-se fora da região de hotspot para mutações deste gene encontradas em outros tumores e localiza-se no domínio de tetramerização da P53, levando à instabilidade da proteína na dependência do $\mathrm{pH}$ tecidual elevado, como encontrado nas adrenais. A glândula adrenal sofre intensas mudanças no período pré e pós-natal, o que requer uma intensa atividade apoptótica. Células apoptóticas tem um aumento de $\mathrm{pH}(\mathrm{pH}$ 7,9) e durante o desenvolvimento desta glândula, esta alteração de $\mathrm{pH}$ pode contribuir para a desestabilização do domínio de tetramerização da P53 p.R337H. Esta desestabilização leva à perda da atividade supressora de tumor desta proteína. As células com pH mais próximos de 7,0, mesmo com a mutação, podem ter a proteína suficientemente estável para funcionar normalmente. Esta disfunção do P53 nas células adrenais resulta em crescimento anormal das células, favorecendo o desenvolvimento de tumores [71]. A perda do alelo normal 
representaria o segundo dano, conforme descrito na literatura [72], e é crucial para o desenvolvimento deste tipo de tumor [73, 74].

Nas regiões Sul e Sudeste do Brasil, em torno de 75 a $90 \%$ das crianças e, aproximadamente, 20 a 30\% dos adultos com TAC apresentam a mutação germinativa P53 p.Arg337His em heterozigose [75]. No tecido tumoral há perda do alelo nativo [17, 18]. Em trabalho anterior de nosso grupo, esta mutação foi observada em $75 \%$ dos pacientes na faixa etária pediátrica e em $20 \%$ dos pacientes adultos com TAC atendidos no HCFMRP-USP entre os anos de 1985 e 2000 [62].

Em crianças, onde a mutação P53 p.R337H foi mais freqüente, não houve associação direta entre a presença desta mutação, o grau de malignidade ou no prognóstico destes pacientes $[17,18,62]$. Em adultos, no entanto, esta e outras mutações do gene TP53 parecem associar-se a prognóstico mais desfavorável $[18,76]$.

\section{miRNAs}

Micro RNAs (miRNAs) são uma nova classe de RNAs não codificantes de 19-25 nucleotídeos envolvidos em diversos processos celulares, incluindo diferenciação, proliferação e apoptose [77]. Na última década, trabalhos tem associado alterações na expressão de miRNAs à tumorigênese [78]. O envolvimento dos miRNAs foi demonstrado em câncer de mama, leucemia, câncer de pulmão, linfoma de Burkitt, glioblastoma e câncer de tireóide, sugerindo que os miRNAs podem ter um papel importante na tumorigênese [79, $80]$.

Estudos de microarray realizados com TAC em pacientes adultos demonstraram que alguns miRNAs foram diferencialmente expressos e estes dados foram validados por qPCR. Os miRNAs-100, miR-125b e miR-195 foram significativamente hipoexpressos e que o miR483-5p foi hiperexpresso em TAC malignos, podendo inclusive categorizar os tumores como benignos e malignos [81]. Recentemente, foi identificado um grupo de miRNAs diferencialmente expressos em TAC pediátricos. Análise funcional em linhagens de células tumorais adrenais demonstrou que os miRNAs, miR-99a and miR-100, regulam a expressão da via IGF-1/mTOR, que se encontra alterada na maioria destes TAC [82]. 


\section{Via Wnt / $\beta$-catenina}

A via Wnt (Figura 3) é importante no desenvolvimento embrionário, incluindo a determinação do eixo, a formação de órgãos e o destino celular em vertebrados e invertebrados. Além disto, está envolvida na homeostase de tecidos no organismo adulto [83-85]. Estudos recentes apontam que esta via também é essencial na auto-renovação de células tronco [43, 83].

A via canônica Wnt ou via Wnt/ $\beta$-catenina atua por meio da regulação da proteólise da $\beta$-catenina, uma proteína multifuncional que age na adesão celular e na regulação gênica. Nas células epiteliais, a $\beta$-catenina localiza-se nas junções de adesão célula-célula, onde estão as caderinas, proteínas transmembrana de adesão. As proteínas Wnts (Wingless-type) atuam nesta via por meio da interação ligante-receptor com o receptor Frizzled. O resultado final desta ligação será a regulação da transcrição gênica.

Inibidores da via Wnt na matriz extracelular, como secreted Frizzled-related protein, SFRPs, antagonizam a via por meio do sequestro de ligantes Wnts na matriz extracelular [86]. Usando diferentes mecanismos, Dickkopf ou DKK antagoniza a via Wnt através da interação com o co-receptor low-density lipoprotein receptor-related protein ou LRP. DKK, em conjunto com outra proteína transmembrana (Kremen), induzem a endocitose de LRP e sem LRP viável na superfície celular, a via Wnt é efetivamente inibida [87].

A ligação extracelular das proteínas Wnts aos receptores Frizzled e LRP modula componentes intracelulares por mecanismos distintos [83]. Primeiro, a ligação de Wnt induz mudanças estruturais no receptor, que resulta no recrutamento de Dishevelled ou DVL1 para a porção citoplasmática do receptor [88]. Então, o LRP interage com a proteína AXIN, que quando recrutada à membrana celular, tem sua função inibida, resultando na estabilização da $\beta$-catenina [89].

A degradação das $\beta$-cateninas citoplasmáticas depende de um complexo protéico denominado de "complexo de degradação". Os principais componentes desse complexo são as proteínas casein-kinase 1 (CK1), glycogen synthase kinase 3 (GSK3), AXIN e adenomatous polyposis coli (APC). O complexo de degradação se liga à $\beta$-catenina degradando-a e a impedindo de entrar no núcleo para ativar genes-alvo. Esta degradação só acontece na ausência de um ligante, no caso, uma proteína Wnt (Figura 3a). Na presença de um ligante, a $\beta$-catenina entra no núcleo e desencadeia ativação transcricional (Figura 3b). Entre os genes ativados pela $\beta$ catenina está o $M Y C$, que codifica uma proteína de mesmo nome. A proteína MYC é um potente estimulador do crescimento e da proliferação celular [83, 90]. 

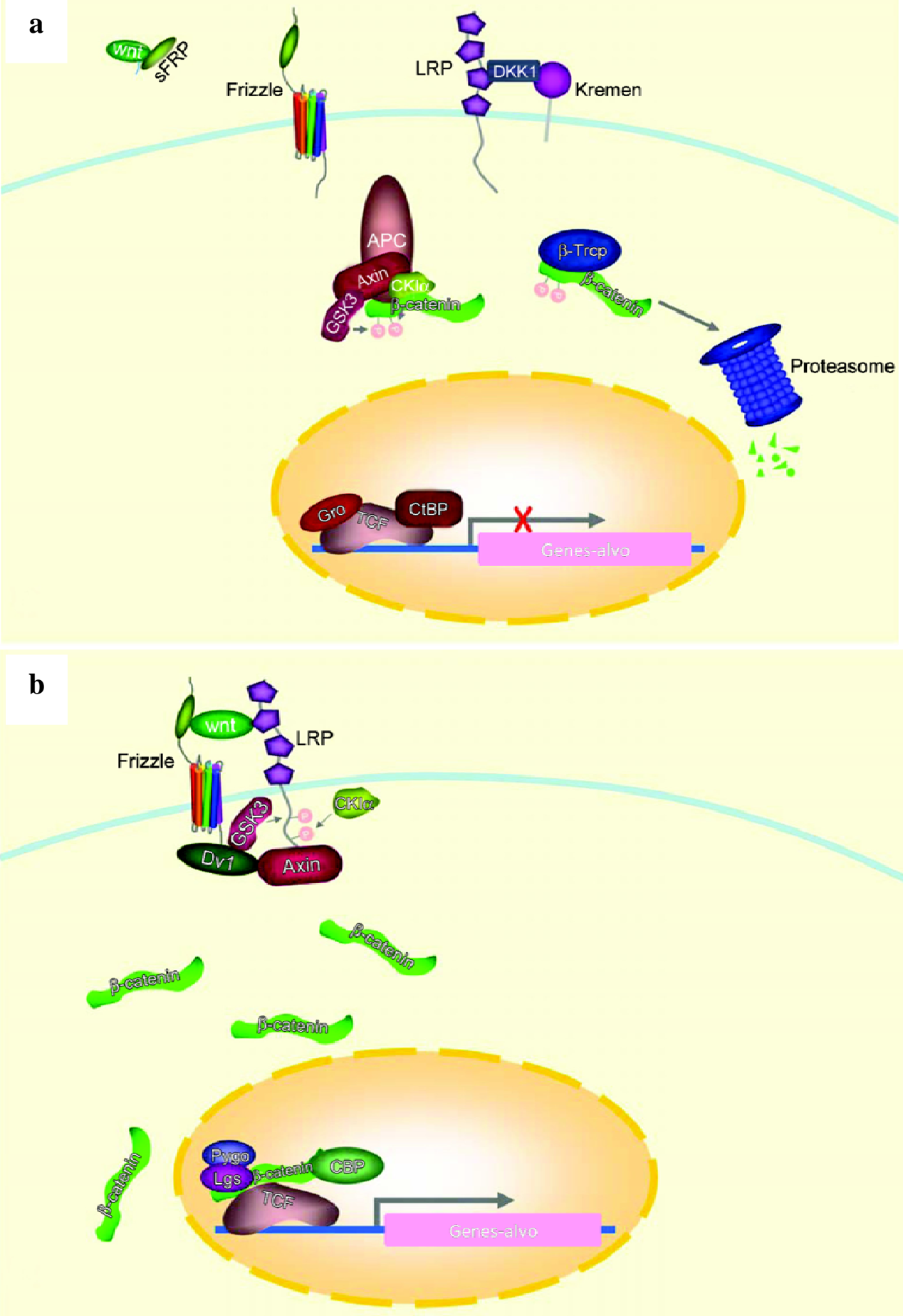

Figura 3. Sinalização da Via Wnt/ $\beta$-catenina. (a) Quando a via Wnt está desativada, a $\beta$-catenina citoplasmática é degradada pelo complexo formado por AXIN, APC, GSK3 e CKI $\alpha$. CKI $\alpha$ e GSK3 fosforilam $\beta$-catenina, $\beta$ catenina fosforilada é reconhecida por $\beta$-Trcp e degradada via ubiquitina-proteossomo. Os ligantes Wnt podem ser inibidos pelas SFRPs e LRP pode ser inibido por DKK. (b) Quando a via Wnt está ativa, as proteínas Wnt se ligam ao receptor Frizzled e ao co-receptor LRP e estimulam a fosforilação do LRP com a ajuda de DVL. LRP fosforilado recruta o AXIN à membrana e rompe o complexo de degradação da $\beta$-catenina. $\beta$-catenina acumulase no citoplasma e entra no núcleo, onde se liga aos fatores de transcrição TCF/LEF e co-ativadores, como Pygo, Lgs e p300/CBP, ativando a expressão gênica. Adaptado de Chen X et al, 2008. 
O gene que codifica a $\beta$-catenina, CTNNB1 (OMIM 116806), localiza-se na região 3 p22 - p21.3, é composto por 16 exons e codifica uma proteína de $88 \mathrm{kDa}$. O principal sítio para iniciação da transcrição foi identificado como uma Adenina, 214 nucleotídeos antes do códon de iniciação ATG, resultando em um transcrito de 3362 nucleotídeos [91].

Mutações no gene CTNNB1 e/ou nos genes que codificam os componentes do complexo de degradação impedem a ligação deste complexo à $\beta$-catenina. A ausência de degradação da $\beta$-catenina provoca seu acúmulo no núcleo e, consequentemente, estimula a transcrição de genes-alvo de Wnt. Esse acúmulo pode levar a crescimento e proliferação celular descontrolados por desregulação da Via Wnt/ $\beta$-catenina $[92,93]$.

A desregulação da via Wnt resulta em crescimento celular aberrante e está associada a doenças na espécie humana, principalmente formação de tumores. $\mathrm{O}$ aumento da proliferação celular aumenta a susceptibilidade das células a mutações em oncogenes ou genes supressores de tumor, que levam à acumulação de modificações genéticas específicas, características de tumores [73]. A principal causa de descontrole desta via são mutações em algum de seus componentes, principalmente no gene CTNNB1 e em genes que codificam os componentes do complexo de degradação da $\beta$-catenina, como os genes $A P C$ e $A X I N 1$ [90, 92].

Estudos sugeriram o envolvimento da via Wnt no desenvolvimento e/ou manutenção do córtex adrenal por meio da regulação de células adrenocorticais indiferenciadas [43, 94]. Estas propriedades conferem um papel importante a esta via na tumorigênese adrenocortical [95]. A ativação da via Wnt/ $\beta$-catenina tem sido encontrada em hiperplasias, adenomas e carcinomas desta glândula [96]. Em adenomas, anormalidades desta via parecem estar associadas a mutações no gene da subunidade regulatória $1 \alpha$ da proteína quinase $\mathrm{A}$ (PRKAR1A). No entanto, o papel da via da proteína quinase A na patogênese dos TAC ainda é pouco conhecido $[14,95]$.

Em pacientes com Hiperplasia Adrenal Macronodular independente de ACTH (AIMAH), a expressão do gene WISP2 está significativamente elevada. Neste mesmo grupo de pacientes, outros genes relacionados à via Wnt/ $\beta$-catenina foram diferencialmente expressos [97]. Na patogênese da AIMAH, outros genes candidatos estão sendo identificados, sugerindo que eventos moleculares que afetam a regulação do ciclo celular, os mecanismos de adesão e o processo de transcrição possam atuar no desenvolvimento de anormalidades adrenocorticais [98].

Alterações da via Wnt/ $\beta$-catenina parecem estar associadas a pior prognóstico em TAC de adultos. Estudos recentes demonstraram que mutações no gene da $\beta$-catenina 
(CTNNB1) e acúmulo nuclear desta proteína estão associados a desfecho clínico desfavorável em pacientes adultos com TAC $[63,96]$.

A incidência de TAC em crianças é elevada nas regiões Sul e Sudeste de nosso país e até o momento não há estudos que avaliaram sistematicamente a expressão de genes da via Wnt/ $\beta$-catenina em TAC pediátricos e sua relação com a mutação P53 p.R337H. No presente estudo investigamos a presença de mutações nos genes CTNNB1 e TP53 em TAC pediátricos. Adicionalmente, avaliamos a expressão de alguns dos principais genes envolvidos na via Wnt/ß-catenina e reconhecidamente importantes no desenvolvimento e/ou manutenção do córtex adrenal normal. Entre estes genes estão o ligante WNT4 (WNT4), o seqüestrador de ligantes SFRP1 (SFRP1), o antagonista do co-receptor LRP (DKK3), os componentes do complexo de degradação APC $(A P C)$ e AXIN $(A X I N)$, o fator de transcrição TCF (TCF7) e dois genes alvo desta via (MYC and WISP2). 
2. Objetivos 


\section{Geral}

Avaliar o papel da via Wnt/ $\beta$-catenina na tumorigênese adrenocortical.

\section{Específicos}

Em tumores adrenocorticais, avaliar:

- A expressão de genes relacionados à via Wnt/ $\beta$-catenina e sua associação com características clínicas e tumorais, bem como com o prognóstico do pacientes.

- A presenca de mutações no gene $C T N N B 1$ e sua associação com características clínicas e tumorais, bem como com o prognóstico do pacientes. 
3. Pacientes e Métodos 


\section{Pacientes}

Foram incluídos 62 pacientes com diagnóstico de TAC procedentes de 2 centros de referência no tratamento desta doença no estado de São Paulo, o Hospital das Clínicas da Faculdade de Medicina de Ribeirão Preto - USP e o Centro Infantil Boldrini, Campinas - SP.

Foram analisadas amostras de tecido tumoral microdissecado, obtidas por ressecção cirúrgica e armazenadas nos bancos de tumores do Laboratório de Endocrinologia e Metabologia e Laboratório de Pediatria do HCFMRP-USP e do Centro Infantil Boldrini.

Como controles, foram utilizadas 8 amostras de adrenais obtidas de indivíduos adultos jovens previamente saudáveis, sem antecedentes de doenças crônicas, que tiveram morte súbita. Estas amostras foram colhidas no Centro de Medicina Legal (CEMEL) desta faculdade.

As seguintes variáveis clínicas e laboratoriais foram analisadas: sexo, idade ao diagnóstico, perfil hormonal (síndrome virilizante, hipercortisolismo ou tumor misto) e estadiamento tumoral de acordo com os critérios clínicos de Sandrini [16]. Nos pacientes provenientes do HCFMRP-USP, analisamos também os critérios histopatológicos de Weiss [27]. Avaliou-se também a evolução pós-cirúrgica, incluindo a ocorrência de recidivas tumorais, tempo de sobrevida e / ou cura.

\section{Análise Molecular}

\section{Extração de DNA}

\section{DNA Genômico}

A extração de DNA foi realizada utilizando-se o kit "QIAmp Flexigene" (QIAGEN, CA, USA). Em tubo eppendorf de 1,5 mL foram adicionados $300 \mu \mathrm{L}$ do sangue total e $750 \mu \mathrm{L}$ de FGF1 para lise celular. Após centrifugação a 13200 rpm por 1 minuto, o sobrenadante foi descartado sendo o tubo invertido 2 minutos para secagem. Adicionou-se então $150 \mu \mathrm{L}$ da solução FGF2 com protease, sendo o tubo vortexado e a seguir centrifugado por 5 minutos na mesma velocidade anterior. Foi então realizada incubação em banho-maria $\left(65^{\circ} \mathrm{C}\right)$ por 5 minutos e a seguir adicionado $150 \mu \mathrm{L}$ de isopropanol absoluto. Foi realizada centrifugação 
por 3 minutos e o sobrenadante descartado. Adicionou-se $150 \mu \mathrm{L}$ de etanol $70 \%$ sendo novamente centrifugado por 3 minutos. $\mathrm{O}$ sobrenadante foi então descartado, restando no fundo do tubo o "pellet". Adicionou-se o FGF3 e a solução foi incubada por 10 minutos a $65^{\circ} \mathrm{C}$ para a sua dissolução. As amostras de DNA extraídas foram submetidas à eletroforese em gel de agarose 1\% em TAE (Tris- acetato 0,004M; EDTA 0,001M; pH 8,0) para confirmar sua integridade.

\section{DNA Tumoral}

Após a microdissecção, a extração de DNA tumoral pelo método de Trizol foi realizada em três etapas: precipitação, lavagem e ressuspensão do DNA. Em temperatura ambiente, adicionou-se à fase orgânica (que havia sido estocada após a extração do RNA) 0,3 $\mathrm{ml}$ de etanol $100 \%$ para cada $0.75 \mathrm{ml}$ de Trizol; a amostra foi homogeneizada por inversão do tubo e incubada em temperatura ambiente durante 2-3 minutos; centrifugação da amostra a $2000 \mathrm{rpm}$ durante 5 minutos a $4^{\circ} \mathrm{C}\left(\right.$ de 2 a $8^{\circ} \mathrm{C}$ ). Após a centrifugação, retirou-se todo o sobrenadante, que foi transferido para um novo tubo para posterior extração de proteína, se necessário (o sobrenadante deve ser retirado totalmente para uma melhor qualidade do DNA que será ressuspendido). Lavagem do pellet de DNA com $1 \mathrm{ml}$ de uma solução de citrato de sódio diluído em etanol $10 \%$ e incubação por 30 minutos em temperatura ambiente, homogeneizando a cada 5 minutos; centrifugação da amostra em 2000g durante 5 minutos a temperatura de $4^{\circ} \mathrm{C}$ (de 2 a $8^{\circ} \mathrm{C}$ ). Novamente lavagem do pellet de DNA com $1 \mathrm{ml}$ da citrato de sódio diluído em etanol $10 \%$ e incubação durante 30 minutos em temperatura ambiente, homogeneizando a cada 5 minutos; centrifugação da amostra em $2.000 \mathrm{~g}$ durante 5 minutos a temperatura de $4^{\circ} \mathrm{C}$ (de 2 a $8^{\circ} \mathrm{C}$ ). Após as 2 lavagens, o pellet foi ressuspendido com 1.5-2.0 $\mathrm{ml}$ de etanol 75\% e mantido em temperatura ambiente por 10 minutos, homogeneizando periodicamente; centrifugação da amostra em $2000 \mathrm{~g}$ durante 5 minutos a $4^{\circ} \mathrm{C}\left(2-8^{\circ} \mathrm{C}\right)$. Uma lavagem adicional foi requerida quando houve um pellet grande, contendo acima de $200 \mathrm{ug}$ de DNA ou contendo algum outro material que não o DNA. Para ressuspenção do DNA, um volume de $10 \mu 1$ de $\mathrm{NaOH}$ a $8 \mathrm{mM}$ foi adicionado (é recomendado deixar o DNA com uma concentração final de 0.2-0.3 ug/ul). Em caso de pellet insolúvel, o material insolúvel foi removido por centrifugação a 12000 g por 10 minutos e o sobrenadante contendo o DNA transferido para um novo tubo. 


\section{Avaliação de Mutação nos genes TP53 e CTNNB1}

Em todos os pacientes foi avaliada a presença da mutação P53 p.R337H no DNA genômico e no DNA tumoral. Os oligonucleotídeos iniciadores utilizados para a triagem desta mutação estão nas regiões intrônicas entre os exons 9-10 e 10-11 (Tabela 2). No cDNA tumoral, também foi avaliada a presença de mutações na região codificadora dos sítios de fosforilação do gene CTNNB1 (oligonucleotídeos localizdos entre os exon 2 e 5 - Tabela 3). As reações de PCR e de sequenciamento foram realizadas com os seguintes pares de oligonucleotídeos iniciadores:

Tabela 2. Oligonucleotídeos utilizados no sequenciamento do exon 10 do gene TP53 (mutação P53 p.R337H).

\begin{tabular}{cc}
\hline Primer & Sequência \\
\hline 10P53 S & 5'-GGATCCTGTTGCTGCAGATCCGTGGG-3' \\
10P53 AS & 5'-GAATTCGAGGTCACTCACCTGGAGTG-3' \\
\hline
\end{tabular}

Tabela 3. Oligonucleotídeos utilizados no sequenciamento da região codificadora do CTNNB1.

\begin{tabular}{cc}
\hline Primer & Sequência \\
\hline Beta-Catenina cDNA S & 5'- CCCTGAGGGTATTTGAAGTAT -3' \\
Beta-Catenina cDNA AS & 5'-ATAGCAGACACCATCTGAGG -3' \\
\hline
\end{tabular}

\section{Extração de RNA}

O RNA total foi extraído pelo método do TRIzol ${ }^{\circledR}$ Reagent (Invitrogen), segundo o protocolo do fabricante. Em caso de contaminação por DNA genômico, as amostras foram tratadas com RQ1-DNase (Promega Corp., Madison, WI) por 30 min a $37^{\circ} \mathrm{C}$, seguida pela inativação da enzima a $85^{\circ} \mathrm{C}$, para remover eventual contaminação. A quantificação do RNA foi realizada pela leitura em espectrofotômetro Eppendorf BioPhotometer plus (Eppendorf International, Hamburg, Germany) em comprimento de onda de $260 \mathrm{~nm}$. O cálculo da razão entre a DO em 260 e $280 \mathrm{~nm}$ foi observado para estimar o grau de pureza do RNA total (1,8 \pm 0,2). A integridade das amostras também foi verificada pela visualização das bandas de RNA ribossômico $28 \mathrm{~S}$ e $18 \mathrm{~S}$ em gel de agarose $1,2 \%$ corado com solução de brometo de etídeo $0,5 \%$. 


\section{PCR quantitativa (PCRq)}

A transcrição reversa foi realizada utilizando a enzima MultiScribe ${ }^{\mathrm{TM}}$ e o kit High capacity cDNA Reverse Transcription (Applied Biosystems). O volume final da reação foi de $25 \mu \mathrm{L}$ contendo $500 \mathrm{ng}$ do RNA total, 2,5 $\mu \mathrm{L}$ de randon primers, 5,5 $\mathrm{mM} \mathrm{MgCl} 2,2,0 \mathrm{mM}$ de dNTP, 50U Multiscribe ${ }^{\mathrm{TM}}$ e $2,5 \mu \mathrm{L}$ tampão $10 \mathrm{X}$. As reações foram incubadas a $25^{\circ} \mathrm{C}$ por 10 minutos, $37^{\circ} \mathrm{C}$ por 120 minutos e $85^{\circ} \mathrm{C}$ por 5 segundos.

O cDNA foi diluído (1:5) para sua utilização nos ensaios de qPCR. As reações foram feitas em duplicatas, utilizando placas de 96 poços com $0,5 \mu \mathrm{L}$ do produto contido em cada reação TaqMan ${ }^{\mathrm{TM}}$ do ensaio específico para cada gene, $5 \mu \mathrm{L}$ de Master mix, 2,5 $\mu \mathrm{L}$ de cDNA diluído e $2 \mu \mathrm{L}$ de água DEPC. As reações foram submetidas a uma temperatura inicial de $50^{\circ} \mathrm{C}$ por $2 \mathrm{~min}$, seguida de uma desnaturação a $95^{\circ} \mathrm{C}$ por 10 min e 40 ciclos sucessivos a $95^{\circ} \mathrm{C}$ por $15 \mathrm{~s} \mathrm{e} 60^{\circ} \mathrm{C}$ por $1 \mathrm{~min}$. A fluorescência foi detectada a cada ciclo, obtendo-se um gráfico da variação da fluorescência $(\Delta \mathrm{Rn})$ pelo número de ciclos (Cycle Number), ao final dos ciclos amplificação. As curvas de amplificação foram visualizadas pelo software ABI Prism ${ }^{\circledR}$ 7500, a linha de base (Baseline) estabelecida e o limiar de detecção (Threshold) ajustado na fase exponencial do gráfico. O Threshold indica o ponto de referência onde todas as amostras possuem a mesma intensidade fluorescente, teoricamente correspondente a mesma quantidade de produto de PCR. A identificação do Threshold determina o estabelecimento do cycle threshold $(\mathrm{Ct})$, ciclo em que cada curva de amplificação atravessa o limiar, servindo como base para comparação entre amostras. Após o estabelecimento do $\mathrm{Ct}$ de cada amostra, os dados foram exportados em tabelas compatíveis com o software Excel, contendo valores médios dos Cts de cada amostra e respectivos desvios padrão.

A normalização dos resultados de cada amostra foi realizada pela subtração do Ct para o gene (alvo) pela média combinada dos Cts dos 3 controles endógenos. A calibração foi realizada com a mediana de $\Delta \mathrm{Ct}$ das amostras dos controles (adrenais normais) e os resultados obtidos por meio do cálculo de $\Delta \Delta \mathrm{Ct}$, respectivamente. A expressão de determinado gene nas amostras foi dada pela fórmula $2^{-\Delta \Delta C t}$. A mediana do valor obtido de $2^{-}$ ${ }^{\Delta \Delta \mathrm{Ct}}$ das amostras de tecido tumoral de adrenal foi comparada com o valor da mediana dos valores obtidos de $2^{-\Delta \Delta C t}$ das amostras de tecido adrenal normal, obtendo o valor que revela $o$ numero de vezes $(f o l d)$ que este gene está hiper ou hipo expresso no tecido tumoral em comparação ao tecido normal [99]. 
Avaliamos a expressão de genes relacionados diretamente e indiretamente à via Wnt/ $\beta$-catenina e que apresentam ou possam ter ações estimulatórias ou inibitórias sobre a via. Os ensaios de qPCR para a análise da expressão dos genes CTNNB1, APC, WNT4, SFRP1, TCF7, WISP2, DKK3, AXIN1, MYC e TP53 (Tabela 4) e controles endógenos ACTB, GUSB e TBP utilizados na normalização dos resultados foram obtidos no endereço eletrônico do fabricante (http://www.appliedbiosystems.com).

Tabela 4. Genes da via Wnt- $\beta$ /catenina e respectiva identificação dos ensaios utilizandos para realização das qPCR.

\begin{tabular}{cc}
\hline Gene & $\begin{array}{c}\text { Identificação do Ensaio } \\
\text { (TaqMan }{ }^{\circledR} \text { Applied Biosystems) }\end{array}$ \\
\hline CTNNB1 & Hs00170025_m1 \\
APC & Hs01568270_m1 \\
WNT4 & Hs00229142_m1 \\
SFRP1 & Hs00610060_m1 \\
TCF7 & Hs00175273_m1 \\
WISP2 & Hs00180242_m1 \\
MYC & Hs99999003_m1 \\
DKK3 & Hs00247426_m1 \\
AXIN1 & Hs00394718_m1 \\
TP53 & Hs01034249_m1 \\
\hline
\end{tabular}

\section{Imunoistoquímica (IHQ)}

A partir de amostras de fragmentos tumorais processadas para a análise histopatológica, foi realizado estudo imunoistoquímico para algumas proteínas da via Wnt/Bcatenina ou que tenham alguma relação com esta via.

Avaliamos a expressão das proteínas DKK3, WISP2, MYC, $\beta$-catenina e P53. Resumidamente, os cortes de $5 \mu \mathrm{m}$ foram desparafinizados utilizando xileno, rehidratados com álcool e água e, subseqüentemente, submetidos à recuperação antigênica por 45 minutos. Em seguida, os cortes foram incubados com os anticorpos primários adquiridos junto à Santa Cruz Biotechnology ${ }^{\circledR}$, anti-DKK3 (cat. $n^{0}$ sc-25518), anti-WISP2 (cat. $n^{0}$ sc- 25442), antiMYC (cat. $n^{0}$ sc-788), anti- $\beta$-catenina (cat. $n^{0}$ sc- 7963) e anti-P53 (cat. $n^{0}$ sc-263) por 2 horas. Para a coloração, foi utilizado o sistema avidina-biotina (Vectastain Elite ABC Kit, Universal, Vector Laboratories Inc., Burlingame, CA, USA). A marcação nuclear e/ou citoplasmática foi desenvolvida com NovoRed (Vector Laboratories Inc.), conferindo coloração vermelha ao acúmulo das proteínas e a contra-coloração foi realizada com Hematoxilina de Harris, conferindo cor azul. 
Análise quantitativa do número de células coradas foi realizada utilizando-se microscópio Zeiss equipado com câmera digital, anexada a um dispositivo de contraste para células positivas. As preparações para cada marcador foram avaliadas aleatoriamente em, pelo menos, 10 campos representativos de grande aumento (X 400) por patologista experiente, em colaboração junto ao Departamento de Patologia do HCFMRP-USP.

Para cada amostra foi atribuído um escore de acordo com a porcentagem de células coradas: negativo (menos que 1\%), +1 (fraco: 1\%-10\%), +2 (moderado: 10\%-50\%) e +3 (forte: mais que 50\%) [100]. Tecido da glândula adrenal normal adjacente foi utilizado como controle negativo. Acúmulo de $\beta$-catenina ou P53 foi caracterizado quando a marcação nuclear e/ou citoplasmática foi observada.

\section{Análise Estatística}

A expressão diferencial dos genes em tumores adrenais e adrenais normais foi analisada pelo teste de Mann-Whitney. O teste de Kruskal-Wallis com pós-teste de Dunn foi utilizado para a comparação entre controles e os tumores de diferentes estágios tumorais. A associação entre óbito e a presença ou não da mutação no gene TP53 e associação entre óbito e a presença ou não de mutações no gene CTNNB1 foram avaliadas pelo Teste Exato de Fisher. Para avaliar associação entre o acúmulo protéico e presença da mutação P53 p.R337H, estágio tumoral ou óbito foram utilizados Teste Exato de Fisher ou Teste do Qui-quadrado. Para as análises de correlação foi utilizados o teste de correlação de Spearman. O software GraphPad Prism 4.0 (GraphPad, San Diego, CA) foi utilizado para as análises citadas anteriormente. A associação entre a presença das mutações avaliadas ou expressão gênica com o prognóstico foi feita por meio do teste de Log-rank e curva Kaplan-Meier com o auxílio dos softwares Minitab ${ }^{\circledR} 15$ (Minitab, State College, PA) e $\mathrm{R}^{\circledR}$ (R Foundation). Para as análises de Kaplan-Meier e expressão gênica, a expressão do gene de interesse nos TAC foi categorizada como reduzida (hipoexpresso) ou aumentada (hiperexpresso), se abaixo ou acima da mediana de $2^{-\mathrm{MCt}}$ das amostras dos controles (tecido adrenal normal), respectivamente. O limite de significância para todos os testes foi de $95 \%(\mathrm{p}<0,05)$.

\section{Aspectos Éticos}

O projeto de pesquisa e o termo de Consentimento Livre e Esclarecido foram aprovados pelo Comitê de Ética do HC-FMRP-USP (Parecer \#7534/2010). 
4. Resultados 


\section{Características clínicas}

As características de todos os pacientes avaliados estão detalhadas no anexo A. Foram avaliados 62 pacientes, sendo 48 do sexo feminino (77\%) e 14 do sexo masculino (23\%). A idade mediana ao diagnóstico foi 1,8 anos e a média foi $3,4 \pm 3,7$ anos $(0,4$ a 15 anos). Todos os pacientes avaliados apresentaram tumores secretores de hormônios, sendo 34 secretores de andrógenos, 2 secretores de cortisol e 26 mistos (secretores de andrógenos e cortisol) (Figura 4). Quanto ao estágio da doença ao diagnóstico de acordo com a classificação de Sandrini, 37 pacientes foram diagnosticados com estágio I, 10 com estágio II, 8 estágio com III e 7 estágio IV da doença.

As características histopatológicas de Weiss dos TAC provenientes do HCFMRP-USP estão descritas no anexo B.

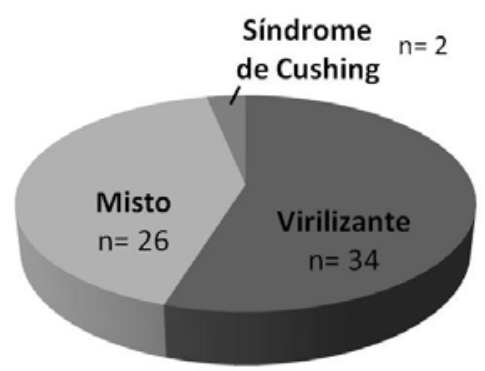

Figura 4. Distribuição dos TAC de acordo com o perfil de secreção hormonal.

\section{Tratamento e Evolução clínica}

Todos os pacientes foram submetidos à ressecção cirúrgica, sendo que, 12 pacientes, além da cirurgia, receberam tratamento complementar (mitotano isolado ou associado a quimioterápicos).

O período de seguimento variou de 0,1 a 14 anos, com mediana 4,3 e média \pm DP de 4,9 $\pm 4,1$ anos. A análise da curva Kaplan-Meier (Figura 5) revelou que a sobrevida global esteve associada com estágio tumoral, sendo mais elevada em pacientes em estágios iniciais (Log-rank: $\mathrm{p}<0,0001)$. Onze pacientes (18\%) morreram (5 estágio IV, 2 estágio III, 3 estágio II e 1 estágio I), com tempo médio de sobrevida de 10,8 meses e 3 perderam seguimento. A tabela 5 resume a evolução, bem como a causa dos óbitos destes pacientes. 


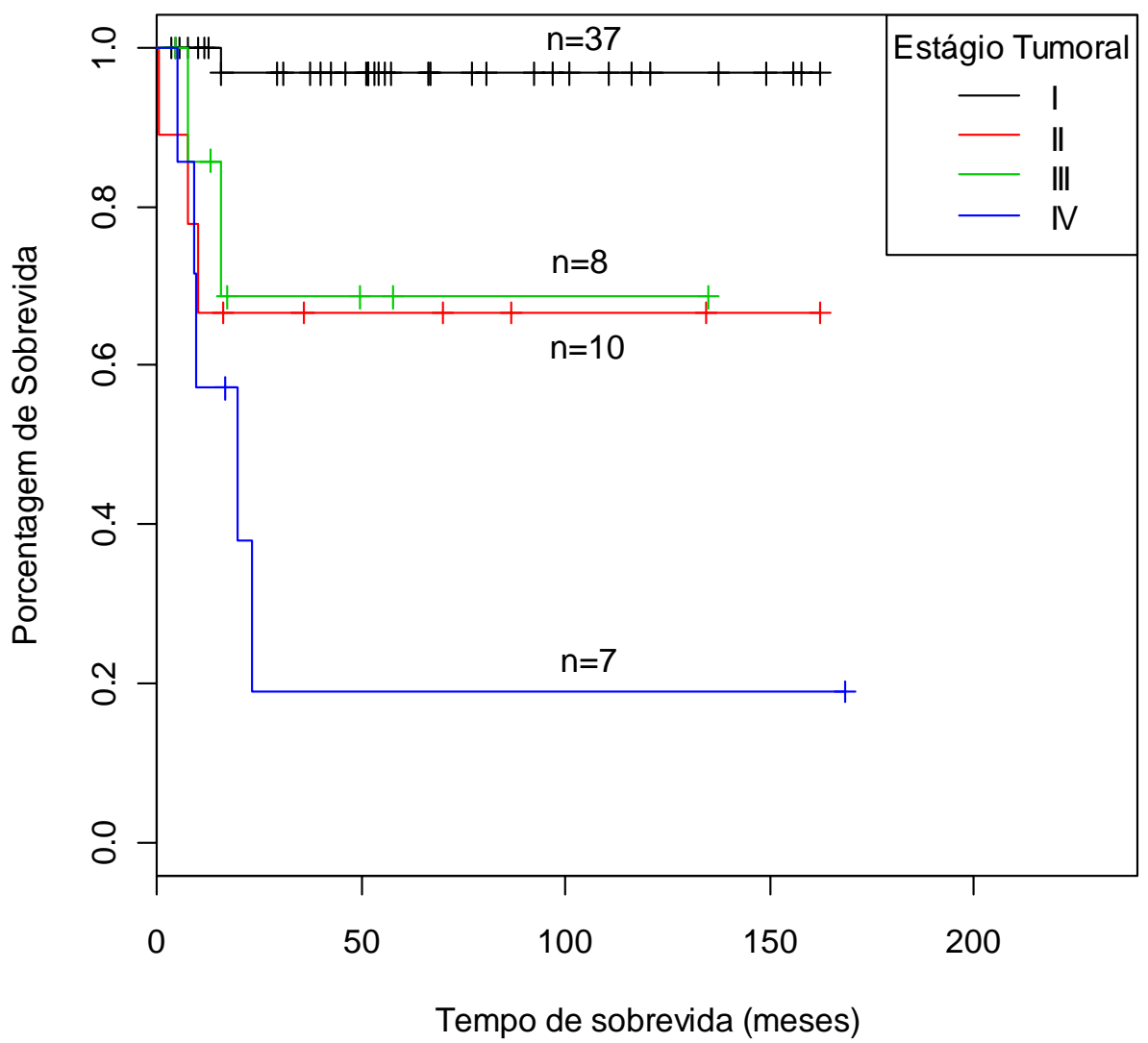

Figura 5. Sobrevida geral em pacientes com TAC de acordo com o estágio tumoral ao diagnóstico (Classificação de Sandrini).

Tabela 5 - Desfecho clínico dos 62 pacientes portadores de TAC analisados neste estudo segundo estadiamento tumoral.

\begin{tabular}{lll}
\hline \multicolumn{1}{c}{ Característica } & Estágio da Doença (n) & Causa morte (n=11) \\
\hline Óbito precoce & II (1) & Complicações do pós-operatório \\
Doença metastática & IV (4) e III (1) & Progressão da doença \\
Recidiva/Metástase & I (1), II (2) e III (2) & Progressão da doença \\
Vivo com recidiva/metástase & I (3) e II (1) & NA \\
Vivo em remissão total da doença & I (32), II (6), III (5) e IV ( 1) & NA \\
Perda de seguimento & I (1), III (1) e IV (1) & NA \\
\hline
\end{tabular}

NA: não se aplica 


\section{Mutação no gene TP53}

A mutação P53 p.R337H (c.1110G>A) do gene TP53 foi encontrada em 54 de 62 (87\%) TACs (Figura 6).

a)

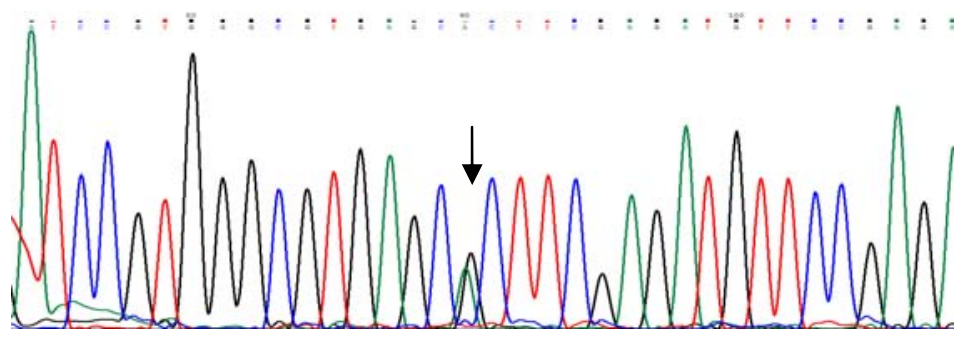

b)

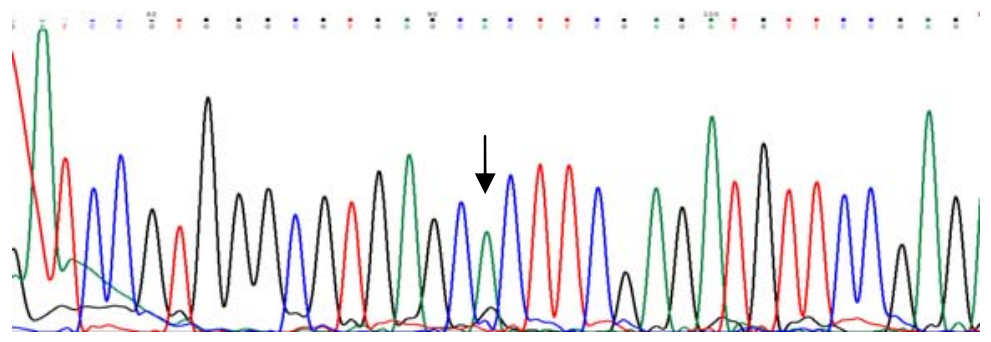

Figura 6. Mutação P53 p.R337H encontrada em heterozigose no DNA genômico (a) de paciente com TAC e a mesma mutação encontrada no tumor (b) deste paciente, demonstrando a perda do alelo nativo (LOH).

A presença desta mutação não esteve associada com estágio tumoral (Teste exato de Fisher: $\mathrm{p}=0,14$ ) ou sobrevida (Log-rank: $\mathrm{p}=0,148$; Figura 7).

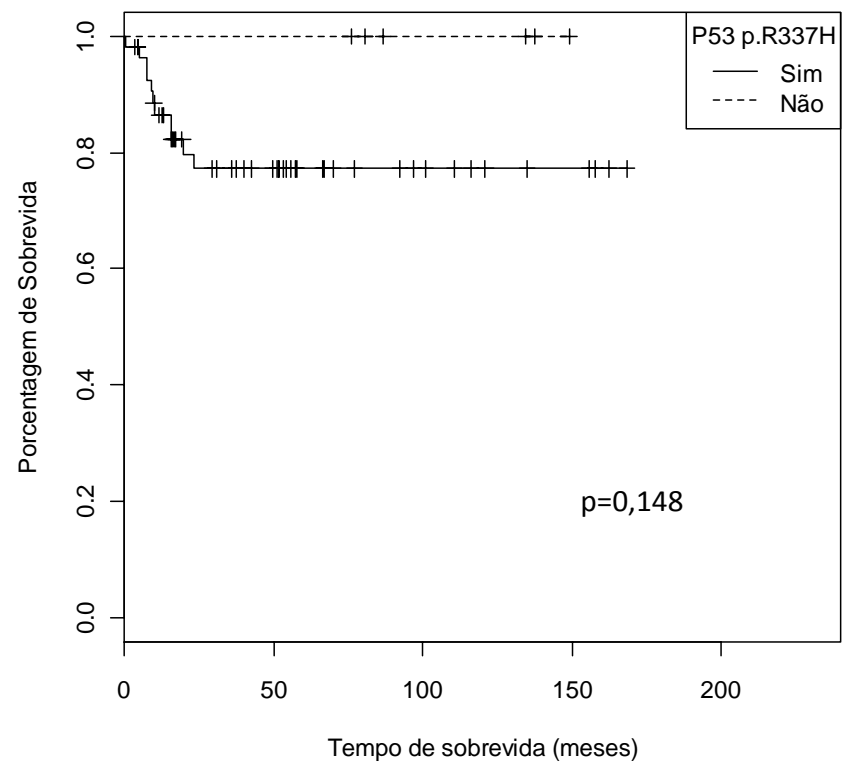

Figura 7. Sobrevida em pacientes com TAC de acordo com a presença da mutação P53 p.R337H. 


\section{Mutações no gene CTNNB1}

Mutações somáticas no gene CTNNB1 foram encontradas em 4 de $62(6 \%)$ dos TACs analisados. Estas mutações eram do tipo mutações em ponto no exon 3 alterando resíduos de serina nos códons 33 (c.97C >T, p.S33F; Figura 8a), 37 (c.109T >C, p.S37P; Figura 8b) e 45 (c.134C $>$ T, p.S45F, Figura 8c e p.S45P, c.133T $>$ C, Figura 8d). Estes resultados foram confirmados pelo ressequenciamento, utilizando-se primers sense e antissense. Todas as mutações encontradas já haviam sido descritas. Todas as mutações do gene CTNNB1 foram encontradas em TACs que também apresentavam a mutação P53 p.R337H. Estas mutações foram encontradas em TACs de pacientes com estágio tumoral variando de I a IV (Tabela 6).

a)

a)

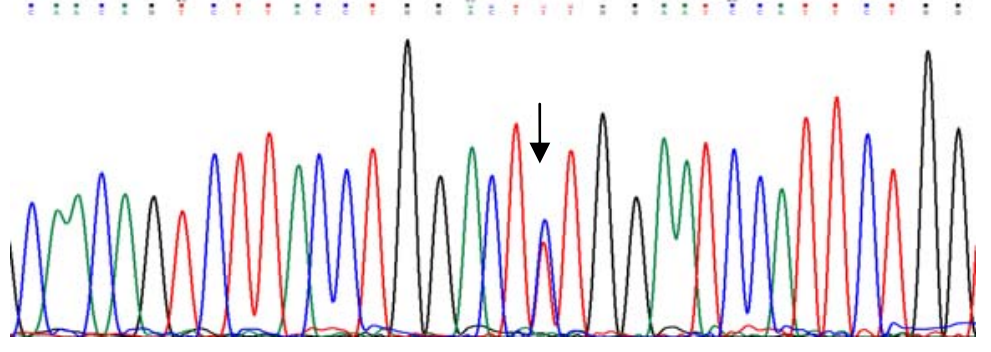

b)

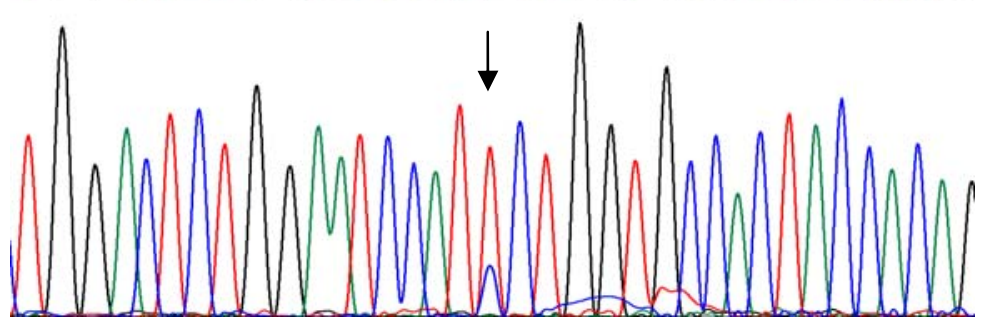

c)
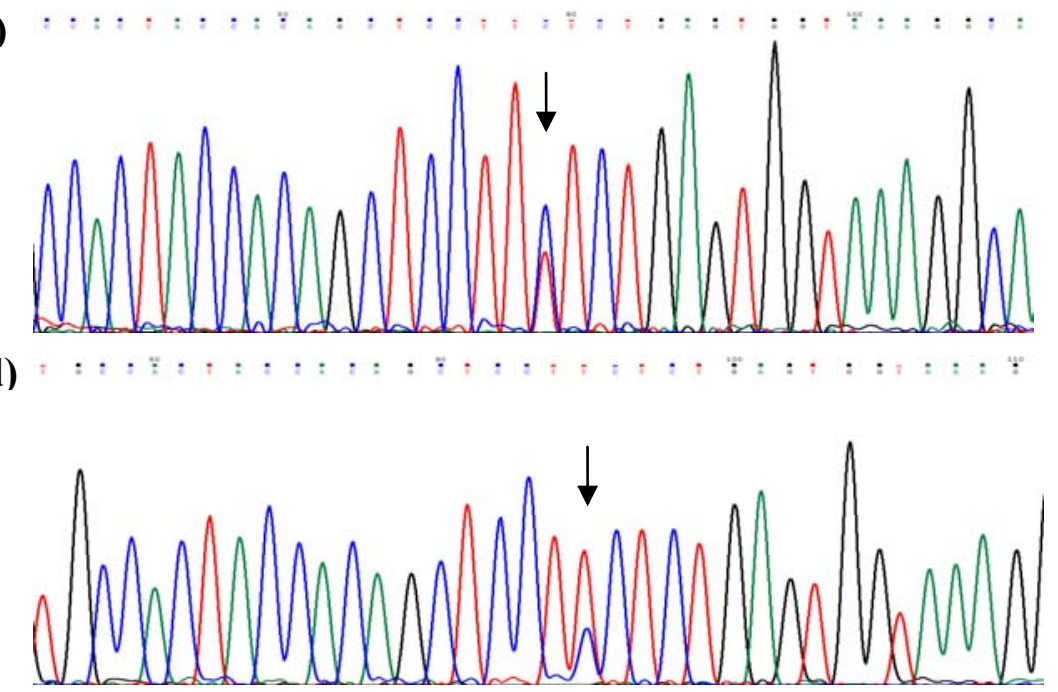

Figura 8. Seqüenciamento do cDNA do gene $C T N N B 1$, demonstrando as mutações identificadas em 4 TAC pediátricos: (a) p.S33F; (b) p.S37P; (c) p.S45F e (d) p.S45P. 
Tabela 6. Características dos pacientes com TAC com mutações no gene CTNNB1.

\begin{tabular}{cccccccc}
\hline ID & $\begin{array}{c}\text { Idade ao } \\
\text { diagnóstico } \\
\text { (meses) }\end{array}$ & $\begin{array}{c}\text { Estágio } \\
\text { tumoral }\end{array}$ & $\begin{array}{c}\text { Tipo } \\
\text { hormonal }\end{array}$ & $\begin{array}{c}\text { P53 } \\
\text { p.R337H }\end{array}$ & $\begin{array}{c}\text { Mutações } \\
\text { CTNNB1 }\end{array}$ & $\begin{array}{c}\text { Sobrevida } \\
\text { (meses) }\end{array}$ & Óbito \\
\hline 18 & 17 & I & Virilizante & Sim & p.S45F & 37,5 & Não \\
29 & 29 & I & Virilizante & Sim & p.S33F & 15,7 & Sim \\
51 & 19 & III & Virilizante & Sim & p.S37P & 7,6 & Sim \\
57 & 33 & IV & Virilizante & Sim & p.S45P & 4,9 & Sim \\
\hline
\end{tabular}

ID: identificação do paciente na tabela do anexo A.

Houve associação entre a presença de mutação no gene $C T N N B 1$ e óbito (Teste exato de Fisher: $\mathrm{p}=0,02)$ : três dos 4 pacientes no grupo com mutação no CTNNB1 morreram (75\%) enquanto que 8 dos 55 pacientes sem mutação neste gene morreram (15\%). Nesta análise não foram incluídos os 3 pacientes que perderam seguimento. Nestes 3 pacientes não foram observadas mutações no gene CTNNB1 e o tempo médio de seguimento foi de $12 \pm 7$ meses (5 a 17 meses).

\section{Expressão dos genes da via Wnt/ $\beta$-catenina}

\section{$\operatorname{RNAm}(\mathbf{P C R q})$}

\section{CTNNB1}

A expressão do RNAm do gene CTNNB1 foi aumentada 1,9 vezes nos tumores em comparação ao tecido de córtex adrenal normal (Figura 9a). A expressão deste gene em relação aos tumores de estágios I-II e aos tumores de estágios III-IV não foi diferente (Figura 9b). Em relação ao padrão hormonal, tumores mistos não apresentaram diferença de expressão do gene CTNNB1 quando comparados aos tumores virilizantes (Figura 9c). A expressão do RNAm deste gene não esteve associada à presença ou ausência da mutação P53 p.R337H (Figura 9d). Em relação à presença de mutações no gene CTNNB1, não houve diferença entre a expressão do RNAm do gene CTNNB1 nos tumores com mutações em relação aos tumores sem mutações deste gene (Figura 9e). 

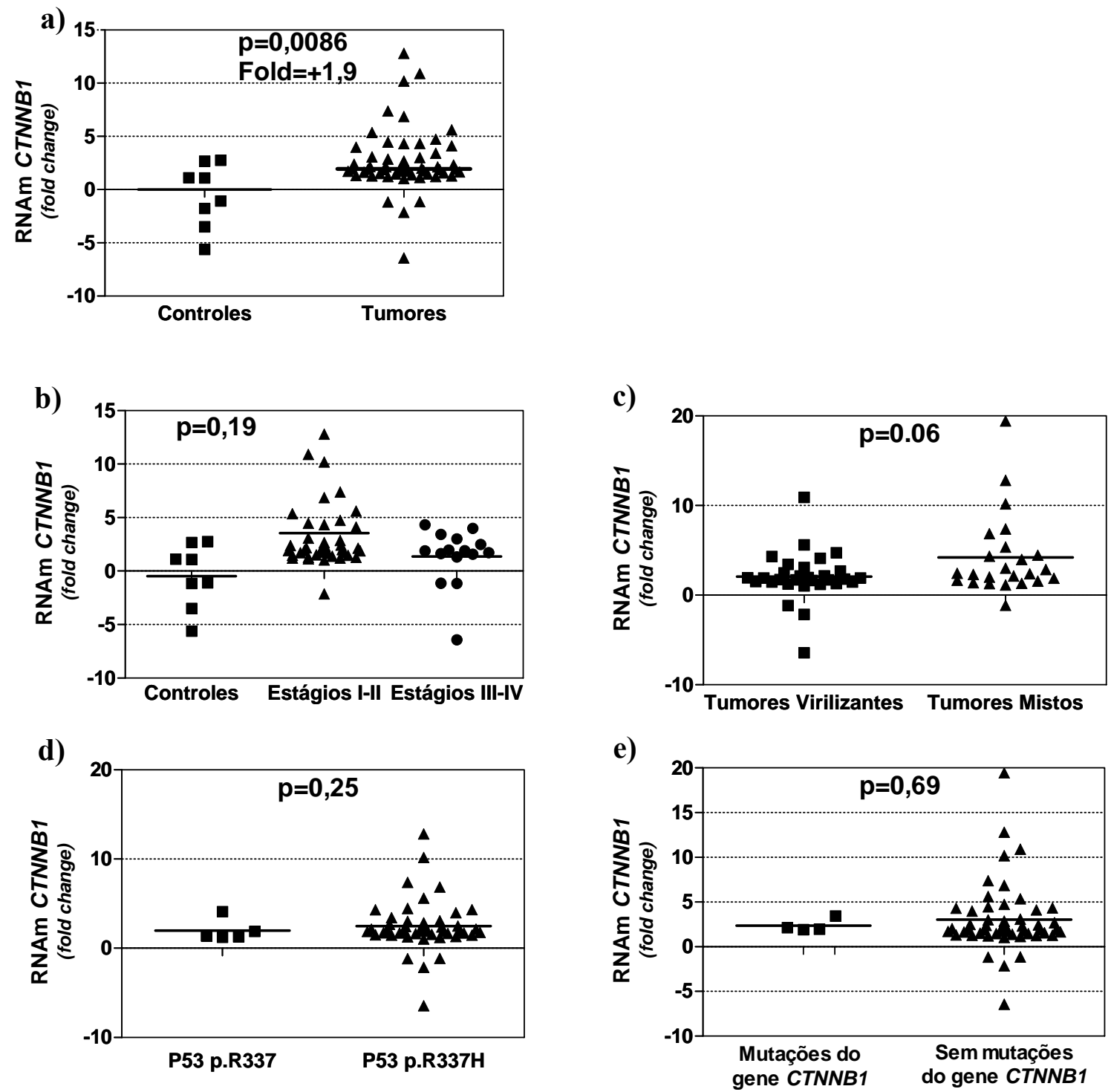

Figura 9. Expressão do RNAm de CTNNB1 em TAC pediátricos e controles (a), de acordo com o estágio tumoral (b), de acordo com o padrão de secreção hormonal (c) e em relação à presença da mutação P53 p.R337H (d) e à presença de mutações no gene $C T N N B 1$ (e). - corresponde à mediana de $2^{-\Delta \Delta C t}$ do grupo de amostras analisado. 
$D K K 3$

A expressão do RNAm do gene $D K K 3$ foi 14 vezes menor nos TACs comparados aos controles (Figura 10a). A expressão deste gene em relação aos tumores de estágios I-II e aos tumores de estágios III-IV não foi diferente (Figura 10b). Em relação ao padrão hormonal, tumores mistos não apresentaram diferença de expressão do gene $D K K 3$ quando comparados aos tumores virilizantes (Figura 10c). A expressão do RNAm deste gene não esteve associada à presença ou ausência da mutação P53 p.R337H (Figura 10d). Em relação à presença de mutações no gene da $\beta$ catenina, a expressão do RNAm do gene $D K K 3$ esteve 11,4 vezes diminuída nos tumores sem mutações da $\beta$-catenina em relação aos tumores com mutações da $\beta$-catenina (Figura 10e).

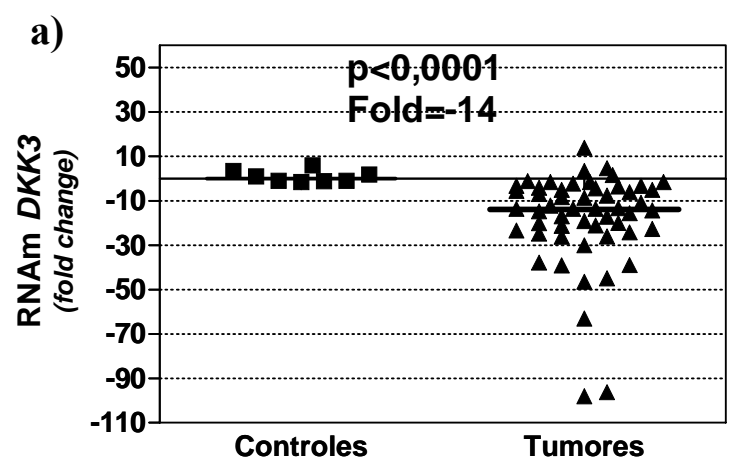

b)

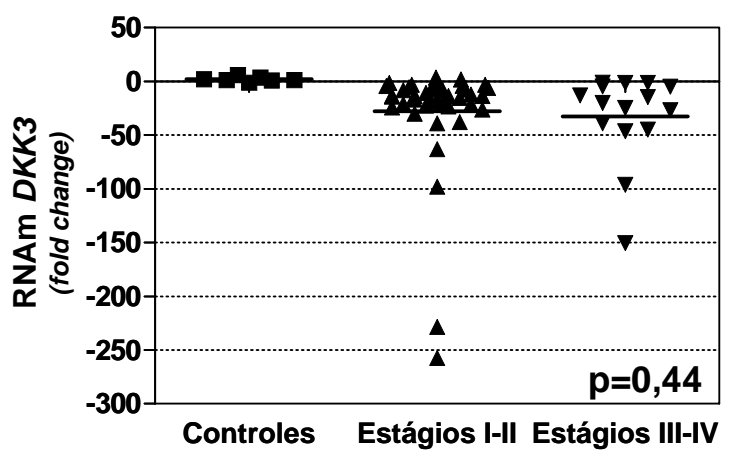

c)
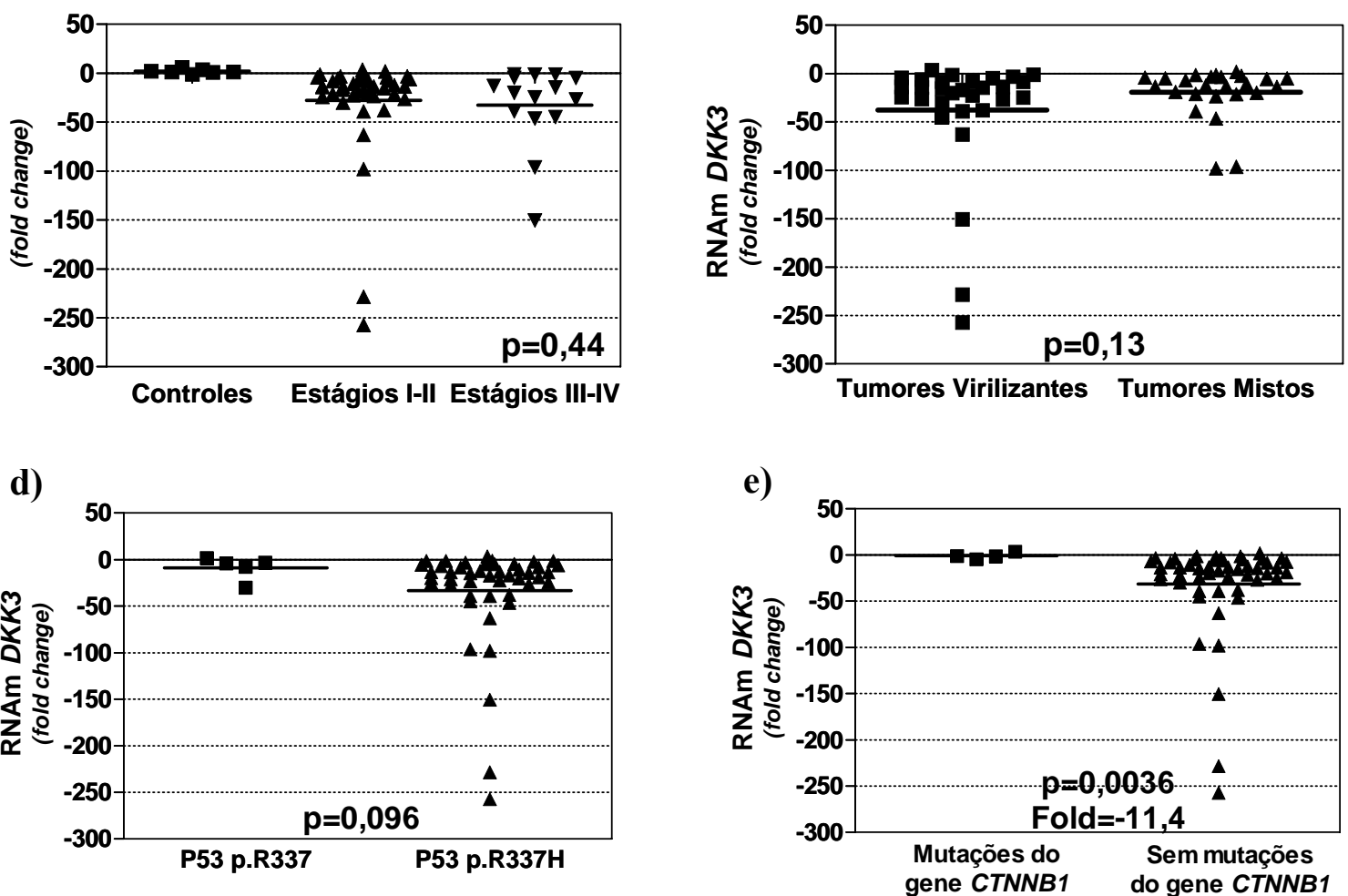

Figura 10. Expressão do RNAm de $D K K 3$ em TAC pediátricos e controles (a), de acordo com o estágio tumoral (b), de acordo com o padrão de secreção hormonal (c) e em relação à presença da mutação P53 p.R337H (d) e à presença de mutações no gene $C T N N B 1$ (e). - corresponde à mediana de $2^{-\Delta \Delta \mathrm{Ct}}$ do grupo de amostras analisado. 
SFRP1

A expressão do RNAm do gene $S F R P 1$ foi 4 vezes menor nos tumores em relação aos controles ( $p=0,05$; Figura 11a). Houve uma tendência de menor expressão deste gene nos tumores em estágios I-II comparada à expressão nos tumores de estágios III-IV $(p=0,06)$. Porém, a expressão do SFRP1 em TAC estágio I comparado com TAC estágio IV foi 6,5 vezes menor ( $p=0,015$; Figura $11 b$ ). Em relação ao padrão hormonal, tumores mistos não apresentaram diferença de expressão do gene SFRP1 quando comparados aos tumores virilizantes (Figura 11c). A expressão do RNAm deste gene não esteve associada à presença ou ausência da mutação P53 p.R337H (Figura 11d) e à mutações do gene CTNNB1 (Figura 11e). Em relação à sobrevida, a expressão reduzida do gene $S F R P 1$ associou-se com maior sobrevida (Log-rank: p=0,01; Figura 11f).
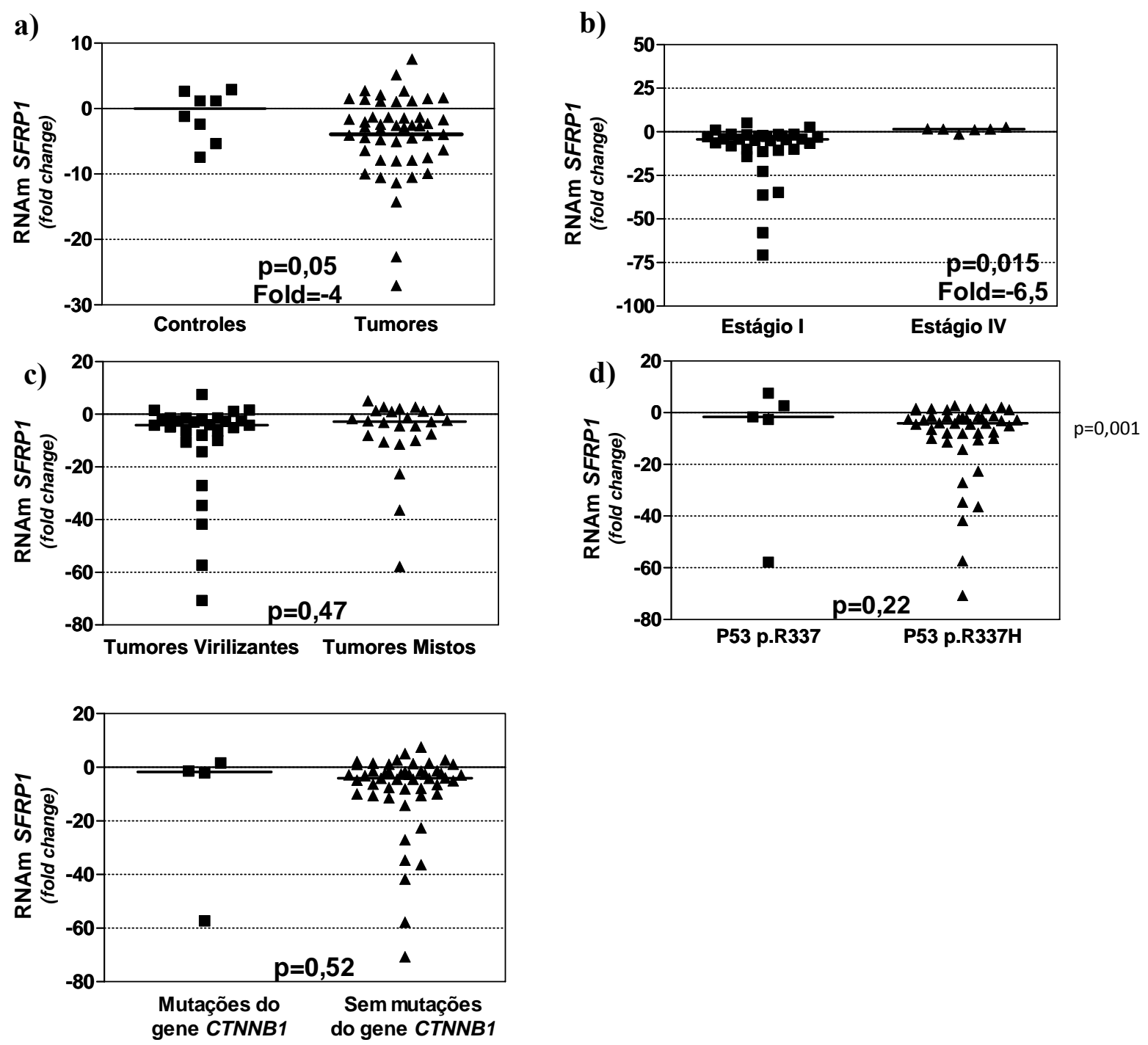

Figura 11(a-e). Expressão do RNAm de SFRP1 em TAC pediátricos e controles (a), de acordo com o estágio tumoral (b), padrão de secreção hormonal (c), em relação à presença da mutação P53 p.R337H (d), em relação à presença de mutações no gene $C T N N B 1$ (e). - corresponde à mediana de $2^{-\Delta \Delta C t}$ do grupo de amostras analisado. 


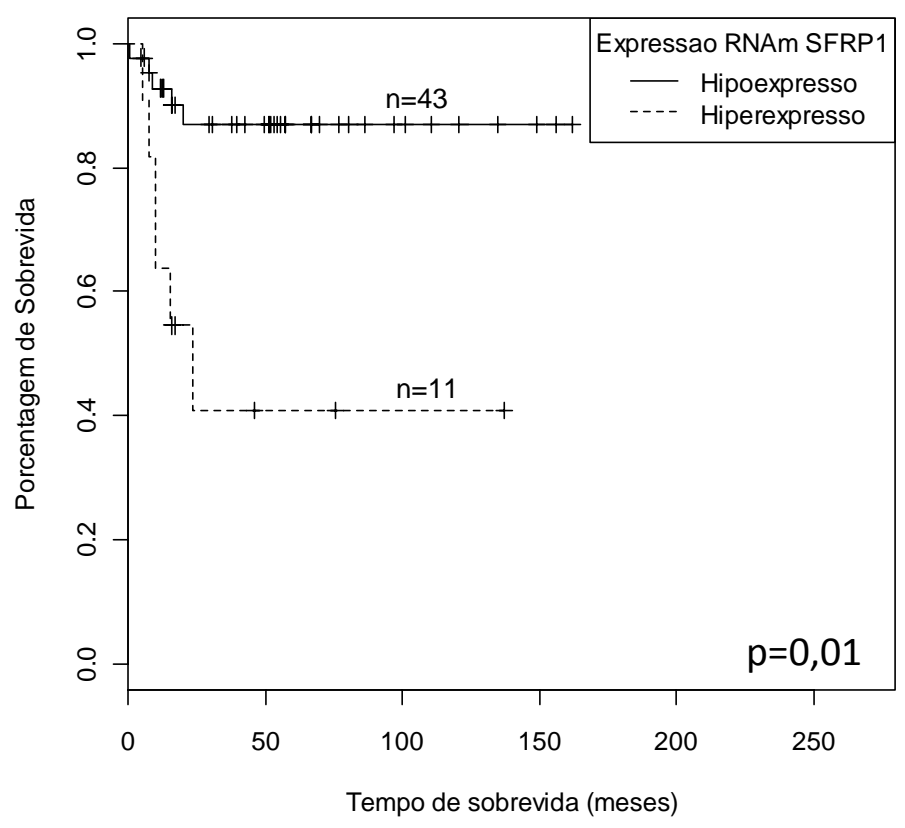

Figura 11(f). Expressão do RNAm de $S F R P 1$ em TAC pediátricos em relação à sobrevida.

AXIN1

A expressão do RNAm do gene $A X I N 1$ foi reduzida 1,6 vezes nos tumores em relação aos controles ( $p=0,04$; Figura 12a). A expressão deste gene em relação aos tumores de estágios I-II e aos tumores de estágios III-IV não foi diferente (Figura 12b). Em relação ao padrão hormonal, tumores mistos não apresentaram diferença de expressão do gene $A X I N 1$ quando comparados aos tumores virilizantes (Figura 12c). A expressão do RNAm deste gene não esteve associada à presença ou ausência da mutação P53 p.R337H (Figura 12d) e à mutações do gene CTNNB1 (Figura 12e). 

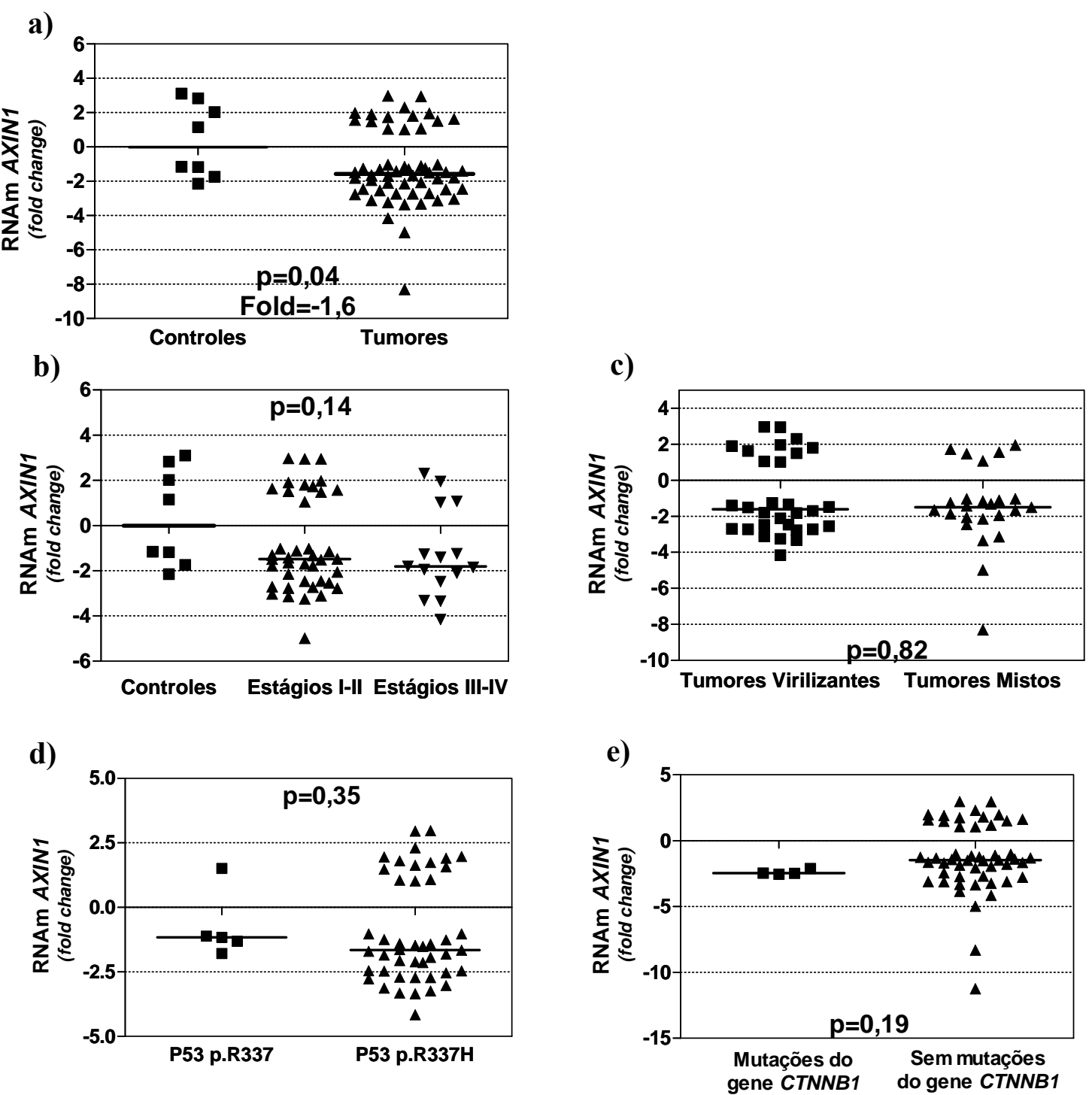

Figura 12. Expressão do RNAm de $A X I N 1$ em TAC pediátricos e controles (a), de acordo com o estágio tumoral (b), de acordo com o padrão de secreção hormonal (c) e em relação à presença da mutação P53 p.R337H (d) e à presença de mutações no gene $C T N N B 1$ (e). - corresponde à mediana de $2^{-\Delta \Delta C t}$ do grupo de amostras analisado.

A expressão do RNAm do gene $M Y C$ foi 2,8 vezes menor nos tumores comparados aos controles (Figura 13a; $\mathrm{p}=0,03$ ) e observamos que menor expressão deste gene estava presente nos estágios mais avançados da doença (-2,9 vezes; Figura 13b; $\mathrm{p}=0,028)$ quando comparados aos estágios iniciais da doença e aos controles. Em relação ao padrão hormonal, tumores virilizantes e tumores mistos não apresentaram expressão diferencial de $M Y C$ (figura 13c). A expressão do RNAm deste gene não esteve associada à presença ou ausência da mutação P53 p.R337H (Figura 13d) e à mutações do gene CTNNB1 (Figura 13e). 


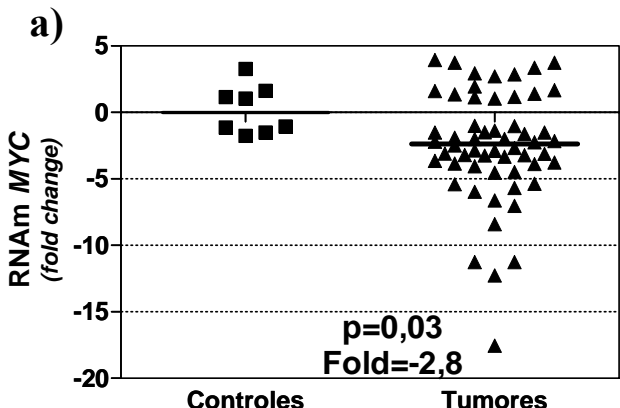

b)

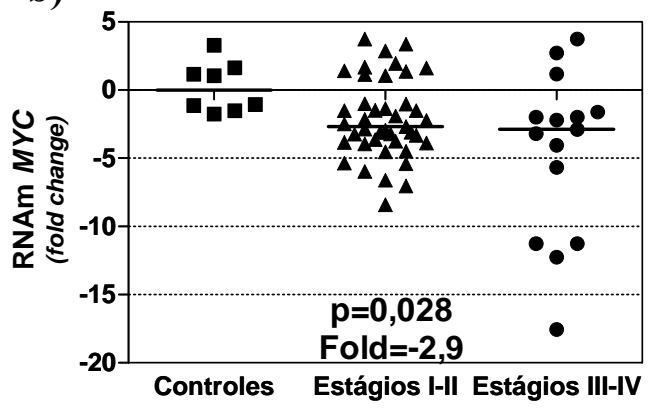

d)

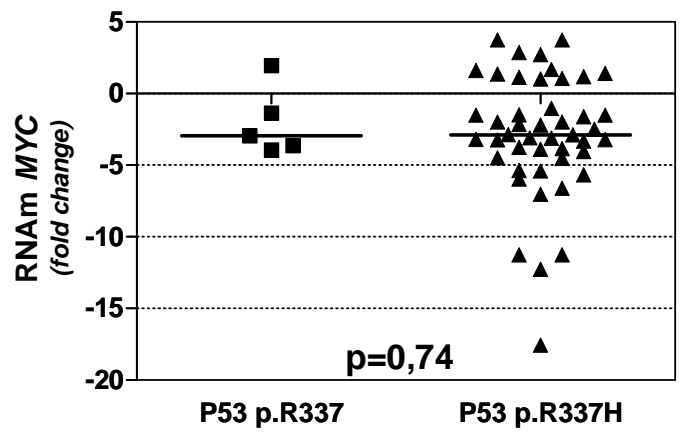

c)

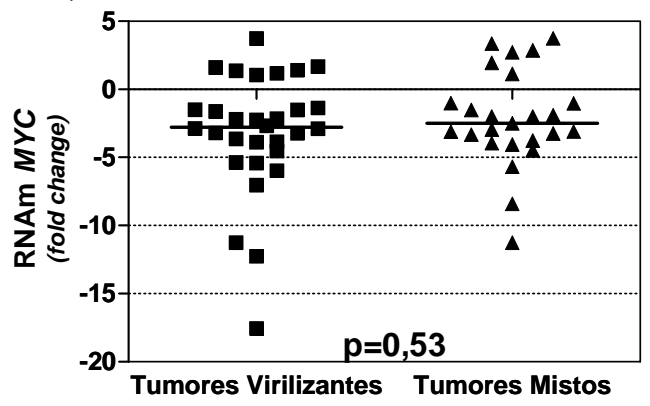

e)

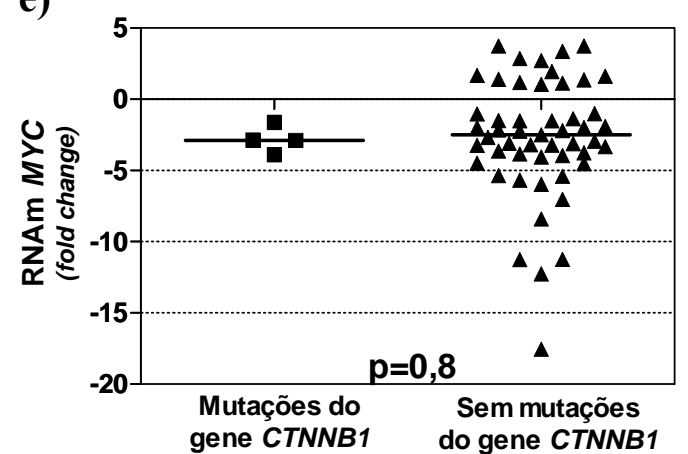

Figura 13. Expressão do RNAm de $M Y C$ em TAC pediátricos e controles (a), de acordo com o estágio tumoral (b), de acordo com o padrão de secreção hormonal (c) e em relação à presença da mutação P53 p.R337H (d) e à presença de mutações no gene $C T N N B 1(\mathrm{e})$. - corresponde à mediana de $2^{-\Delta A \mathrm{Ct}}$ do grupo de amostras analisado.

TCF7

A expressão do RNAm do fator de transcrição $T C F 7$ foi 3 vezes menor nos tumores comparados aos controles (Figura $14 \mathrm{a} p=0,007$ ) e observamos que menor expressão deste gene esteve presente principalmente nos tumores em estágios iniciais $(-4,9$ vezes; Figura $14 \mathrm{~b}$ $\mathrm{p}=0,006)$. Em relação ao padrão hormonal, tumores virilizantes e tumores mistos não apresentaram expressão diferencial de TCF7 (Figura 14c). A expressão do RNAm deste gene não esteve associada à presença ou ausência da mutação P53 p.R337H (Figura 14d). Quanto à presença de mutações no gene $C T N N B 1$, a expressão do RNAm do gene $T C F 7$ esteve 11,1 
vezes diminuída nos tumores sem mutações em relação aos tumores com mutações neste gene (Figuras 14e). Em relação à sobrevida, a expressão reduzida do gene TCF7 associou-se com maior sobrevida (Log-Rank: $\mathrm{p}<0,01$ Figura 14f).
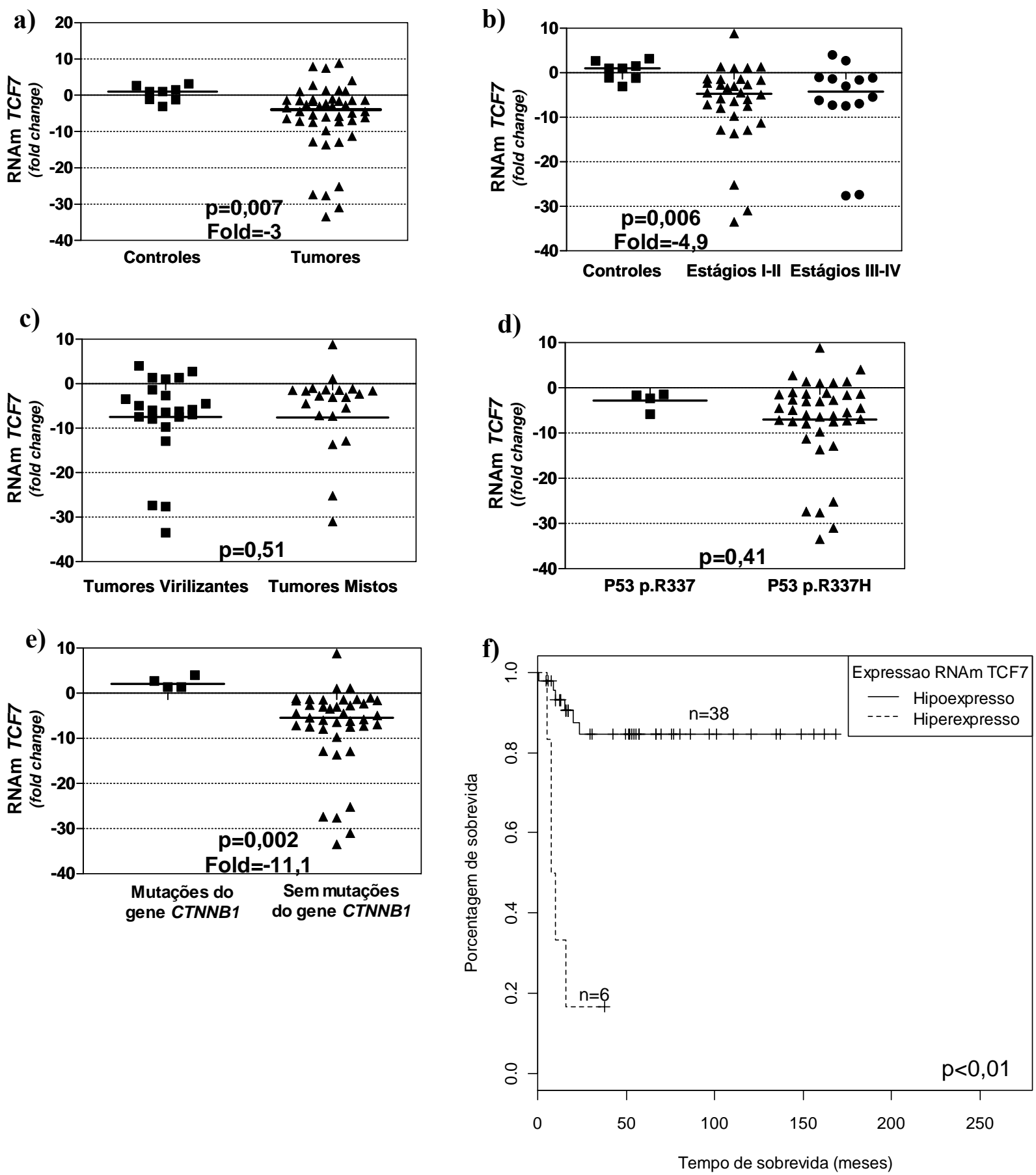

Figura 14. Expressão do RNAm de TCF7 em TAC pediátricos e controles (a), de acordo com o estágio tumoral (b), padrão de secreção hormonal (c), em relação à presença da mutação $\mathrm{P} 53$ p.R337H (d), em relação à presença de mutações no gene $C T N N B 1$ (e) e sobrevida (f). - corresponde à mediana de $2^{-\Delta \Delta C t}$ do grupo de amostras analisado. 
WNT4

A expressão do RNAm do gene WNT4 foi 6,1 vezes menor nos tumores comparados aos controles (Figura 15a p=0,02) e observamos que menor expressão deste gene estava presente nos estágios iniciais da doença $(-13,9$ vezes; Figura $15 b$ p=0,02). Em relação ao padrão hormonal, tumores virilizantes e tumores mistos não apresentaram expressão diferencial de WNT4 (Figura 15c). A expressão do RNAm deste gene não esteve associada à presença ou ausência da mutação P53 p.R337H (Figura 15d). Em relação à presença de mutações no gene no gene $C T N N B 1$, a expressão do RNAm do gene WNT4 esteve 16,4 vezes diminuída nos tumores sem mutações compardos aos tumores com mutações neste gene (Figura 15e). A hipoexpressão deste gene esteve associado a maior sobrevida dos pacientes avaliados (Log-Rank: $\mathrm{p}=0,004$; Figura 15f).

a)
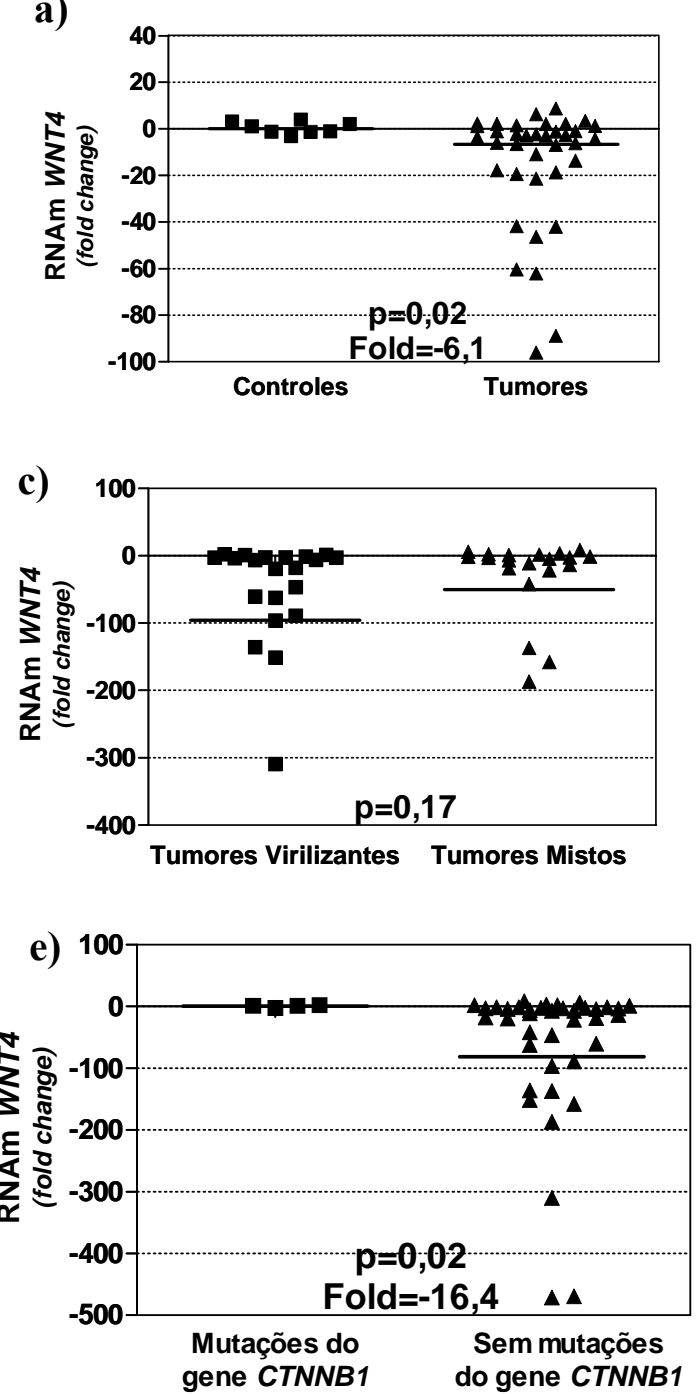
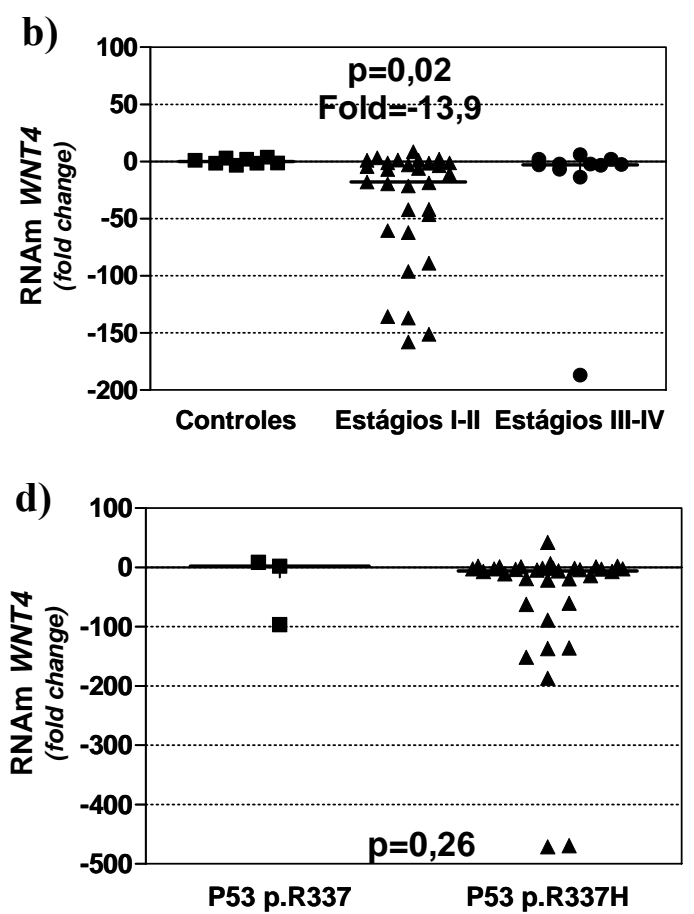

Figura 15 (a-e). Expressão do RNAm de WNT4 em TAC pediátricos e controles (a), de acordo com o estágio tumoral (b), padrão de secreção hormonal (c), em relação à presença da mutação P53 p.R337H (d), em relação à presença de mutações no gene $\operatorname{CTNNB1}(\mathrm{e})$. - corresponde à mediana de $2^{-\Delta C \mathrm{Ct}}$ do grupo de amostras analisado. 


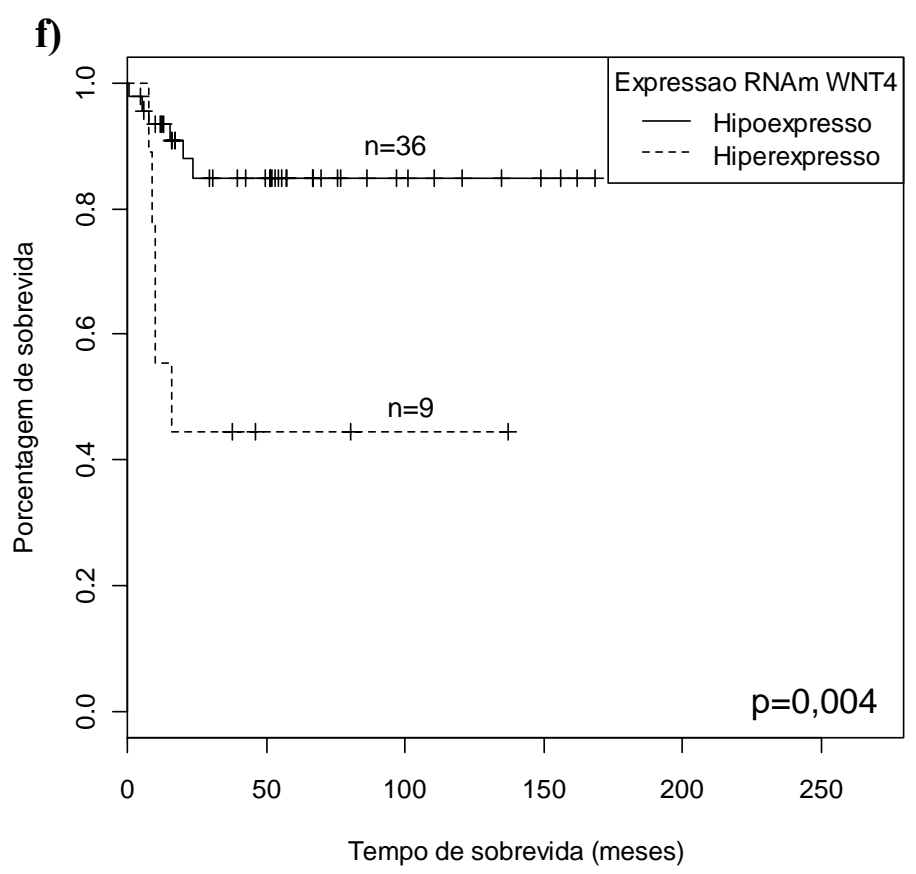

Figura 15 (f). Expressão do RNAm de WNT4 em TAC pediátricos em relação à sobrevida.

TP53

A expressão do RNAm do gene TP53 não foi diferente entre os tumores e as amostras controles (Figura 16a), mas quando analisados de acordo com o estágio tumoral, os tumores de estágios mais avançados apresentaram menor expressão deste gene quando comparados aos tumores de estágios inicias e aos controles (-2 vezes; $p=0,004$ - figura 16b). Em relação ao padrão hormonal, tumores virilizantes e tumores mistos não apresentaram diferença na expressão de TP53 (Figura 16c). Os tumores carreando a mutação P53 p.R337H apresentaram expressão reduzida do RNAm de TP53 em relação aos tumores sem esta mutação (-2,3 vezes; $\mathrm{p}=0,04$ - Figura 16d). Em relação à presença de mutações no gene $C T N N B 1$, não houve diferença entre a expressão do RNAm do gene TP53 nos tumores com mutações em relação aos tumores sem mutações (Figura 16e). 
a)

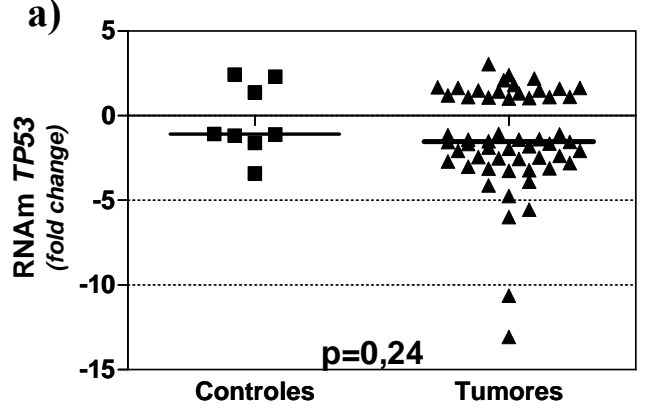

b)
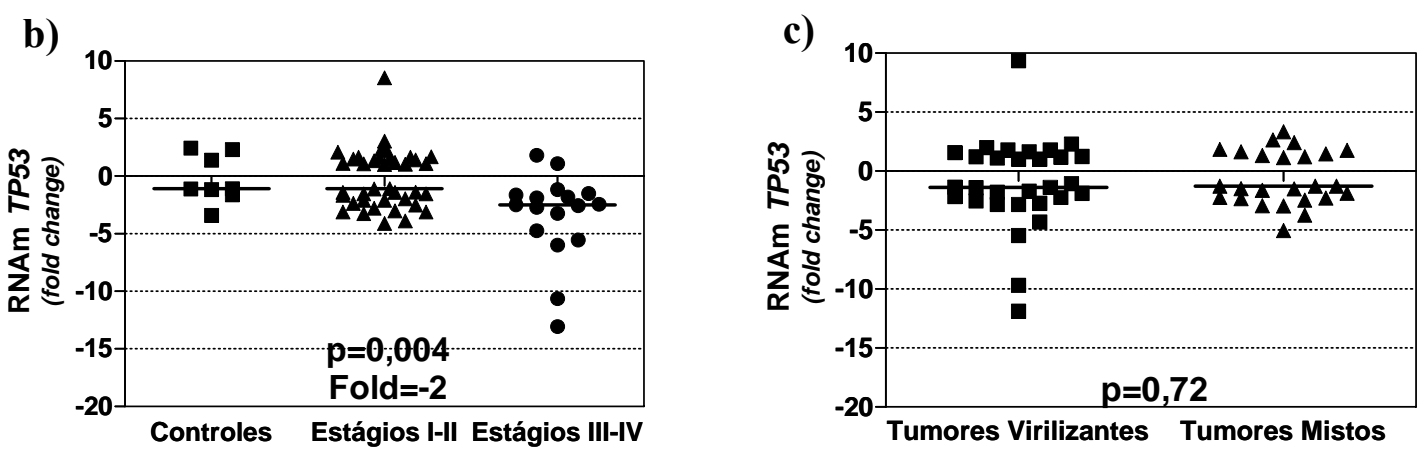

d)

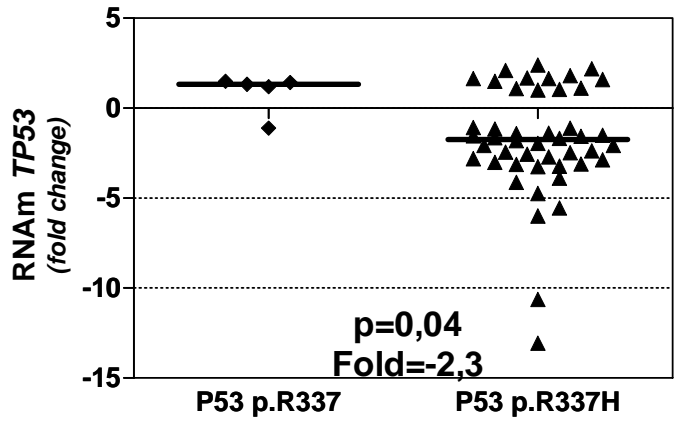

e)

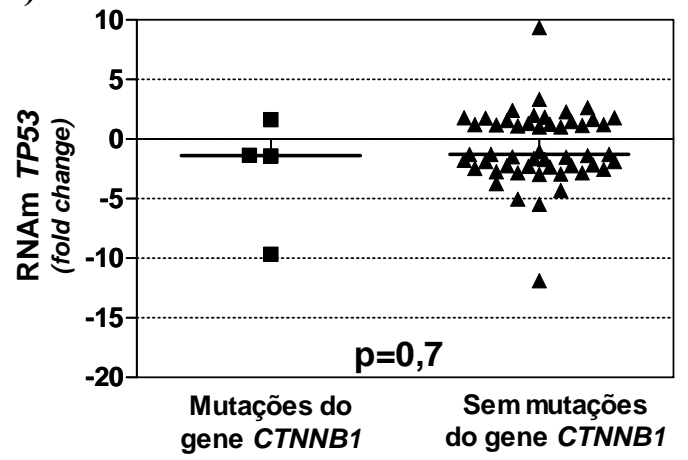

Figura 16. Expressão do RNAm de TP53 em TAC pediátricos e controles (a), de acordo com o estágio tumoral (b), de acordo com o padrão de secreção hormonal (c) e em relação à presença da mutação p.P53 R337H (d) e à presença de mutações no gene $C T N N B 1$ (e). - corresponde à mediana de $2^{-\Delta \Delta C t}$ do grupo de amostras analisado.

$A P C$

A expressão do RNAm do gene $A P C$ foi 2,4 vezes maior nos TAC comparados aos controles ( $p=0,01$ Figura 17a) e observamos que maior expressão deste gene estava presente nos estágios iniciais da doença (2,8 vezes; $\mathrm{p}=0,04$; figura $17 \mathrm{~b})$. A expressão deste gene não esteve associada ao padrão hormonal (Figura 17c), à presença ou ausência da mutação P53 p.R337H (Figura 17d) e à presença de mutações no gene CTNNB1 (Figura 17e). 


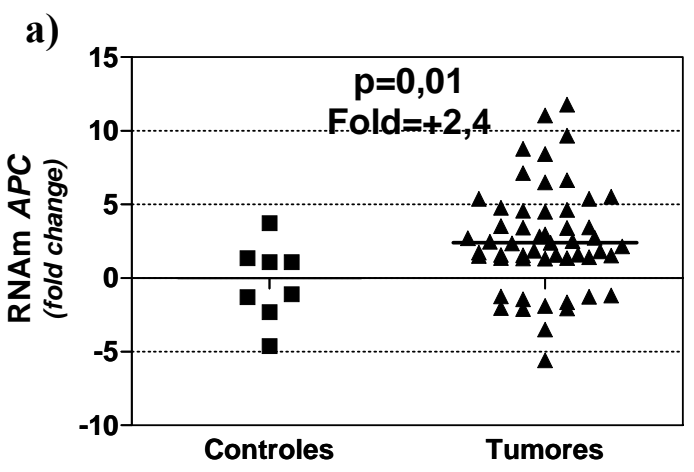

b)
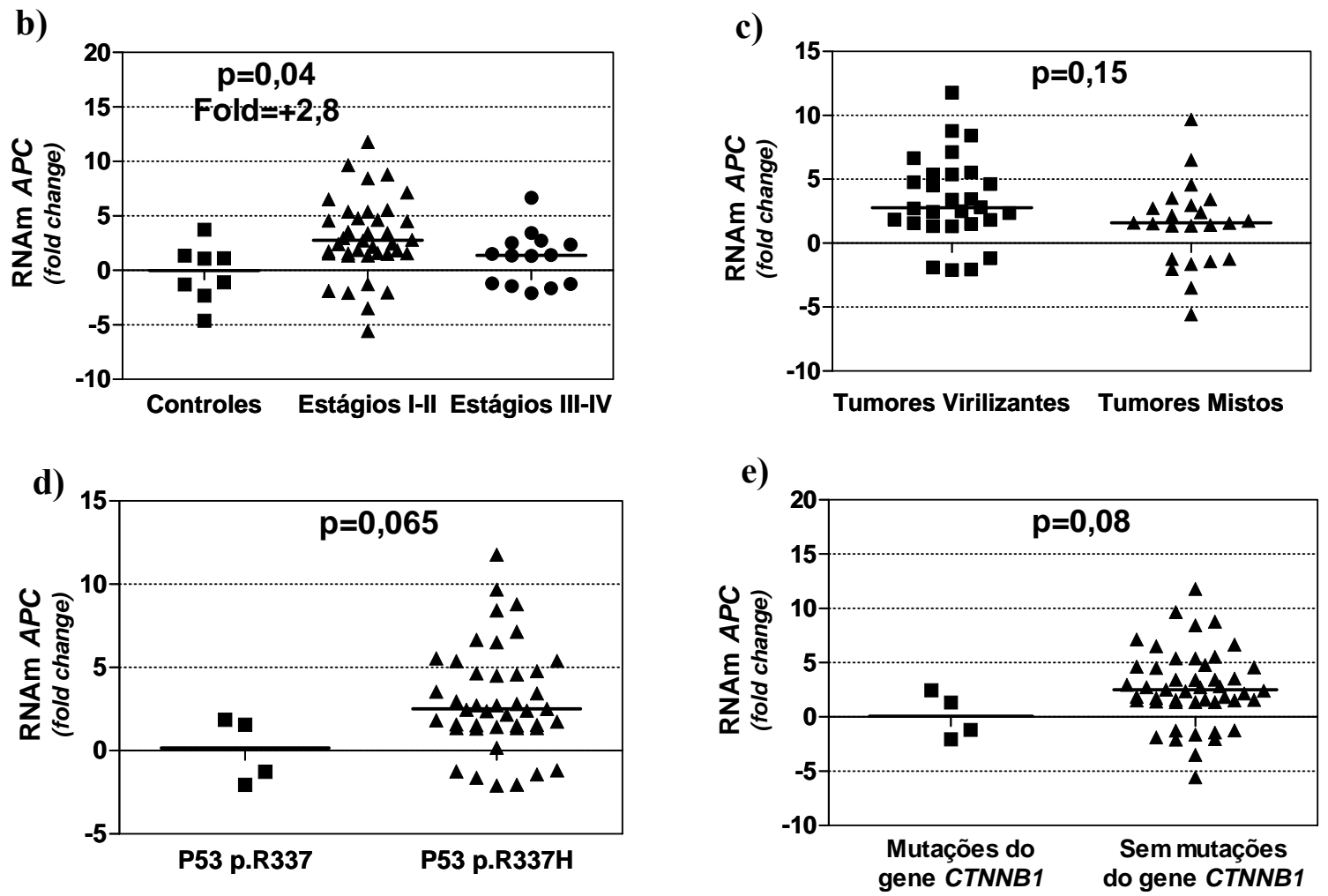

Figura 17. Expressão do RNAm de $A P C$ em TAC pediátricos e controles (a), de acordo com o estágio tumoral (b), de acordo com o padrão de secreção hormonal (c) e em relação à presença da mutação p.P53 R337H (d) e à presença de mutações no gene $C T N N B 1$ (e). - corresponde à mediana de $2^{-\Delta \Delta \mathrm{Ct}}$ do grupo de amostras analisado.

WISP2

A expressão do RNAm do gene WISP2 não foi diferente entre os tumores e as amostras controles (Figura 18a) e quando analisada em relação aos diferentes estágios tumorais, a expressão deste gente também não foi diferente (figuras 18b). Em relação ao padrão hormonal, tumores virilizantes e tumores mistos não apresentaram diferença na expressão de WISP2 (figuras 18c). A expressão deste gene não esteve associada à presença ou ausência da mutação P53 p.R337H (figuras 18d). Em relação à presença de mutações no gene CTNNB1, a expressão do RNAm do gene WISP2 esteve 15,2 vezes diminuída nos tumores com mutações em relação aos tumores sem mutações (figuras 18e). 
a)

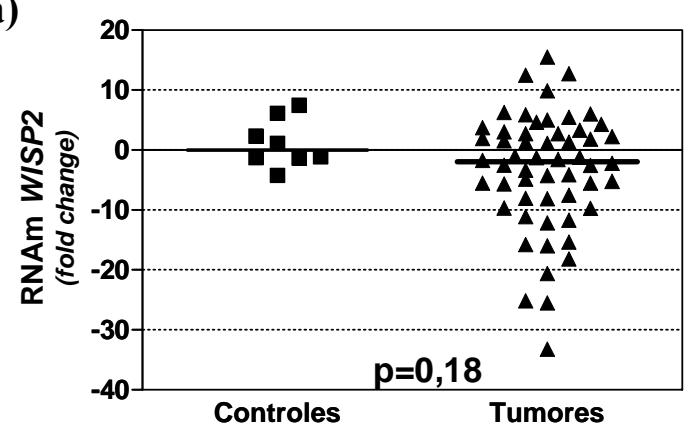

b)

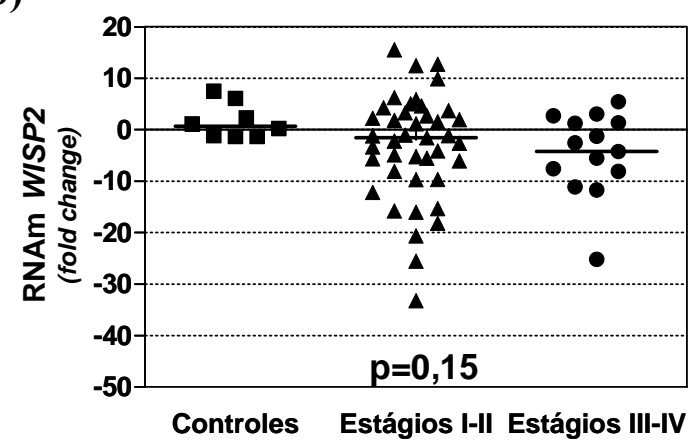

d)

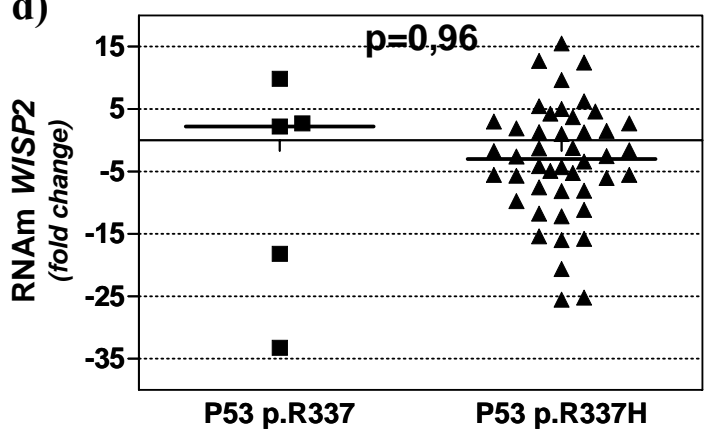

c)

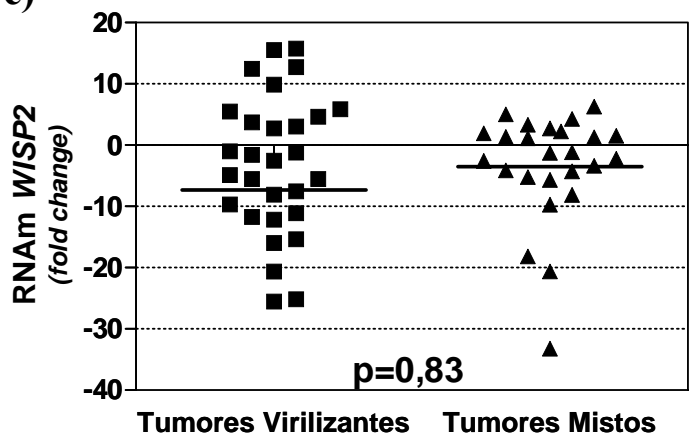

e)

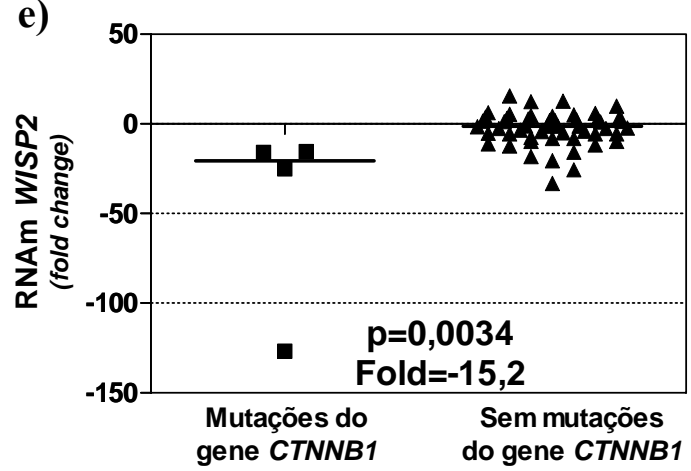

Figura 18. Expressão do RNAm de WISP2 em TAC pediátricos e controles (a), de acordo com o estágio tumoral (b), de acordo com o padrão de secreção hormonal (c) e em relação à presença da mutação p.P53 R337H (d) e à presença de mutações no gene $C T N N B 1(\mathrm{e})$. - corresponde à mediana de $2^{-\Delta \Lambda \mathrm{Ct}}$ do grupo de amostras analisado.

Correlação entre a expressão de RNAm do gene TP53 e dos genes da via Wnt/B-catenina

O teste de correlação de Spearman demonstrou que a expressão do RNAm gene TP53 correlacionou-se positivamente com a expressão do RNAm de alguns genes da via Wnt: DKK3 ( $\mathrm{p}=0,0039 ; \mathrm{r}=0,39 ;$ Figura 19a), MYC ( $\mathrm{p}=0,0003 ; \mathrm{r}=0,47 ;$ Figura 19b), WISP2 $(\mathrm{p}=0,0017 ; \mathrm{r}=0,42$; Figura 19c) e $A X I N 1$ ( $<<0,0001 ; \mathrm{r}=0,52$; Figura 19d). 
a)

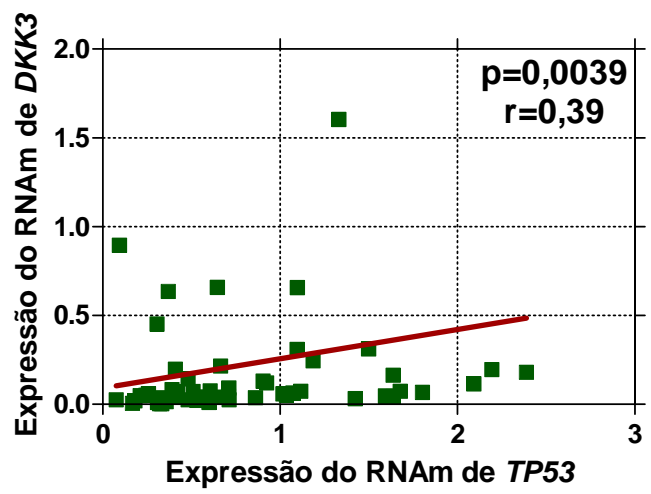

c)

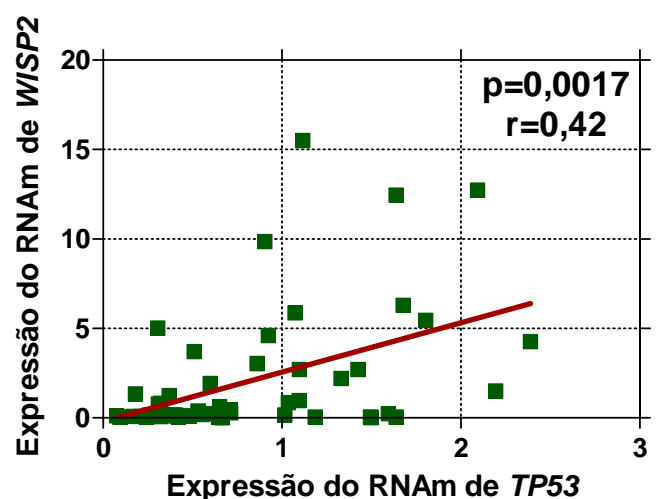

b)

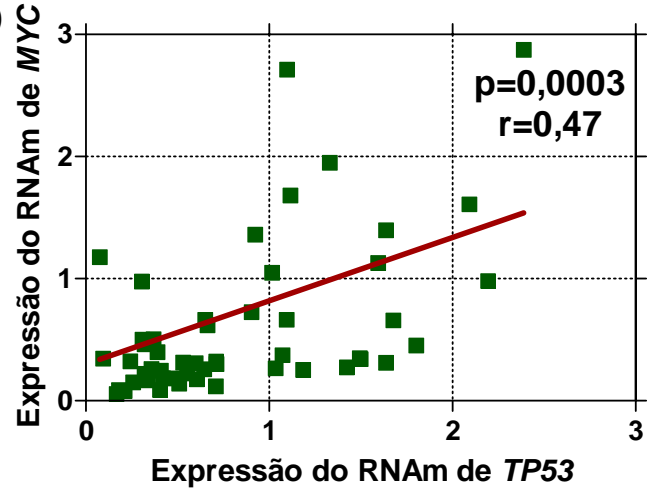

d)

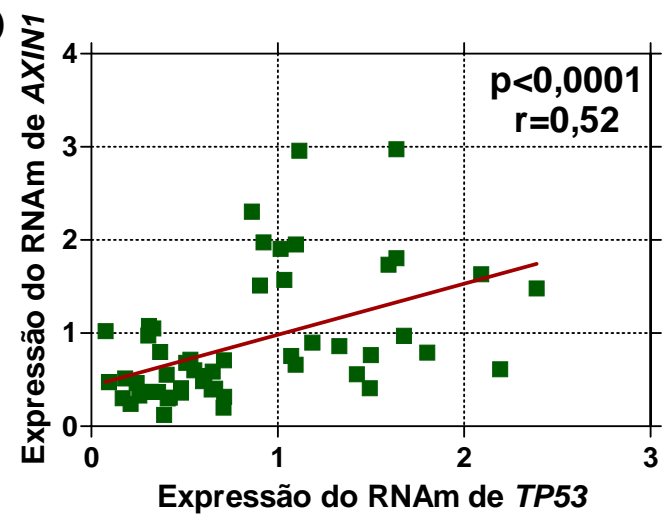

Figura 19. Correlação entre a expressão do RNAm de TP53 e alguns componentes e genes-alvo da via Wnt/ $\beta$ catenina em TAC pediátricos. DKK3 (a), MYC (b), WISP2 (c) e AXIN1 (d).

\section{Expressão Protéica (Imunoistoquímica)}

A expressão protéica de $\beta$-catenina, alguns componentes da via Wnt, genes alvo e de P53 foi avaliada em um subgrupo de TAC $(n=25)$. Para cada marcador específico o número de amostras tumorais incluídas na análise pode ter variado discretamente, em função de limitações técnicas do procedimento.

\section{$\beta$-CATENINA}

Em 17 de 24 TAC analisados (71\%) foi observado acúmulo citoplasmático e/ou nuclear (Figura 20a e Figura 20b) de $\beta$-catenina. Acúmulo nuclear de $\beta$-catenina foi encontrado em 3 TAC analisados (13\%), nenhum deles carreando mutações de CTNNB1. Nos 4 tumores carreadores de mutações do $C T N N B 1$, foi observado acúmulo citoplasmático fraco ou moderado. $\mathrm{O}$ acúmulo de $\beta$-catenina não se associou a estágio tumoral (Teste quiquadrado: $\mathrm{p}=0,8$ ) ou desfecho desfavorável (Teste exato de Fisher: $\mathrm{p}=1,0$ ). 

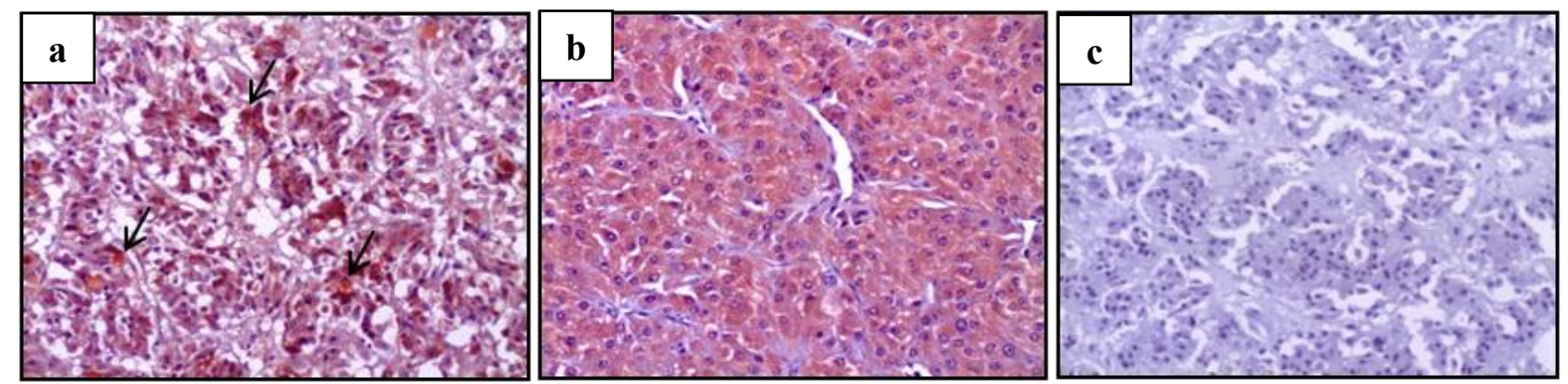

Figura 20. Imunoistoquímica para $\beta$-Catenina (em vermelho) em TAC pediátrico demonstrando acúmulo nuclear (a; setas) e citoplasmático (b); tecido adrenal normal adjacente (Hematoxilina de Harris; c). Magnificação X 400.

P53

Em 15 dos 25 TAC analisados (60\%) foi observado pouco (1+) ou nenhum acúmulo de P53. Em alguns tumores, o padrão clássico de acúmulo nuclear foi observado (Figura 21a). Acúmulo difuso forte $(+3)$ ou moderado $(+2)$ foi observado em 10 das 25 amostras analisadas (40\%) (Figura 21b). IHQ para P53 não se associou com a presença da mutação P53 p.R337H (Teste exato de Fisher: $p=0,6$ ), estágio tumoral (Teste qui-quadrado: $p=0,3$ ) ou óbito (Teste exato de Fisher: $\mathrm{p}=1,0)$.
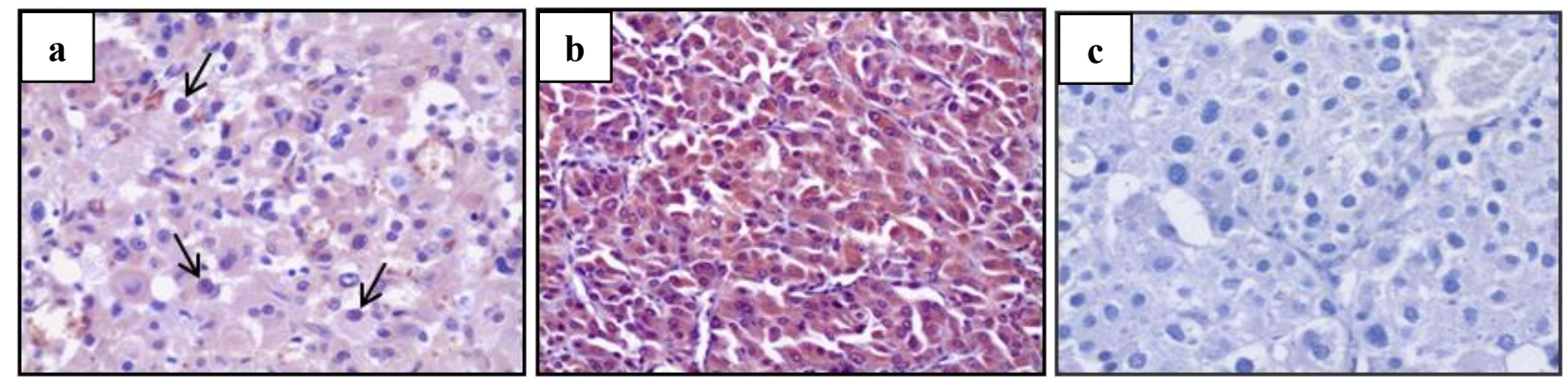

Figura 21. Imunoistoquímica para P53 (em vermelho) em TAC pediátricos demonstrando acúmulo nuclear (a; setas) e citoplasmático (b); tecido adrenal normal adjacente (c). Magnificação X 400.

DKK3

Em 13 de 22 TAC analisados (59\%), foi observado nenhum ou pouco (1+) acúmulo de DKK3 (Figura 22a). Marcação difusa, demonstrando acúmulo de DKK3, foi observada em 9 dos 22 TAC analisados (41\%; Figura 22b). 

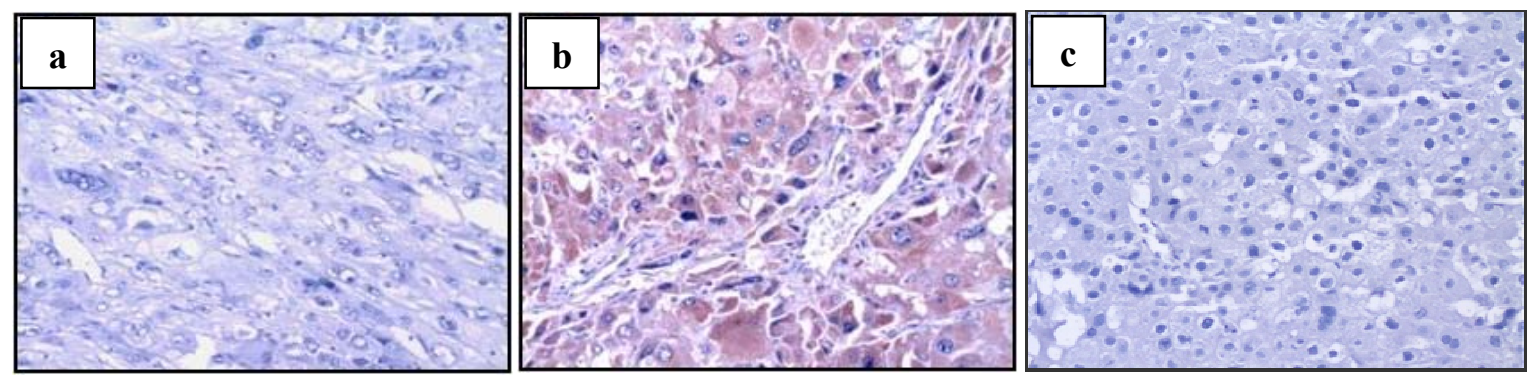

Figura 22. Imunoistoquímica para DKK3 (em vermelho) em TAC pediátrico indicando ausência (a) e presença de marcação (b); tecido adrenal normal adjacente (c). Magnificação X 400.

MYC

Em 15 de 23 dos TAC analisados (65\%), foi observada ausência ou expressão fraca de MYC. Marcação focal, demonstrando expressão de MYC em TAC está representada na Figura 23a.
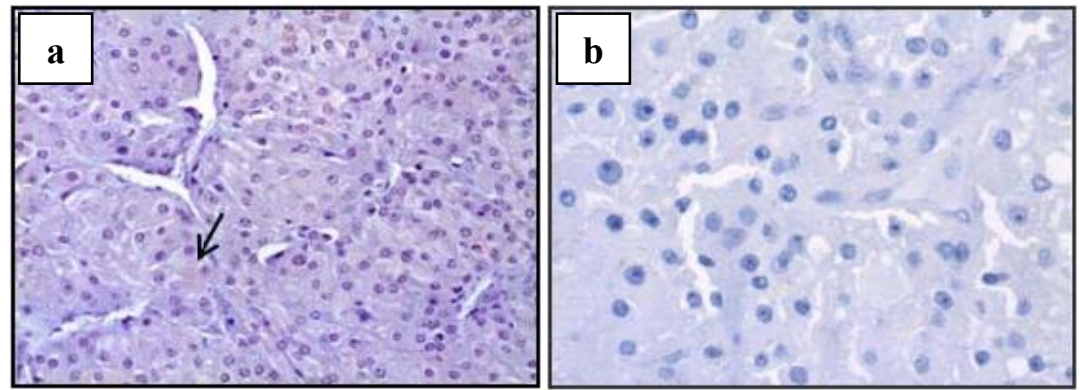

Figura 23. Imunoistoquímica para MYC em TAC pediátrico evidenciando marcação focal (em vermelho; seta; a); tecido adrenal normal adjacente (b). Magnificação X 400.

\section{WISP2}

Em 19 de 23 dos TAC analisados (83\%), foi observado acúmulo da proteína WISP2 (Figura 24a).
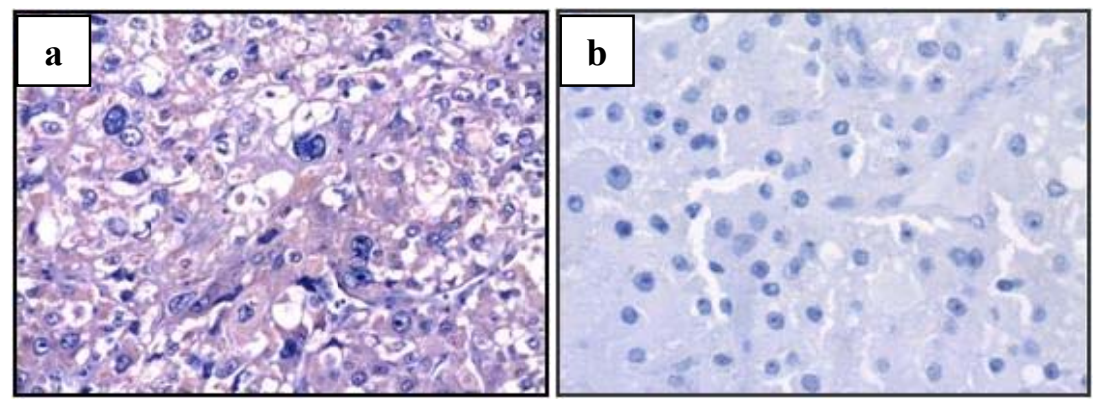

Figura 24. Imunoistoquímica para WISP2 (em vermelho) em TAC pediátrico demonstrando marcação difusa desta proteína (a); tecido adrenal normal adjacente (b). Magnificação X 400.

A figura 25 resume as características individuais dos 25 pacientes / TACs analisados em relação à presença de mutações e o padrão observado na IHQ na análise dos genes CTNNB1 e TP53. 
Figura 25. Estágio tumoral e desfecho em parte dos TAC $(n=25)$ de acordo com anormalidades de $\beta$-catenina e P53.

\begin{tabular}{|c|c|c|c|c|c|c|c|c|c|c|c|c|c|c|c|c|c|c|c|c|c|c|c|c|c|}
\hline Tumor ID & 22 & 1 & 8 & 25 & 27 & 16 & 13 & 9 & 21 & 37 & 20 & $33^{*}$ & $23^{*}$ & $18^{\mathrm{a}}$ & $29^{b}$ & 43 & 47 & $51^{\mathrm{c}}$ & 53 & 55 & $57^{d}$ & 59* & 61 & 62 & 58 \\
\hline $\begin{array}{l}\text { Estágio } \\
\text { tumoral }\end{array}$ & I & I & I & I & I & I & I & I & I & I & I & I & I & I & I & II & II & III & III & III & IV & IV & IV & IV & IV \\
\hline Óbito & & & & & & & & & & & & & PS & & & & & & & & & PS & & & \\
\hline $\begin{array}{c}\text { IHQ } \\
\beta \text {-catenina }\end{array}$ & & & & & & & & & & & ND & & & & & & & & & & & & & & \\
\hline $\begin{array}{l}\text { Mutações } \\
\text { CTNNB1 }\end{array}$ & & & & & & & & & & & & & & & & & & & & & & & & & \\
\hline IHQ P53 & & & & & & & & & & & & & & & & & & & & & & & & & \\
\hline Mutação TP53 & & & & & & & & & & & & & & & & & & & & & & & & & \\
\hline
\end{tabular}

Tumor ID como apresentado na Tabela 1. Ocorrência de óbito e mutações dos genes TP53 e CTNNB1: retângulos pretos; PS: perda de seguimento, 15,8 e 16,8 meses após cirurgia, respectivamente. ND: não disponível. Mutações do gene CTNNB1: ${ }^{a}$ p.S45F; ${ }^{b}$ p.S33F; ${ }^{c}$ p.S37P; ${ }^{\mathrm{d}}$ p.S45P. *: Acúmulo nuclear de $\beta$-catenina.

Imunoistoquímica (IHQ) de 53 e $\beta$-catenina. Negativo: branco; +: cinza claro; ++: cinza escuro, e +++: preto.

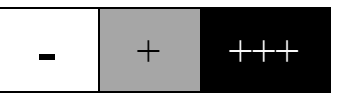


5. Discussão 
A via Wnt/ $\beta$-catenina tem um importante papel no desenvolvimento normal da glândula adrenal [101]. Recentemente, anormalidades desta via foram demonstradas em CAC em pacientes adultos. Nestes pacientes, a ativação desta via em decorrência de mutações no gene CTNNB1 e o correspondente acúmulo nuclear de $\beta$-catenina se associaram a fenótipo tumoral mais agressivo e menor sobrevida [76]. No entanto, até o presente, ainda não existiam dados sobre o papel da via Wnt/ $\beta$-catenina em TAC pediátricos.

No presente estudo, analisando uma grande coorte de crianças brasileiras com TAC, apresentamos evidências de que mutações no exon 3 do gene $C T N N B 1$, codificador dos sítios de fosforilação da $\beta$-catenina, são raras nestes pacientes e que existe alteração na expressão de diversos genes importantes da via Wnt/ $\beta$-catenina, mesmo na ausência de mutações no gene CTNNB1.

Em concordância com estudos prévios em TAC pediátricos de crianças brasileiras, a mutação p.P53 R337H foi encontrada na maioria dos pacientes $[18,62,102]$. Em TAC de adultos, a presença de mutações do gene TP53 tem sido relacionada a um pior prognóstico e desfecho clínico desfavorável [63]. Em nosso trabalho, mostramos que a mutação P53 p.R337H não está associada com estágio tumoral ou pior prognóstico dos pacientes pediátricos com este tipo de tumor. Este achado e dados da literatura indicam que outras anormalidades moleculares podem influenciar no desfecho de pacientes pediátricos com TAC.

A $\beta$-catenina é uma proteína que, quando ativada, transloca-se do citoplasma para o núcleo e ativa a transcrição de genes alvos $[8,95,103]$. Mutações neste gene correspondem ao defeito genético mais freqüente em adenomas adrenocorticais (AAC) em adultos [92, 104]. Apenas um relato de caso descreveu a presença de mutação no gene CTNNB1 em um lactente de quatro meses de idade com síndrome de Cushing causada por tumores adrenais bilaterais e metástase hepática. A deleção dos códons 44 e 45 no gene CTNNB1 foi encontrada no tumor da adrenal direita, mas não no tumor da adrenal esquerda. Acúmulo nuclear de $\beta$-catenina foi encontrado no tumor contendo a mutação no gene $C T N N B 1$ e no nódulo metastático, mas não no tumor da adrenal esquerda. No tumor contendo esta mutação o escore histopatológico de Weiss foi maior comparado ao tumor sem mutação no gene CTNNB1 [105].

No presente estudo encontramos mutações do gene CTNNB1 em somente $6 \%$ dos TAC pediátricos. Todas as mutações encontradas já haviam sido previamente descritas em TAC de pacientes adultos [100] e resultam em substituição do aminoácido serina em sítios envolvidos na fosforilação e degradação da $\beta$-catenina (p.S33F, p.S37P, p.S45F e p.S45P). A mutação em ponto no exon 3 (p.S45P) localiza-se no sítio de fosforilação da $\beta$-catenina por 
GSK3- $\beta$ e CKI e compromete esta função $[100,104,106]$. A ausência de fosforilação da $\beta$ catenina impede o reconhecimento desta proteína pelo $\beta$-Trcp, bem como sua degradação pela via da ubiquitina. A $\beta$-catenina não sendo degradada, acumula-se no citoplasma e transloca-se para o núcleo, onde aumenta a transcrição de genes alvo.

Um estudo recente descreveu a presença de mutações neste gene em 36\% dos TAC de adultos, predominantemente em TAC não-secretores. [96]. Mutações no gene CTNNB1 foram encontradas em freqüências semelhantes em AAC e CAC em adultos [104]. Blaker et al. não encontraram mutações no gene CTNNB1 em AAC de um paciente com polipose intestinal, porém observaram a presença de mutação somática do gene $A P C$ no tecido tumoral adrenal [107]. Em nosso trabalho, a comparação da frequência de mutações entre adenomas e carcinomas foi dificultada em função da falta de critérios bem estabelecidos para classificar TAC pediátricos como adenomas ou carcinomas baseados na histopatologia [16].

Um achado interessante do presente estudo é que todos os tumores apresentando mutação no gene CTNNB1 também carreavam a mutação P53 p.R337H. Este achado indica que, em TAC pediátricos, mutações dos genes CTNNB1 e TP53 não são mutuamente exclusivas, como foi sugerido recentemente em TAC de adultos, carreando outras mutações do gene TP53 [63]. Ragazzon et al. também sugeriram que a presença de mutação no genes CTNNB1 ou TP53 caracterizavam dois grupos de CAC distintos com prognóstico ruim [63]. Em nosso trabalho, a ocorrência de mutações no gene CTNNB1 parece estar associada com prognóstico mais desfavorável. A freqüência de óbito foi maior em pacientes com TAC contendo mutações no gene CTNNB1 comparada àquela observada em pacientes com TAC sem mutações neste gene. No entanto, devido ao pequeno número de TAC carreando mutações de CTNNB1, este dado necessita ser confirmado em outras séries de pacientes. É interessante observar que nenhum dos TAC sem a mutação P53 p.R337H carreava mutações de CTNNB1 e que todos os pacientes, cujo tumor não apresentava mutação em nenhum destes dois genes, foram diagnosticados em estágio tumoral I da doença. Este dado parece estar em concordância com um relato de caso prévio que demonstrou a presença de mutação no gene CTNNB1 somente em uma porção maligna de TAC heterogêneo [95].

Avaliando a expressão do gene CTNNB1 por meio de PCRq encontramos hiperexpressão deste gene. Estes resultados foram confirmados pela análise por IHQ no grupo de amostras analisadas. Nossos resultados evidenciaram que na maioria dos TAC pediátricos ocorre acúmulo difuso, tanto citoplasmático quanto nuclear de $\beta$-catenina. Este padrão imunoistoquímico difere do padrão observado em TAC de adultos, onde o acúmulo de $\beta$ - 
catenina é tipicamente nuclear $[63,76,96,100]$. Dados ainda não publicados de nosso grupo avaliando TAC de pacientes adultos são concordantes com os achados da literatura e reforçam que o padrão imunoistoquímico de acúmulo da $\beta$-catenina é realmente distinto entre TAC de crianças e TAC de adultos.

Mutações no gene CTNNB1 tem sido encontradas frequentemente em TAC de adultos apresentando acúmulo nuclear de $\beta$-catenina $[96,100]$. É possível que a presença de mutação do CTNNB1 é um fator determinante no acúmulo nuclear de $\beta$-catenina [96]. Por outro lado, o acúmulo citoplasmático também tem sido encontrado em TAC sem mutações do CTNNB1. Entretanto, no presente estudo, nenhum dos TAC pediátricos carreando mutações do CTNNB1 apresentou acúmulo nuclear da $\beta$-catenina. Observamos predominantemente acúmulo citoplasmático de $\beta$-catenina na maioria de nossas amostras, independente da presença de mutações no exon 3 do gene CTNNB1.

Embora sugiram, nosso dados ainda não permitem afirmar que os achados de expressão elevada do RNAm de CTNNB1 e o acúmulo anormal de $\beta$-catenina em TAC pediátricos sem mutações de CTNNB1 correspondam a ativação da via Wnt/ $\beta$-catenina. Caso esta via esteja de fato ativada em TAC pediátricos, é provável que esta ativação ocorra por mecanismos diferentes em tumores de crianças comparados aos tumores de adultos. Desta forma, outros fatores poderiam modular esta via e desempenhar funções na tumorigênese adrenocortical pediátrica [63, 104, 108]. Para identificar alguns destes possíveis mecanismos, nós avaliamos a expressão de alguns dos mais importantes componentes da via Wnt canônica incluindo um ligante Wnt (WNT4), antagonistas Wnt (SFRP e DKK3), dois componentes chave do complexo de degradação (AXIN e APC), um fator de transcrição (TCF7), e genesalvo (MYC e WISP2) [83, 109].

A proteína Dickkopf, codificada pelo gene $D K K 3$, é um inibidor da via Wnt e está diminuída em uma variedade de cânceres, podendo atuar como um gene supressor de tumor [110]. Observamos uma hipoexpressão marcante do RNAm de $D K K 3$ e marcação ausente ou fraca da proteína DKK3 na maioria das amostras. A proteína DKK3 antagoniza a via Wnt através da interação com LRP, co-receptor, induzindo sua endocitose. Na ausência de LRP viável na superfície celular, a via Wnt é inibida efetivamente [83, 87].

As SFRPs (secreted Frizzled Related Protein) são proteínas codificadas pelo gene $S F R P 1$, que têm a função de sequestrar as proteínas Wnts, impedindo a interação ligantereceptor e, consequentemente, impedindo a transcrição de genes alvo, devido a não ativação da via [111]. Nós também observamos uma hipoexpressão de SFRP1, um antagonista da via Wnt por seqüestrar proteínas Wnt na matriz extracelular. Consequentemente, a baixa 
expressão de $S F R P 1$ e $D K K 3$ em TAC pediátricos poderia resultar em ativação da via Wnt/ßcatenin devido ao aumento da disponibilidade de ligantes Wnts ou ao aumento da afinidade dos mesmos ao receptor Frizzled [83]. Recentemente, foi demonstrado que moléculas semelhantes à SFRP (SFRP-like) inibem a via Wnt/ß-catenin induzidas por Wnt3a [112]. Além disso, em células de câncer de pulmão, o silenciamento do gene $D K K 3$ por mecannismos epigenéticos ativou a via Wnt/ $\beta$-catenina, resultando no acúmulo nuclear da $\beta$ catenina [113]. O $D K K 3$ é o único gene da família $D K K$ expresso em altos níveis na adrenal normal [101, 109], no entanto, o mecanismo pelo qual $D K K 3$ pode atuar na função de células adrenocorticais, proliferação e diferenciação das zonas não está claro [101]. Em vários tipos celulares de células imortalizadas, $D K K 3$ inibe proliferação celular, atuando como um possível gene supressor de tumor [114]. Recentemente, expressão reduzida de DKK3 tanto em nível de RNAm como de proteína foi descrito em todos os estágios tumorais de câncer ovariano [115]. Por esta razão, nossos achados sugerem que a perda de função de DKK3 pode exercer um efeito estimulatório na proliferação celular e ter um importante papel no desenvolvimento de TAC pediátricos.

Entre as proteínas Wnts, a proteína WNT4, codificada pelo gene de mesmo nome, parece ser a mais importante na ativação da via Wnt/ $\beta$-catenina no córtex adrenal $[9,85,94]$. Nós encontramos expressão reduzida de RNAm de WNT4, principalmente em TAC de estágio inicial e a hipoexpressão deste gene esteve associada com maior sobrevida dos pacientes. Kuulasmaa et al. encontraram discreto aumento da expressão de WNT4 em três dos quatro carcinomas virilizantes analisados [85].WNT4, um ligante Wnt, atua como um fator de sinalização com múltiplas funções na organogênese e sua deficiência leva ao desenvolvimento anormal de vários órgãos [116]. Expressão detectável de RNAm de WNT4 foi observada nas zonas fasciculada e glomerulosa de adrenal normal e tem várias funções na esteroidogênese normal [101]. Nossos achados mostrando hipoexpressão de WNT4 em TAC pediátricos sugerem que a via Wnt/ $\beta$-catenina pode ser ativada por outros ligantes Wnt nestes tumores.

A proteína AXIN, codificada pelo gene AXIN1, é um componente do complexo de degradação da $\beta$-catenina e expressão reduzida deste gene está associada a uma variedade de cânceres [117]. Observamos também uma expressão reduzida de $A X I N 1$, mas sem associação com estágio tumoral ou sobrevida. O gene AXIN1 é constitutivamente expresso e é essencial para a manutenção da atividade da via Wnt em estado basal. Além disso, AXIN é um componente importante na supressão tumoral via P53-dependente, induz morte celular e reduz proliferação celular em células de astrocitoma [118]. AXIN diminui os níveis de $\beta$-catenina 
em células de câncer de pulmão e pode também inibir a proliferação e invasão destas células [119]. Juntos, estes dados sugerem que a expressão reduzida do gene AXIN1 pode contribuir para o acúmulo de $\beta$-catenina observado nos TAC pediátricos no presente estudo.

O fator de transcrição TCF, codificado pelo gene $T C F 7$, apresenta sítios de interação com a $\beta$-catenina. Mutações ativadoras da $\beta$-catenina em linhagem celular levaram a uma transcrição eficiente TCF-dependente [104]. Entretanto, no presente estudo, observamos expressão reduzida do RNAm de TCF7. A observação de expressão reduzida de RNAm de TCF7 sugere que a ativação da via Wnt/ $\beta$-catenina em TAC pediátricos pode ser induzida por outros fatores de transcrição genes regulados por esta via.

O gene $M Y C$ codifica uma proteína nuclear multifuncional de mesmo nome que tem um importante papel na progressão do ciclo celular e apoptose e a expressão aumentada deste gene tem sido observada em muitos tipos tumorais. Esta proteína também funciona como um fator de transcrição de genes alvo específicos, além de ser alvo de proteínas específicas que ativam a transcrição, tal como a $\beta$-catenina $[120,121]$. No presente estudo observamos expressão reduzida de MYC, tanto de RNAm quanto da proteína. A proteína MYC participa de processos que consomem energia como proliferação e biossíntese ribossomal. A diminuição da expressão de $M Y C$ foi encontrada em linhagens celulares de cânceres e pode ser uma estratégia para as células cancerosas sobreviver sob condições de limitação de energia [122]. Nossos achados mostrando expressão reduzida de $M Y C$ em estágios mais avançados de TAC estão de acordo com estas condições.

Dados de uma meta-análise de três estudos de microarray mostrando expressão reduzida do gene $M Y C$ em TAC confirmam o achado do presente estudo, aparentemente paradoxal [123]. Baseado em modelos topológicos obtidos por meio de ferramentas de bioinformática e em observações experimentais prévias, Szabó et al. acreditam que a proteína MYC possa desempenhar papel relevante na tumorigênese adrenocortical. Estes dados necessitam ser confirmados em estudos futuros.

As razões da expressão diferencial de genes relacionados à via Wnt em TAC pediátricos comparadas à expressão observada em adrenais normais ainda não são claras. É importante lembrar que nossa análise de expressão de RNAm dos genes candidatos comparou a expressão observada nos tumores com aquela observada em adrenais normais de indivíduos adultos sem doença adrenal conhecida. Neste modelo, cabe o questionamento de comparar tecidos tumorais de crianças com tecidos normais de adultos. A razão de não termos utilizado tecidos-controles de crianças foi a dificuldade técnica de obter estas amostras. Optamos por 
não utilizar amostras de adrenais de pacientes pediátricos submetidos à nefrectomia para remoção de tumor de Wilms, pois já foi demonstrado que muitas destas adrenais apresentam padrão de expressão anormal do gene IGF2 [124]. Como revisado anteriormente, o gene IGF2 tem papel fundamental no desenvolvimento de TAC em crianças. Por outro lado, como discutido anteriormente, o padrão de involução da adrenal fetal finaliza-se logo após o nascimento e a diferenciação da adrenal adulta já ocorre nos primeiros anos de vida [2, 4]. Portanto, acreditamos que a utilização de amostras de adrenal de indivíduos adultos seja adequada para os objetivos do presente estudo.

Um possível mecanismo também envolvido na tumorigênese adrenocortical pediátrica é a regulação alterada por miRNAs. Recentemente, foi identificado um grupo de miRNAs diferencialmente expressos em TAC pediátricos. Análise funcional em linhagens de células tumorais adrenais demonstrou que os miRNAs miR-99a and miR-100 regulam a expressão da via IGF-1/mTOR, que se encontram alterada na maioria destes TAC [82].

Foi demonstrado que o miRNA-315 diminui a expressão de $A X I N 1$, resultando na ativação da via Wnt [125]. Ao contrário, miR-8 antagoniza a via Wnt em diferentes níveis, desde a secreção do ligante à transcrição de genes-alvo [126]. A proteína P53 aumenta a maturação pós-transcricional de miR-16-1, miR-143 e miR-145, que tem funções supressores de crescimento e mutações no gene TP53 resultam na diminuição da expressão destes miRNAs [127]. Em um estudo preliminar de nosso grupo foi observada expressão elevada do miR-449 nos TAC carreando a mutação p.R337H P53 comparada àquela observada nos tumores sem esta mutação [128]. Correlação inversa entre a expressão do miR-449 e WISP2 foi demonstrada em PPNAD, sugerindo a regulação da Via Wnt/ $\beta$-catenina por este miRNA. Estes dados foram validados em estudos funcionais com indução de expressão deste miRNA em cultura celular primária de PPNAD. Dados deste mesmo estudo também demonstraram que a inibição da atividade da proteína quinase A (PKA) pela substância H89 aumentou a expressão do miR-449, seguido pela diminuição da expressão de WISP2. Estes dados sugerem que a ativação da PKA inibe a expressão do miR-449 e esta inibição permite o aumento da expressão de seu gene alvo, WISP2. Por meio de análise de bioinformática, utilizando a ferramenta miRMAP [129], verificamos que o gene AXIN1 pode ser alvo da ação do miR449 , reforçando a hipótese do envolvimento da via Wnt/ $\beta$-catenina com miRNAs. Desta maneira, a alteração na expressão de alguns miRNAs poderia levar a desregulação em TAC. Todos estes dados sugerem um envolvimento destes miRNAs com a Via Wnt e doenças adrenocorticais [130]. 
Outro possível mecanismo podendo ativar a via Wnt/ $\beta$-catenina é o silenciamento epigenético de reguladores negativos da via, como DKK e WIF1 [131]. No presente estudo, observamos expressão reduzida de $D K K 3$, sugerindo que essa possibilidade pode ser um mecanismo importante para a desregulação da via Wnt/ $\beta$-catenina observada nos TAC pediátricos.

O aumento da expressão do gene CTNNB1 e o acúmulo difuso da $\beta$-catenina observado na maioria dos tumores demonstram a existência de anormalidades desta via nestes tumores, pois amostras de tecido adrenal adjacente não tumoral não apresentaram acúmulo desta proteína. Frente a nossos achados, uma possibilidade é que a via $W n t / \beta$-catenina esteja realmente ativada nos TACs pediátricos. A ausência de associação entre as anormalidades na expressão da maioria dos genes desta via com o prognóstico dos pacientes pediátricos sugere que esta ativação possa ser responsável por uma etapa inicial da tumorigênese adrenocortical e que outros fatores, envolvidos ou não com a via Wnt, podem estar envolvidos na progressão da doença.

Em síntese, no presente estudo demonstramos que em TAC pediátricos carreando a mutação P53 p.R337H, mutações ativadoras somáticas de CTNNB1 são bem menos freqüentes que em TAC de pacientes adultos. Porém, à semelhança dos pacientes adultos, estas mutações parecem estar associadas a prognóstico mais desforável. Adicionalmente, apresentamos evidências de anormalidades na expressão de diversos genes importantes na via Wnt/ß-catenina em TAC pediátricos, incluindo expressão elevada do gene CTNNB1 e acúmulo de $\beta$-catenina e WISP2, que parecem ser independentes de mutações do gene CTNNB1. Este achado indica a possibilidade da existência de outros mecanismos envolvidos na desregulação desta via nestes tumores. Nossos dados sugerem que a diminuição da expressão de genes inibidores da via Wnt, como os genes DKK3, SFRP1 e AXIN1, pode estar envolvida neste mecanismo. É importante ressaltar, entretanto, que os dados do presente estudo não provam, de maneira conclusiva, que a via Wnt/ $\beta$-catenina está ativada em TAC pediátricos. Portanto, mais estudos são necessários para confirmar o envolvimento da via Wnt/ $\beta$-catenina na tumorigênese adrenocortical pediátrica. 
6. Conclusões 
- TAC pediátricos apresentam expressão aumentada do RNAm do gene CTNNB1 e acúmulo difuso da $\beta$-catenina. Estes tumores também apresentaram expressão reduzida de genes inibidores da via $\mathrm{Wnt} / \beta$-catenina como os genes $D K K 3$, SFRP1 e AXIN1, expressão reduzida de MYC e acúmulo de WISP2, genes alvo desta via. Houve associação entre a expressão dos genes WNT4, SFRP1 e TCF7 e sobrevida dos pacientes analisados.

- Mutações no gene CTNNB1 são infreqüentes em TAC de crianças e ocorrem simultaneamente em tumores contendo a mutação P53 p.R337H. A presença de mutação no gene $C T N N B 1$ se associou com a ocorrência de óbito. As alterações na expressão do gene $C T N N B 1$ parecem ser independentes de mutações no gene CTNNB1. 
7. Referências bibliográficas 
1. West, A.N., et al., Gene expression profiling of childhood adrenocortical tumors. Cancer Res, 2007. 67(2): p. 600-8.

2. Mesiano, S. and R.B. Jaffe, Developmental and functional biology of the primate fetal adrenal cortex. Endocr Rev, 1997. 18(3): p. 378-403.

3. Chamoux, E., et al., Fibronectin, laminin, and collagen IV as modulators of cell behavior during adrenal gland development in the human fetus. J Clin Endocrinol Metab, 2002. 87(4): p. 1819-28.

4. Ishimoto, H. and R.B. Jaffe, Development and Function of the Human Fetal Adrenal Cortex: A Key Component in the Feto-Placental Unit. Endocr Rev.

5. Ben-David, S., et al., Parturition itself is the basis for fetal adrenal involution. J Clin Endocrinol Metab, 2007. 92(1): p. 93-7.

6. Aron, D.C., J.W. Findling, and B. Tyrrel, Glicocorticóides e androgênios suprarenais, in Endocrinologia Básica e Clínica, F.S. Greenspan and D.G. Gardner, Editors. 2006: McGraw-Hill. p. 295-296.

7. Latronico, A.C., Tumores Adrenocorticais, in Endocrinologia, M.J.A. Saad, R.M.B. Maciel, and B.B. Mendonca, Editors. 2007, Editora Atheneu: São Paulo. p. 555-560.

8. Soon, P.S., et al., Molecular markers and the pathogenesis of adrenocortical cancer. Oncologist, 2008. 13(5): p. 548-61.

9. Stratakis, C.A., Adrenocortical tumors, primary pigmented adrenocortical disease (PPNAD)/Carney complex, and other bilateral hyperplasias: the NIH studies. Horm Metab Res, 2007. 39(6): p. 467-73.

10. Szabo, D., et al., [Pathogenesis of adrenocortical cancer]. Orv Hetil, 2010. 151(29): p. 1163-70.

11. Abecassis, M., et al., Serendipitous adrenal masses: prevalence, significance, and management. Am J Surg, 1985. 149(6): p. 783-8.

12. Wajchenberg, B.L., et al., Adrenocortical carcinoma: clinical and laboratory observations. Cancer, 2000. 88(4): p. 711-36.

13. Almeida, M.Q. and A.C. Latronico, The molecular pathogenesis of childhood adrenocortical tumors. Horm Metab Res, 2007. 39(6): p. 461-6. 
14. Rodriguez-Galindo, C., et al., Biology, clinical characteristics, and management of adrenocortical tumors in children. Pediatr Blood Cancer, 2005. 45(3): p. 265-73.

15. Stiller, C.A., International variations in the incidence of childhood carcinomas. Cancer Epidemiol Biomarkers Prev, 1994. 3(4): p. 305-10.

16. Sandrini, R., R.C. Ribeiro, and L. DeLacerda, Childhood adrenocortical tumors. J Clin Endocrinol Metab, 1997. 82(7): p. 2027-31.

17. Ribeiro, R.C., et al., An inherited p53 mutation that contributes in a tissue-specific manner to pediatric adrenal cortical carcinoma. Proc Natl Acad Sci U S A, 2001. 98(16): p. 9330-5.

18. Latronico, A.C., et al., An inherited mutation outside the highly conserved DNAbinding domain of the p53 tumor suppressor protein in children and adults with sporadic adrenocortical tumors. J Clin Endocrinol Metab, 2001. 86(10): p. 4970-3.

19. Hospital, S.J.C.s.R. International Pediatric Adrenocortical Tumor Registry for Physicians. International Pediatric Adrenocortical Tumor Registry for Physicians 2009 [cited 2011 March, 14]; Available from: http://www.stjude.org/stjude/v/ index.jsp?vgnextoid=189fa40e24482210VgnVCM1000001e0215acRCRD\&vgnextchannel =5abdb516fe982210VgnVCM1000001e0215acRCRD.

20. Michalkiewicz, E., et al., Clinical and outcome characteristics of children with adrenocortical tumors: a report from the International Pediatric Adrenocortical Tumor Registry. J Clin Oncol, 2004. 22(5): p. 838-45.

21. Ribeiro, R.C. and B. Figueiredo, Childhood adrenocortical tumours. Eur J Cancer, 2004. 40(8): p. 1117-26.

22. Ciftci, A.O., et al., Adrenocortical tumors in children. J Pediatr Surg, 2001. 36(4): p. 549-54.

23. Latronico, A.C. and G.P. Chrousos, Extensive personal experience: adrenocortical tumors. J Clin Endocrinol Metab, 1997. 82(5): p. 1317-24.

24. Macfarlane, D.A., Cancer of the adrenal cortex; the natural history, prognosis and treatment in a study of fifty-five cases. Ann R Coll Surg Engl, 1958. 23(3): p. 155-86.

25. Allolio, B. and M. Fassnacht, Clinical review: Adrenocortical carcinoma: clinical update. J Clin Endocrinol Metab, 2006. 91(6): p. 2027-37. 
26. Sullivan, M., M. Boileau, and C.V. Hodges, Adrenal cortical carcinoma. J Urol, 1978. 120(6): p. 660-5.

27. Weiss, L.M., L.J. Medeiros, and A.L. Vickery, Jr., Pathologic features of prognostic significance in adrenocortical carcinoma. Am J Surg Pathol, 1989. 13(3): p. 202-6.

28. Mendonca, B.B., et al., Clinical, hormonal and pathological findings in a comparative study of adrenocortical neoplasms in childhood and adulthood. J Urol, 1995. 154(6): p. 2004-9.

29. Fassnacht, M., et al., Adrenocortical carcinoma: a clinician's update. Nat Rev Endocrinol.

30. Tucci, S., Jr., et al., The impact of tumor stage on prognosis in children with adrenocortical carcinoma. J Urol, 2005. 174(6): p. 2338-42, discussion 2342.

31. Carvalho, V.C. and C.E. Kater, Carcinoma adrenal, in Endocrinologia, A.R. Chacra, Editor 2009, Manole Ltda: Barueri, SP. p. 249-259.

32. Luton, J.P., et al., Clinical features of adrenocortical carcinoma, prognostic factors, and the effect of mitotane therapy. N Engl J Med, 1990. 322(17): p. 1195-201.

33. Berruti, A., et al., Etoposide, doxorubicin and cisplatin plus mitotane in the treatment of advanced adrenocortical carcinoma: a large prospective phase II trial. Endocr Relat Cancer, 2005. 12(3): p. 657-66.

34. Khan, T.S., et al., Streptozocin and o, $p^{\prime} D D D$ in the treatment of adrenocortical cancer patients: long-term survival in its adjuvant use. Ann Oncol, 2000. 11(10): p. 1281-7.

35. Wortmann, S., et al., Bevacizumab plus capecitabine as a salvage therapy in advanced adrenocortical carcinoma. Eur J Endocrinol. 162(2): p. 349-56.

36. Giordano, T.J., Adrenocortical tumors: an integrated clinical, pathologic, and molecular approach at the University of Michigan. Arch Pathol Lab Med. 134(10): p. 1440-3.

37. Almeida, M.Q., et al., Expression of insulin-like growth factor-II and its receptor in pediatric and adult adrenocortical tumors. J Clin Endocrinol Metab, 2008. 93(9): p. 3524-31. 
38. Gicquel, C., et al., [Involvement of the IGF system in the pathogenesis of adrenocortical tumors]. Ann Endocrinol (Paris), 2001. 62(2): p. 189-92.

39. Ilvesmaki, V., et al., Insulin-like growth factors (IGFs) and their receptors in adrenal tumors: high IGF-II expression in functional adrenocortical carcinomas. J Clin Endocrinol Metab, 1993. 77(3): p. 852-8.

40. Logie, A., et al., Autocrine role of IGF-II in proliferation of human adrenocortical carcinoma NCI H295R cell line. J Mol Endocrinol, 1999. 23(1): p. 23-32.

41. Barlaskar, F.M., et al., Preclinical targeting of the type I insulin-like growth factor receptor in adrenocortical carcinoma. J Clin Endocrinol Metab, 2009. 94(1): p. 20412.

42. Barlaskar, F.M. and G.D. Hammer, The molecular genetics of adrenocortical carcinoma. Rev Endocr Metab Disord, 2007. 8(4): p. 343-8.

43. Kim, A., et al., Wnt/betacatenin signaling in adrenocortical stem/progenitor cells: implications for adrenocortical carcinoma. Ann Endocrinol (Paris), 2009. 70(3): p. 156.

44. Schteingart, D.E., et al., Management of patients with adrenal cancer: recommendations of an international consensus conference. Endocr Relat Cancer, 2005. 12(3): p. 667-80.

45. Gicquel, C., et al., Molecular markers and long-term recurrences in a large cohort of patients with sporadic adrenocortical tumors. Cancer Res, 2001. 61(18): p. 6762-7.

46. Gicquel, C., et al., Rearrangements at the 11 p15 locus and overexpression of insulinlike growth factor-II gene in sporadic adrenocortical tumors. J Clin Endocrinol Metab, 1994. 78(6): p. 1444-53.

47. Giordano, T.J., Gene expression profiling of endocrine tumors using DNA microarrays: progress and promise. Endocr Pathol, 2003. 14(2): p. 107-16.

48. Pianovski, M.A., et al., SF-1 overexpression in childhood adrenocortical tumours. Eur J Cancer, 2006. 42(8): p. 1040-3.

49. Slater, E.P., et al., Analysis by cDNA microarrays of gene expression patterns of human adrenocortical tumors. Eur J Endocrinol, 2006. 154(4): p. 587-98. 
50. Almeida, M.Q., et al., Steroidogenic factor 1 overexpression and gene amplification are more frequent in adrenocortical tumors from children than from adults. J Clin Endocrinol Metab. 95(3): p. 1458-62.

51. El Wakil, A., et al., Genetics and genomics of childhood adrenocortical tumors. Mol Cell Endocrinol, 2010.

52. Liu, J., et al., Ribonucleic acid expression of the clustered imprinted genes, p57KIP2, insulin-like growth factor II, and H19, in adrenal tumors and cultured adrenal cells. J Clin Endocrinol Metab, 1997. 82(6): p. 1766-71.

53. Barzon, L., et al., Molecular analysis of CDKN1C and TP53 in sporadic adrenal tumors. Eur J Endocrinol, 2001. 145(2): p. 207-12.

54. Figueiredo, B.C., et al., Amplification of the steroidogenic factor 1 gene in childhood adrenocortical tumors. J Clin Endocrinol Metab, 2005. 90(2): p. 615-9.

55. Sbiera, S., et al., High diagnostic and prognostic value of steroidogenic factor-1 expression in adrenal tumors. J Clin Endocrinol Metab. 95(10): p. E161-71.

56. Soussi, T., The history of p53. A perfect example of the drawbacks of scientific paradigms. EMBO Rep. 11(11): p. 822-6.

57. Newnham, G.M., et al., Integrated mutation, copy number and expression profiling in resectable non-small cell lung cancer. BMC Cancer. 11(1): p. 93.

58. Seidinger, A.L., et al., Association of the highly prevalent TP53 R337H mutation with pediatric choroid plexus carcinoma and osteosarcoma in Southeast Brazil. Cancer, 2010.

59. Goranova, T.E., et al., Dynamics of cancer cell subpopulations in primary and metastatic colorectal tumors. Clin Exp Metastasis.

60. Gluck, S., et al., TP53 genomics predict higher clinical and pathologic tumor response in operable early-stage breast cancer treated with docetaxel-capecitabine +/- trastuzumab. Breast Cancer Res Treat.

61. Pinto, E.M., et al., Inherited germline TP53 mutation encodes a protein with an aberrant C-terminal motif in a case of pediatric adrenocortical tumor. Fam Cancer. 10(1): p. 141-6. 
62. Sandrini, F., et al., Inheritance of R337H p53 gene mutation in children with sporadic adrenocortical tumor. Horm Metab Res, 2005. 37(4): p. 231-5.

63. Ragazzon, B., et al., Transcriptome analysis reveals that p53 and \{beta\}-catenin alterations occur in a group of aggressive adrenocortical cancers. Cancer Res, 2010. 70(21): p. 8276-81.

64. Ko, J.H., et al., Virilizing adrenocortical carcinoma in a child with Turner syndrome and somatic TP53 gene mutation. Eur J Pediatr. 169(4): p. 501-4.

65. Si, N., et al., [Identification of a novel TP53 germline mutation in one child with adrenocortical carcinoma]. Zhonghua Yi Xue Za Zhi, 2009. 89(20): p. 1402-4.

66. Lin, M.T., et al., Early detection of adrenocortical carcinoma in a child with LiFraumeni syndrome. Pediatr Blood Cancer, 2009. 52(4): p. 541-4.

67. Ruijs, M.W., et al., TP53 germline mutation testing in 180 families suspected of LiFraumeni syndrome: mutation detection rate and relative frequency of cancers in different familial phenotypes. J Med Genet. 47(6): p. 421-8.

68. Palmero, E.I., et al., Tumor protein 53 mutations and inherited cancer: beyond LiFraumeni syndrome. Curr Opin Oncol. 22(1): p. 64-9.

69. Fiszer-Maliszewska, L., B. Kazanowska, and J. Padzik, p53 Tetramerization domain mutations: germline $R 342 X$ and $R 342 P$, and somatic $R 337 G$ identified in pediatric patients with Li-Fraumeni syndrome and a child with adrenocortical carcinoma. Fam Cancer, 2009. 8(4): p. 541-6.

70. Garritano, S., et al., Detailed haplotype analysis at the TP53 locus in p.R337H mutation carriers in the population of Southern Brazil: evidence for a founder effect. Hum Mutat. 31(2): p. 143-50.

71. DiGiammarino, E.L., et al., A novel mechanism of tumorigenesis involving $p H-$ dependent destabilization of a mutant 553 tetramer. Nat Struct Biol, 2002. 9(1): p. 126.

72. Knudson, A.G., Jr., Mutation and cancer: statistical study of retinoblastoma. Proc Natl Acad Sci U S A, 1971. 68(4): p. 820-3.

73. Bielinska, M., et al., Review paper: origin and molecular pathology of adrenocortical neoplasms. Vet Pathol, 2009. 46(2): p. 194-210. 
74. Pinto, E.M., et al., Deletion mapping of chromosome 17 in benign and malignant adrenocortical tumors associated with the Arg337His mutation of the p53 tumor suppressor protein. J Clin Endocrinol Metab, 2005. 90(5): p. 2976-81.

75. Figueiredo, B.C., et al., Penetrance of adrenocortical tumours associated with the germline TP53 R337H mutation. J Med Genet, 2006. 43(1): p. 91-6.

76. Gaujoux, S., et al., \{beta\}-catenin activation is associated with specific clinical and pathological characteristics and a poor outcome in adrenocortical carcinoma. Clin Cancer Res, 2010.

77. Croce, C.M. and G.A. Calin, miRNAs, cancer, and stem cell division. Cell, 2005. 122(1): p. 6-7.

78. Lagos-Quintana, M., et al., Identification of tissue-specific microRNAs from mouse. Curr Biol, 2002. 12(9): p. 735-9.

79. Carthew, R.W. and E.J. Sontheimer, Origins and Mechanisms of miRNAs and siRNAs. Cell, 2009. 136(4): p. 642-55.

80. Tong, A.W. and J. Nemunaitis, Modulation of miRNA activity in human cancer: a new paradigm for cancer gene therapy? Cancer Gene Ther, 2008. 15(6): p. 341-55.

81. Patterson, E.E., et al., MicroRNA profiling of adrenocortical tumors reveals miR-483 as a marker of malignancy. Cancer.

82. Doghman, M., et al., Regulation of insulin-like growth factor-mammalian target of rapamycin signaling by microRNA in childhood adrenocortical tumors. Cancer Res. 70(11): p. 4666-75.

83. Chen, X., et al., Wnt signaling: the good and the bad. Acta Biochim Biophys Sin (Shanghai), 2008. 40(7): p. 577-94.

84. Conacci-Sorrell, M.E., et al., Nr-CAM is a target gene of the beta-catenin/LEF-1 pathway in melanoma and colon cancer and its expression enhances motility and confers tumorigenesis. Genes Dev, 2002. 16(16): p. 2058-72.

85. Kuulasmaa, T., et al., WNT-4 mRNA expression in human adrenocortical tumors and cultured adrenal cells. Horm Metab Res, 2008. 40(10): p. 668-73. 
86. Rattner, A., et al., A family of secreted proteins contains homology to the cysteine-rich ligand-binding domain of frizzled receptors. Proc Natl Acad Sci U S A, 1997. 94(7): p. 2859-63.

87. Mao, B. and C. Niehrs, Kremen2 modulates Dickkopf2 activity during Wnt/LRP6 signaling. Gene, 2003. 302(1-2): p. 179-83.

88. Wong, H.C., et al., Direct binding of the PDZ domain of Dishevelled to a conserved internal sequence in the C-terminal region of Frizzled. Mol Cell, 2003. 12(5): p. 125160.

89. Mao, J., et al., Low-density lipoprotein receptor-related protein-5 binds to Axin and regulates the canonical Wnt signaling pathway. Mol Cell, 2001. 7(4): p. 801-9.

90. Fuerer, C., R. Nusse, and D. Ten Berge, Wnt signalling in development and disease. Max Delbruck Center for Molecular Medicine meeting on Wnt signaling in Development and Disease. EMBO Rep, 2008. 9(2): p. 134-8.

91. Nollet, F., et al., Genomic organization of the human beta-catenin gene (CTNNB1). Genomics, 1996. 32(3): p. 413-24.

92. Olson, L.E., et al., Homeodomain-mediated beta-catenin-dependent switching events dictate cell-lineage determination. Cell, 2006. 125(3): p. 593-605.

93. Yamamoto, H., [Regulation of Wnt signaling pathway and its relationship with tumorigenesis]. Seikagaku, 2008. 80(12): p. 1079-93.

94. Chen, M. and P.J. Hornsby, Adenovirus-delivered DKK3/WNT4 and steroidogenesis in primary cultures of adrenocortical cells. Horm Metab Res, 2006. 38(9): p. 549-55.

95. Gaujoux, S., et al., Wnt/beta-catenin and 3',5'-cyclic adenosine 5'monophosphate/protein kinase A signaling pathways alterations and somatic betacatenin gene mutations in the progression of adrenocortical tumors. J Clin Endocrinol Metab, 2008. 93(10): p. 4135-40.

96. Bonnet, S., et al., Wnt/\{beta\}-Catenin Pathway Activation in Adrenocortical Adenomas Is Frequently due to Somatic CTNNB1-Activating Mutations, Which Are Associated with Larger and Nonsecreting Tumors: A Study in Cortisol-Secreting andNonsecreting Tumors. J Clin Endocrinol Metab, 2010. 
97. Bourdeau, I., et al., Gene array analysis of macronodular adrenal hyperplasia confirms clinical heterogeneity and identifies several candidate genes as molecular mediators. Oncogene, 2004. 23(8): p. 1575-85.

98. Antonini, S.R., M.C. Fragoso, and A. Lacroix, [Clinical and molecular aspects of the ACTH-independent bilateral macronodular adrenal hyperplasia]. Arq Bras Endocrinol Metabol, 2004. 48(5): p. 620-36.

99. Livak, K.J. and T.D. Schmittgen, Analysis of relative gene expression data using realtime quantitative PCR and the 2(-Delta Delta C(T)) Method. Methods, 2001. 25(4): p. 402-8.

100. Tadjine, M., et al., Frequent mutations of beta-catenin gene in sporadic secreting adrenocortical adenomas. Clin Endocrinol (Oxf), 2008. 68(2): p. 264-70.

101. Suwa, T., et al., Zonal expression of dickkopf-3 and components of the Wnt signalling pathways in the human adrenal cortex. J Endocrinol, 2003. 178(1): p. 149-58.

102. Ribeiro, R.C., et al., Adrenocortical tumors in children. Braz J Med Biol Res, 2000. 33(10): p. 1225-34.

103. Bielinska, M., et al., Origin and Molecular Pathology of Adrenocortical Neoplasms. Vet Pathol, 2009.

104. Tissier, F., et al., Mutations of beta-catenin in adrenocortical tumors: activation of the Wnt signaling pathway is a frequent event in both benign and malignant adrenocortical tumors. Cancer Res, 2005. 65(17): p. 7622-7.

105. Pusantisampan, T., et al., Cushing's syndrome in an infant secondary to malignant adrenocortical tumors with somatic mutation of beta-catenin. Pediatr Dev Pathol. 13(3): p. 238-42.

106. Tadjine, M., et al., Detection of somatic beta-catenin mutations in primary pigmented nodular adrenocortical disease (PPNAD). Clin Endocrinol (Oxf), 2008. 69(3): p. 36773.

107. Blaker, H., et al., Analysis of somatic APC mutations in rare extracolonic tumors of patients with familial adenomatous polyposis coli. Genes Chromosomes Cancer, 2004. 41(2): p. 93-8.

108. Szabo, P.M., et al., Meta-analysis of adrenocortical tumour genomics data: novel pathogenic pathways revealed. Oncogene, 2010. 29(21): p. 3163-72. 
109. El Wakil, A. and E. Lalli, The Wnt/beta-catenin pathway in adrenocortical development and cancer. Mol Cell Endocrinol, 2011. 332(1-2): p. 32-7.

110. Caneparo, L., et al., Dickkopf-1 regulates gastrulation movements by coordinated modulation of Wnt/beta catenin and Wnt/PCP activities, through interaction with the Dally-like homolog Knypek. Genes Dev, 2007. 21(4): p. 465-80.

111. Caldwell, G.M., et al., The Wnt antagonist sFRP1 in colorectal tumorigenesis. Cancer Res, 2004. 64(3): p. 883-8.

112. Lavergne, E., et al., Blocking Wnt signaling by SFRP-like molecules inhibits in vivo cell proliferation and tumor growth in cells carrying active beta-catenin. Oncogene. 30(4): p. 423-33.

113. Yue, W., et al., Downregulation of Dkk3 activates beta-catenin/TCF-4 signaling in lung cancer. Carcinogenesis, 2008. 29(1): p. 84-92.

114. Tsuji, T., et al., A REIC gene shows down-regulation in human immortalized cells and human tumor-derived cell lines. Biochem Biophys Res Commun, 2000. 268(1): p. 204.

115. You, A., et al., Expression of the Wnt antagonist DKK3 is frequently suppressed in sporadic epithelial ovarian cancer. J Cancer Res Clin Oncol, 2010.

116. Heikkila, M., et al., Wnt-4 deficiency alters mouse adrenal cortex function, reducing aldosterone production. Endocrinology, 2002. 143(11): p. 4358-65.

117. Salahshor, S. and J.R. Woodgett, The links between axin and carcinogenesis. J Clin Pathol, 2005. 58(3): p. 225-36.

118. Zhang, L.Y., et al., Axin induces cell death and reduces cell proliferation in astrocytoma by activating the p53 pathway. Int J Oncol, 2009. 35(1): p. 25-32.

119. Yang, L.H., et al., Axin downregulates TCF-4 transcription via beta-catenin, but not p53, and inhibits the proliferation and invasion of lung cancer cells. Mol Cancer, 2010. 9: p. 25.

120. Ciznadija, D., et al., Intestinal adenoma formation and MYC activation are regulated by cooperation between MYB and Wnt signaling. Cell Death Differ, 2009. 16(11): p. 1530-8. 
121. Lepique, A.P., et al., c-Myc protein is stabilized by fibroblast growth factor 2 and destabilized by ACTH to control cell cycle in mouse Y1 adrenocortical cells. J Mol Endocrinol, 2004. 33(3): p. 623-38.

122. Okuyama, H., et al., Downregulation of c-MYC protein levels contributes to cancer cell survival under dual deficiency of oxygen and glucose. Cancer Res, 2010. 70(24): p. 10213-23.

123. Szabo, P.M., K. Racz, and P. Igaz, Underexpression of C-myc in Adrenocortical Cancer: A Major Pathogenic Event? Horm Metab Res.

124. $\mathrm{Hu}, \mathrm{Q}$., et al., Wt1 ablation and Igf2 upregulation in mice result in Wilms tumors with elevated ERK1/2 phosphorylation. J Clin Invest. 121(1): p. 174-83.

125. Silver, S.J., et al., Functional screening identifies miR-315 as a potent activator of Wingless signaling. Proc Natl Acad Sci U S A, 2007. 104(46): p. 18151-6.

126. Kennell, J.A., et al., The microRNA miR-8 is a conserved negative regulator of Wnt signaling. Proc Natl Acad Sci U S A, 2008. 105(40): p. 15417-22.

127. Suzuki, H.I., et al., Modulation of microRNA processing by p53. Nature, 2009. 460(7254): p. 529-33.

128. Colli, L.M., et al. R337H P53 Mutation and the expression of microRNAs in adrenocortical tumor. in The 92nd Annual Meeting \& Expo of Endocrine Society (ENDO 2010). 2010.

129. Hsu, S.D., et al., miRNAMap 2.0: genomic maps of microRNAs in metazoan genomes. Nucleic Acids Res, 2008. 36(Database issue): p. D165-9.

130. Iliopoulos, D., et al., MicroRNA signature of primary pigmented nodular adrenocortical disease: clinical correlations and regulation of Wht signaling. Cancer Res, 2009. 69(8): p. 3278-82.

131. Gehrke, I., R.K. Gandhirajan, and K.A. Kreuzer, Targeting the WNT/betacatenin/TCF/LEF1 axis in solid and haematological cancers: Multiplicity of therapeutic options. Eur J Cancer, 2009. 45(16): p. 2759-67. 
8. Anexos 
Anexo A. Características clinicas, patológicas, moleculares e desfecho em pacientes com TAC pediátricos.

\begin{tabular}{|c|c|c|c|c|c|c|c|c|c|c|}
\hline ID & Sexo & $\begin{array}{l}\text { Idade } \\
\text { (meses) }\end{array}$ & $\begin{array}{c}\text { Tipo } \\
\text { hormonal }\end{array}$ & $\begin{array}{l}\text { Estágio } \\
\text { tumoral }\end{array}$ & $\begin{array}{l}\text { Recorrência } \\
\text { Metástases }\end{array}$ & Tratamento & $\begin{array}{c}\text { P53 } \\
\text { p.R337H }\end{array}$ & $\begin{array}{l}\text { Mutações } \\
\text { CTNNB1 }\end{array}$ & $\begin{array}{c}\text { Tempo de } \\
\text { Sobrevida } \\
\text { (meses) }\end{array}$ & Óbito \\
\hline 1 & $\mathrm{~F}$ & 5 & $\mathrm{M}$ & I & Não & C & Sim & Não & 162,2 & Não \\
\hline 2 & F & 5 & $M^{*}$ & I & Não & C & Sim & Não & 53,2 & Não \\
\hline 3 & M & 5 & V & I & Não & C & Sim & Não & 76,9 & Não \\
\hline 4 & M & 9 & M & I & Não & C & Sim & Não & 46 & Não \\
\hline 5 & $\mathrm{~F}$ & 10 & $M^{*}$ & I & Não & C & Sim & Não & 4,5 & Não \\
\hline 6 & $\mathrm{~F}$ & 10 & V & I & Não & $\mathrm{C}$ & Sim & Não & 57,3 & Não \\
\hline 7 & $\mathrm{~F}$ & 10 & V & I & Não & C & Sim & Não & 51,7 & Não \\
\hline 8 & M & 11 & V & I & Não & $\mathrm{C}$ & Sim & Não & 157 & Não \\
\hline 9 & M & 11 & M & I & Não & C & Não & Não & 148,9 & Não \\
\hline 10 & $\mathrm{~F}$ & 12 & V & I & Não & C & Sim & Não & 66,9 & Não \\
\hline 11 & $\mathrm{~F}$ & 12 & V & I & Não & C & Sim & Não & 29,3 & Não \\
\hline 12 & F & 13 & V & I & Não & $\mathrm{C}$ & Sim & Não & 54,2 & Não \\
\hline 13 & $\mathrm{~F}$ & 16 & M & I & Não & C & Sim & Não & 120,9 & Não \\
\hline 14 & F & 16 & V & I & Não & CQ & Sim & Não & 3,4 & Não \\
\hline 15 & $\mathrm{~F}$ & 16 & V & I & Não & $\mathrm{C}$ & Sim & Não & 30,6 & Não \\
\hline 16 & F & 17 & M & I & Não & $\mathrm{C}$ & Sim & Não & 11,7 & Não \\
\hline 17 & $\mathrm{~F}$ & 17 & V & I & Não & C & Sim & Não & 116,2 & Não \\
\hline 18 & F & 17 & V & I & Não & C & Sim & p.S45F & 37,5 & Não \\
\hline 19 & $\mathrm{~F}$ & 18 & V & I & Sim & C & Sim & Não & 97,0 & Não \\
\hline 20 & M & 20 & M & I & Sim & CQ & Sim & Não & 155,9 & Não \\
\hline 21 & $\mathrm{~F}$ & 20 & M & I & Não & $\mathrm{C}$ & Sim & Não & 12,5 & Não \\
\hline 22 & F & 22 & V & I & Não & C & Sim & Não & 55,5 & Não \\
\hline 23 & F & 22 & $\mathrm{M}^{*}$ & I & Não & C & Sim & Não & 15,8 & PS \\
\hline 24 & F & 22 & $\mathrm{M}$ & I & Não & C & Sim & Não & 7,7 & Não \\
\hline 25 & F & 23 & M & I & Não & C & Sim & Não & 51,6 & Não \\
\hline 26 & F & 25 & V & I & Não & C & Sim & Não & 42,6 & Não \\
\hline 27 & F & 28 & V & I & Não & C & Não & Não & 39,8 & Não \\
\hline 28 & F & 29 & V & I & Não & C & Sim & Não & 51,4 & Não \\
\hline 29 & F & 29 & V & I & Sim & C & Sim & p.S33F & 15,7 & Sim \\
\hline 30 & F & 33 & V & I & Não & C & Sim & Não & 5,6 & Não \\
\hline 31 & M & 34 & M & I & Não & $\mathrm{C}$ & Sim & Não & 101 & Não \\
\hline 32 & M & 36 & M & I & Sim & CQ & Sim & Não & 66,5 & Não \\
\hline 33 & F & 36 & M & I & Não & C & Sim & Não & 92,4 & Não \\
\hline 34 & F & 38 & M & I & Não & C & Sim & Não & 9,8 & Não \\
\hline 35 & $\mathrm{~F}$ & 44 & V & I & Não & C & Sim & Não & 110,4 & Não \\
\hline 36 & F & 73 & M & I & Não & C & Não & Não & 137,3 & Não \\
\hline 37 & $\mathrm{~F}$ & 145 & M & I & Não & C & Não & Não & 80,6 & Não \\
\hline 38 & M & 12 & V & II & Não & C & Sim & Não & 16,0 & Não \\
\hline 39 & $\mathrm{~F}$ & 13 & V & II & Não & C & Não & Não & 86,5 & Não \\
\hline 40 & F & 16 & $\mathrm{~V}^{* *}$ & II & Não & C & Sim & Não & 0,4 & Sim \\
\hline 41 & $\mathrm{~F}$ & 17 & $\mathrm{~V}$ & II & Não & C & Sim & Não & 69,8 & Não \\
\hline 42 & M & 27 & $M^{*}$ & II & Não & C & Sim & Não & 162,2 & Não \\
\hline 43 & M & 72 & M & II & Sim & CQ & Sim & Não & 7,7 & Sim \\
\hline 44 & $\mathrm{~F}$ & 92 & V & II & Não & $\mathrm{C}$ & Sim & Não & 35,7 & Não \\
\hline 45 & $\mathrm{~F}$ & 108 & M & II & Não & C & Sim & Não & 9,9 & Sim \\
\hline 46 & F & 187 & V & II & Não & $\mathrm{C}$ & Não & Não & 75,8 & Não \\
\hline 47 & $\mathrm{~F}$ & 137 & $C^{*}$ & II & Sim & CQ & Não & Não & 134,5 & Não \\
\hline 48 & F & 13 & V & III & Não & $\mathrm{C}$ & Sim & Não & 13 & Não \\
\hline 49 & $\mathrm{~F}$ & 16 & $\mathrm{~V}^{* *}$ & III & Não & $\mathrm{C}$ & Sim & Não & 17 & Não \\
\hline 50 & F & 19 & $\mathrm{~V}$ & III & Não & $\mathrm{C}$ & Sim & Não & 49,6 & Não \\
\hline 51 & $\mathrm{~F}$ & 19 & $\mathrm{~V}^{* *}$ & III & Não & C & Sim & p.S37P & 7,6 & Sim \\
\hline 52 & F & 20 & M & III & Não & CQ & Sim & Não & 4,5 & PS \\
\hline 53 & $\mathrm{~F}$ & 29 & V & III & Não & CQ & Sim & Não & 134,8 & Não \\
\hline 54 & M & 52 & V & III & Não & $\mathrm{C}$ & Sim & Não & 57,6 & Não \\
\hline 55 & $\mathrm{~F}$ & 66 & M & III & Sim & CQ & Sim & Não & 15,5 & Sim \\
\hline 56 & $\mathrm{M}$ & 13 & $\mathrm{~V}^{* *}$ & IV & Não & $\mathrm{C}$ & Sim & Não & 168,4 & Não \\
\hline 57 & M & 33 & V & IV & Sim & CQ & Sim & p.S45P & 4.9 & Sim \\
\hline 58 & $\mathrm{~F}$ & 96 & $\mathrm{M}^{*}$ & IV & Sim & $\mathrm{C}$ & Sim & Não & 23.3 & Sim \\
\hline 59 & F & 84 & $\mathrm{~V}$ & IV & Sim & CQ & Sim & Não & 16.8 & PS \\
\hline 60 & F & 94 & $\mathrm{M}^{* *}$ & IV & Sim & C & Sim & Não & 19.9 & Sim \\
\hline 61 & $\mathrm{~F}$ & 180 & M & IV & Sim & CQ & Sim & Não & 9.8 & Sim \\
\hline 62 & M & 185 & C & IV & Sim & CQ & Sim & Não & 9 & Sim \\
\hline
\end{tabular}

Abreviações: F, sexo feminino; M, sexo masculino; C, somente ressecção cirúrgica; CQ, ressecção cirúrgica+quimioterapia/mitotano; PS, perda de seguimento. Idade e Sobrevida total são expressos em meses. V, Tumor virilizante; C, Síndrome de Cushing; M, Tumor virilizante+Síndrome de Cushing; M*, Tumor virilizante com Cushing subclínico; C*, Cushing. subclínico, **, hipertensão. 
Anexo B. Características histopatológicas de Weiss dos TAC provenientes do HCRP-FMRP/USP (n=22)

\begin{tabular}{|c|c|c|c|c|c|c|c|c|c|c|c|}
\hline ID & Grau nuclear & Índice mitótico & Mitoses atípicas & Citoplasma & Arquitetura & Necrose & Invasão venosa & Invasão sinusoidal & Invasão cápsula & Estágio Tumoral & Escore Weiss \\
\hline 22 & I & $5 / 50$ & $\mathrm{~N}$ & $<25 \%$ & Difusa & $\mathrm{S}$ & $\mathrm{N}$ & $\mathrm{N}$ & $\mathrm{N}$ & $\mathbf{I}$ & 3 \\
\hline 20 & I & $3 / 50$ & $\mathrm{~N}$ & $<25 \%$ & Difusa & S & $\mathrm{N}$ & $\mathrm{N}$ & $\mathrm{N}$ & III & 3 \\
\hline 1 & III & $3 / 50$ & $\mathrm{~S}$ & $>25 \%$ & Difusa & S & $\mathrm{N}$ & $\mathrm{N}$ & $\mathrm{N}$ & $\mathbf{I}$ & 4 \\
\hline 53 & III & $25 / 50$ & S & $>25 \%$ & Difusa & $\mathrm{N}$ & $\mathrm{N}$ & $\mathrm{N}$ & $\mathrm{N}$ & III & 4 \\
\hline 25 & III & $15 / 50$ & $\mathrm{~S}$ & $>25 \%$ & Sólido & $\mathrm{S}$ & $\mathrm{N}$ & $\mathrm{N}$ & $\mathrm{N}$ & $\mathbf{I}$ & 4 \\
\hline 27 & III & $4 / 50$ & $\mathrm{~S}$ & $>25 \%$ & Difusa & $\mathrm{N}$ & $\mathrm{N}$ & $\mathrm{N}$ & $\mathrm{S}$ & $\mathbf{I}$ & 4 \\
\hline 13 & II & $50 / 50$ & $\mathrm{~N}$ & $<25 \%$ & Difusa & $\mathrm{s}$ & $\mathrm{N}$ & $\mathrm{N}$ & $\mathrm{N}$ & I & 4 \\
\hline 21 & IV & $15 / 50$ & $\mathrm{~S}$ & $>25 \%$ & Difusa & $\mathrm{N}$ & $\mathrm{N}$ & $\mathrm{N}$ & $\mathrm{N}$ & $\mathbf{I}$ & 4 \\
\hline 37 & I & $10 / 50$ & $\mathrm{~N}$ & $>25 \%$ & Difusa & S & $\mathrm{N}$ & $\mathrm{N}$ & S & $\mathbf{I}$ & 4 \\
\hline 47 & II & $10 / 50$ & $\mathrm{~N}$ & $<25 \%$ & Difusa & $\mathrm{S}$ & $\mathrm{N}$ & $\mathrm{N}$ & $\mathrm{N}$ & III & 4 \\
\hline 23 & IV & $5 / 50$ & $\mathrm{~N}$ & $>25 \%$ & Sólida/trabecular & $\mathrm{s}$ & $\mathrm{S}$ & $\mathrm{N}$ & $\mathrm{S}$ & III & 4 \\
\hline 8 & IV & $15 / 50$ & $\mathrm{~N}$ & $>25 \%$ & Difusa & $\mathrm{N}$ & $\mathrm{N}$ & $\mathrm{N}$ & S & $\mathbf{I}$ & 5 \\
\hline 9 & IV & $5 / 50$ & S & $>25 \%$ & Difusa & S & $\mathrm{N}$ & $\mathrm{N}$ & $\mathrm{S}$ & $\mathbf{I}$ & 5 \\
\hline 43 & II & $20 / 50$ & $\mathrm{~S}$ & $<25 \%$ & Difusa & $\mathrm{S}$ & $\mathrm{N}$ & $\mathrm{N}$ & $\mathrm{S}$ & II & 6 \\
\hline 58 & I & $20 / 50$ & $\mathrm{~S}$ & $<25 \%$ & Difusa & $\mathrm{S}$ & $\mathrm{S}$ & $\mathrm{N}$ & $\mathrm{S}$ & IV & 6 \\
\hline 16 & III & $6 / 50$ & $\mathrm{~N}$ & $<25 \%$ & Difusa & $\mathrm{S}$ & $\mathrm{S}$ & $\mathrm{N}$ & $\mathrm{S}$ & I & 7 \\
\hline 57 & $\mathrm{I}$ & $50 / 50$ & $\mathrm{~N}$ & $<25 \%$ & Sólida/trabecular & $\mathrm{s}$ & $\mathrm{S}$ & $\mathrm{S}$ & $\mathrm{S}$ & IV & 7 \\
\hline 55 & I & $38 / 50$ & $\mathrm{~S}$ & $<25 \%$ & Difusa & $\mathrm{s}$ & $\mathrm{S}$ & $\mathrm{N}$ & $\mathrm{S}$ & IV & 7 \\
\hline 61 & I & $20 / 50$ & $\mathrm{~S}$ & $<25 \%$ & Trabecular & $\mathrm{S}$ & $\mathrm{S}$ & $\mathrm{S}$ & $\mathrm{S}$ & IV & 7 \\
\hline 62 & III & $6 / 50$ & $\mathrm{~N}$ & $<25 \%$ & Trabecular/sólida & $\mathrm{s}$ & $\mathrm{S}$ & $\mathrm{S}$ & $\mathrm{S}$ & IV & 7 \\
\hline 33 & IV & $10 / 50$ & $\mathrm{~S}$ & $>25 \%$ & Difusa & $\mathrm{s}$ & $\mathrm{S}$ & $\mathrm{N}$ & $\mathrm{S}$ & III & 7 \\
\hline 59 & III & $30 / 50$ & $S$ & $<25 \%$ & Difusa & $\mathrm{S}$ & $\mathrm{S}$ & $\mathrm{S}$ & $\mathrm{S}$ & IV & 9 \\
\hline
\end{tabular}

S: sim; N: não 


\title{
Wnt/ß-catenin Pathway deregulation in Childhood Adrenocortical Tumors
}

Letícia F. Leal ${ }^{1}$, Lívia M. Mermejo ${ }^{2}$, Leandra Z. Ramalho ${ }^{3}$, Carlos E. Martinelli Jr ${ }^{1}$, José A. Yunes ${ }^{4}$, Ana Luiza Seidinger ${ }^{4}$, Maria José Mastellaro ${ }^{4}$, Izilda A. Cardinalli ${ }^{4}$, Silvia R. Brandalise ${ }^{4}$, Ayrton C. Moreira $^{2}$, Luiz G. Tone ${ }^{1}$, Carlos A. Scrideli ${ }^{1}$, Margaret Castro ${ }^{2}$, Sonir R. Antonini ${ }^{1}$.

1. Department of Pediatrics, School of Medicine of Ribeirao Preto, University of Sao Paulo, Brazil.

2. Department of Internal Medicine, School of Medicine of Ribeirao Preto, University of Sao Paulo, Brazil.

3. Department of Pathology, School of Medicine of Ribeirao Preto, University of Sao Paulo, Brazil.

4. Boldrini Children's Center, Campinas, Sao Paulo, Brazil.

\begin{abstract}
Abbreviate Title: Wnt/ $\beta$-catenin in Childhood ACTs.
\end{abstract}
Key Words: Childhood adrenocortical tumor, Wnt/ $\beta$-catenin pathway, $C T N N B 1$ and TP53 mutations.

Word Count: text: 3290; abstract: 240.

\section{Corresponding author and Reprint Requests:}

Sonir Rauber Antonini,. MD.

Departamento de Puericultura e Pediatria, Faculdade de Medicina de Ribeirao Preto, Universidade de Sao Paulo. Av. Bandeirantes 3900. Ribeirao Preto-SP, Brazil. 14091-900. Fone: +55(16)3602-2937. Fax: 55-16-3633 6695.

E-mail: antonini@fmrp.usp.br

Disclosure Statement: The Authors have nothing to disclose.

\section{Source of Funding}

This work was supported by FAPESP and CNPq. L.F.L. is recipient of a M.Sci. Fellowship (CAPES). Précis: CTNNB1 mutations are rare but the Wnt/ $\beta$-catenin pathway is deregulated in childhood adrenocortical tumors. Additional Wnt/ $\beta$-catenin pathway events may be involved in childhood adrenocortical tumorigenesis. 
Abstract

Context: $C T N N B 1 / \beta$-catenin mutations and activation of $\mathrm{Wnt} / \beta$-catenin pathway are frequent in adult adrenocortical tumors (ACTs) but data on childhood ACTs are lacking.

Objective: To investigate the presence of $\mathrm{Wnt} / \beta$-catenin pathway abnormalities in childhood ACTs.

Patients and Methods: Clinicopathological findings and outcome of 62 childhood ACT patients were analyzed regarding to $C T N N B$ mutations and the expression of Wnt-related genes $(C T N N B 1, W N T 4$ : a Wnt ligand, SFRP1, DKK3 and AXIN1: Wnt inhibitors, TCF7: a transcription factor, and $M Y C$ and WISP2: target genes) by qPCR and immunohistochemistry.

Results: CTNNB1 activating mutations were found in only 4/62 ACTs (6\%), all of them harboring TP53 mutation. There was association between the presence of CTNNB1 mutations and death $(\mathrm{p}=0.02)$. Diffuse $\beta$-catenin accumulation was found in $71 \%$ of ACTs, even in ACTs without CTNNB1 mutations. Compared to normal adrenals, ACTs presented increased expression of CTNNB1 $(\mathrm{p}=0.008)$ and underexpression of Wnt inhibitor genes: DKK3 $(\mathrm{p}<0.0001), \operatorname{SFRP1}(\mathrm{p}=0.05)$ and AXIN1 $(\mathrm{p}=0.04)$. With regards to Wnt/ $\beta$-catenin target genes, ACTs presented increased expression of WISP2 but lower expression of $M Y C$. Higher overall survival was associated with underexpression of $S F R P 1(\mathrm{p}=0.01)$, WNT4 $(\mathrm{p}=0.004)$ and TCF7 $(\mathrm{p}<0.01)$.

Conclusions: CTNNB1 mutations are not common in childhood ACTs but appear to associate with poor prognosis. Nevertheless, most ACTs exhibit increased expression of $\beta$-catenin and WISP2 and reduced expression of Wnt inhibitor genes (DKK3, SFRP1 and AXIN1). Thus, in addition to CTNNB1 mutations, other genetic events affecting the Wnt/ $\beta$-catenin pathway may be involved in childhood adrenocortical tumorigenesis. 


\section{Introduction}

Adrenocortical tumors (ACTs) in children are rare $(1,2)$. However, in Southern Brazil the incidence is 10-15 times more frequent than worldwide and is associated with an inherited TP53 mutation (p.R337H) (3-5). Irrespective of histopathological features, childhood ACTs behave differently and survival rate is higher in children compared to adults $(1,2)$, suggesting the presence of distinct molecular abnormalities. The understanding of ACT biology has increased with microarray studies (6-8), but few prognostic molecular markers have been identified in childhood ACTs (2). Childhood ACTs present increased $S F-1$ gene copy number and expression $(9,10)$ as well as $I G F 2$ and $I G F 1 R$ overexpression (11).

Wnt pathway regulates normal adrenal development and function, including zonation, SF-1mediated transcription and steroidogenesis (12). In physiological conditions, the Wnt pathway is activated when a Wnt ligand binds to its cell-surface receptor (13). In adrenal, Wnt4 appears to be the most important Wnt ligand $(12,14) . D K K 3$ is highly expressed in normal adrenal $(12,15)$ and antagonizes Wnt through interaction with the LRP co-receptor, inducing its endocytosis $(12,16)$. SFRP1 antagonizes the Wnt signaling by sequestering Wnt proteins $(13,17)$. Ligand binding results in dissociation of the $\beta$-catenin cytoplasmic degradation complex, mainly composed by GSK-3 $\beta$, APC and AXIN1, resulting in $\beta$-catenin phosphorylation inhibition. $\beta$-catenin thereby accumulates in the cytoplasm, translocates to the nucleus, and by binding to TCF/LEF regulates the expression of several Wnt target genes, including MYC and WISP2, involved in cell growth and differentiation (13).

Activation of the Wnt/ $\beta$-catenin pathway has been found in human cancers and play an important role in adrenocortical tumorigenesis $(13,15,18)$. Mutations of the $\beta$-catenin gene (CTNNB1) resulting in impaired $\beta$-catenin degradation have been frequently found in adult ACTs (1921). CTNNB1 and TP53 mutations are clustered within different sets of a poor prognosis group of adult ACT patients $(22,23)$. To our knowledge, no previous study has investigated the presence of Wnt/ $\beta$-catenin pathway abnormalities in a series of childhood ACTs.

In this study CTNNB1 gene mutations and its expression were evaluated in a large cohort of childhood ACTs. Furthermore, we analyzed the involvement of the important components of the 
Wnt/B-catenin pathway including a Wnt ligand (WNT4), Wnt antagonists (SFRP1 and DKK3), a key component of the degradation complex (AXIN1), a transcription factor $(T C F)$, and target genes $(M Y C$ and $W I S P 2)(13,15)$ in adrenocortical tumorigenesis.

\section{Material and Methods}

\section{Patients}

Sixty-two pediatric patients with ACTs diagnosed between 1991 and 2010 in two reference centers in Southeast Brazil (School of Medicine of Ribeirao Preto, University of Sao Paulo - FMRP and Boldrini Children's Center, Campinas, Sao Paulo) were enrolled in this study. Laboratory evaluation included measurements of morning plasma cortisol, 17-hydroxyprogesterone and androgens obtained before and after dexamethasone suppression test ( $2 \mathrm{mg} /$ day for 5 days). Following the biochemical tests, abdominal computed tomography (CT) and /or magnetic resonance imaging (MRI) were performed. Chest $\mathrm{CT}$ and bone scintigraphy were performed for the detection of metastases. After surgery, patients were examined monthly during the first year and at least twice a year for 5 years and thereafter annually. Stage of the disease was classified according to the Sandrini classification, proposed for childhood ACTs (1). Eight normal adrenal cortices, used as control tissues, were obtained from adult with sudden death without known disease (Center of Forensic Medicine FMRP). This study was approved by local Ethics Committee (\#7534/2010) and a signed statement of informed consent was obtained from the patient's parents and control's relatives.

\section{DNA isolation and amplification}

Genomic DNA from peripheral blood cells and tumoral DNA from microdissected frozen tissues were extracted using the QIAamp®kit (Qiagen Inc., Valencia, CA-USA). The exon 10 of the TP53 gene was amplified by PCR using the forward 5'-TGCATGTTGCTTTTGTACCG-3' and reverse 5'-AGCTGCCTTTGACCATGAAG-3' primers. The 507-bp PCR fragments were automated sequenced using the ABI Prism Big Dye Terminator ${ }^{\circledR}$ v3.1 Cycle Sequencing Kit on an ABI 3130 (Applied Biosystems, Foster City, CA, USA). 


\section{RNA isolation and cDNA synthesis and amplification}

Frozen tumor tissue and control adrenal cortex samples were microdissected by an experienced pathologist. Total RNA was extracted using TRIzol Reagent (Invitrogen ${ }^{\mathrm{TM}}$, Karlsruche, Germany) following the manufacturer's protocol and quantified by spectrometry with an acceptable range of 1.6 to 2.0 . The RNA integrity was evaluated by the $28 \mathrm{~S} / 18 \mathrm{~S}$ band rate in a $1.2 \%$ gel electrophoresis. cDNA synthesis was performed with the High Capacity cDNA Reverse Transcription kit and MultiScribe ${ }^{\mathrm{TM}}$ enzyme (Applied Biosystems, Foster City, CA, USA).

PCR using $1 \mu \mathrm{L}$ of cDNA was employed to amplify the region containing the exon 3 of the CTNNB1 gene using the forward 5'-GCTGATTTGATGGAGTTGGA-3' and reverse 3'-GCTACTTGTTCTTGAGTGAA-5' primers. The 648-bp fragments were automated sequenced. Results were confirmed by a second PCR and sequencing reaction using forward and reverse primers.

\section{mRNA Quantification by Real-Time PCR (qPCR)}

The mRNA expression levels of components of the Wnt canonical pathway including CTNNB1 (Hs00170025_m1), DKK3 (Hs00247426_m1), AXIN1 (Hs00394718_m1), SFRP1 (Hs00610060_m1), TCF (Hs00175273_m1), MYC (Hs99999003_m1), WISP2 (Hs00180242_m1), and TP53 (Hs01034249_m1) genes were analyzed by real-time PCR. Reactions were performed in duplicate using TaqMan ${ }^{\circledR}$ according to the manufacturer recommendation. The $2^{-\Delta \Delta \mathrm{Ct}}$ method was used to determine relative expression of mRNAs in control samples and in tumor samples. The results were normalized by the mean expression of three housekeeper genes: TBP (Hs00920497_m1), GUSB (Hs99999908_m1) and ACTB (Hs99999903_m1). For association analysis between gene expression and outcomes, ACTs were divided into two groups: underexpressed and overexpressed, considering the expression under and above the median of the controls, respectively.

\section{Immunohistochemical (IHC) analysis}

Immunohistochemistry studies were performed in a subset of 25 tumor tissue samples after deparaffinization, rehydration, antigen retrieval in citrate buffer solution (pH 6.0) for $45 \mathrm{~min}$, and incubation with primary antibodies anti- $\beta$-catenin, DKK3, MYC, WISP2, and P53 (Santa Cruz 
141 Biotechnology, Santa Cruz, CA- USA, dilution 1:100) for $2 \mathrm{~h}$ at room temperature, followed by signal

142 detection by the avidin-biotin system (Vectastain Elite ABC Kit, Universal, Vector Laboratories Inc.,

143 Burlingame, CA-USA). The nuclear and/or cytoplasmic labeling was developed with NovoRed

144 (red; Vector Laboratories Inc.) and counterstained with Harri's Hematoxylin (blue). As negative

145 controls, all specimens were incubated with an isotope-matched control antibody under identical

146 conditions. Preparations for each marker were evaluated randomly in at least 10 representative high-

147 power fields (X 400) by an experienced pathologist (LZR). The immunolabeling percentage was

148 evaluated by a ratio of unequivocal nuclei labeling in 100 counted cells or percentage of labeled area

149 using the Image J software.

150 Each sample was assigned as percentage of stained cells: negative (less than $1 \%$ ), +1 (weak:

151 1\%-10\%), +2 (moderate: 10\%-50\%) and +3 (strong: more than 50\%). The normal adjacent adrenal

152 gland was considered as negative control (19).

\section{Statistical analysis}

Quantitative variables were expressed as median and range and analyzed by Mann-Whitney test, One-way ANOVA with Dunn's post-test, and Spearman's Correlation test. Qualitative variables were analyzed by Chi-square or Fisher's exact test. Survival analysis was carried out by Kaplan-Meier curves, considering death as the unfavorable event. Survival curves for different groups were compared by the log-rank test. Patients who were lost to follow-up were censored considering their last follow-up visit. Analyses were performed using the GraphPad Prism 4.0 ${ }^{\circledR}$ (GraphPad, San Diego,CA), Minitab ${ }^{\circledR} 15$ (Minitab, State College, PA) and $\mathrm{R}^{\circledR}$ (R Foundation).

\section{Results}

\section{Clinical and Pathological results}

We evaluated 48 girls (77\%) and 14 boys with a median age at the diagnosis of 1.8 years old (0.4-15.5 years). Forty-six (74\%) patients were diagnosed in the first 3 years of life, including 11 patients $(18 \%)$ younger than 1 year. All patients presented hormone secreting tumors: 34 androgen secreting tumor, 26 mixed cortisol and androgen secreting tumor and 2 cortisol secreting tumor. 
169 Clinical and pathological features including sex, age, clinical presentation, tumor stage, and treatment 170 are described in Table 1.

\section{Clinical Outcome}

Overall survival and follow-up are shown in Table 1. Mean overall survival was 136.9 months. One, 2 and 5 years survival were $88 \%, 80 \%$ and $77 \%$, respectively. Eleven patients (18\%) died, one due to postoperative complications and 10 due to progressive disease. Among survivors, the median follow-up was 56 months (3.4-168 months) and 3 patients were lost to follow-up. Overall survival was significantly associated with tumoral stage (Log-rank test: $p<0.0001$; Figure $1 \mathrm{~A}$ ). Survival was not different regarding the clinical presentation (Log-rank test: $\mathrm{p}=0.16$ ). Overall survival was higher in patients younger than 5 years (Log-rank test: $\mathrm{p}<0.0001)$.

\section{TP53 and CTNNB1 mutations}

\section{Wnt/ $\beta$-catenin pathway genes expression}

ACTs presented decreased mRNA expression of DKK3 (-14-fold; $\mathrm{p}<0.0001$; Figure 2A), WNT4 (-6.1-fold; $\mathrm{p}=0.0083$; Figure 2B), SFRP1 (-4-fold; $\mathrm{p}=0.05$; Figure 2C), TCF7 (-3-fold; $\mathrm{p}=0.007$; Figure 2D), MYC (-2.8-fold; $\mathrm{p}=0.03$; Figure 2E) and AXIN1 (-1.6-fold; $\mathrm{p}=0.04$; Figure 2F). WISP2 mRNA expression was not different between ACTs and normal adrenal tissues. We found increased mRNA expression of CTNNB1 (1.9-fold; $\mathrm{p}=0.008$; Figure $2 \mathrm{G}$ ). In $93 \%$ of the tumor samples, CTNNB1 mRNA levels were above the median of the expression level of normal adrenals. 

$(\mathrm{p}=0.19, \mathrm{p}=0.44$ and $\mathrm{p}=0.14$, respectively). $W N T 4$ and $T C F 7$ underexpression were more pronounced in ACT stages I and II than in ACT stages III and IV (-13.9-fold; $p=0.02$ and -4.9 -fold; $p=0.006$, respectively). On the other hand, MYC and TP53 underexpression were more pronounced in ACT stages III and IV (-2.8-fold; $p=0.03$ and -2.7 -fold; $p=0.02$ ).

There was no association between the level of expression of CTNNB1, DKK3, WNT4, SFRP1, TCF7, MYC and AXIN1 genes and the presence of the p.R337H P53 or CTNNB1 mutations. However, TP53 mRNA levels were lower in TP53 mutated tumors (-2.3-fold; $\mathrm{p}=0.04)$.

There was no association between the level of expression of each analyzed gene and clinical presentation. Higher survival was observed in patients with tumors presenting underexpression of SFRP1 (Log-rank test: $\mathrm{p}=0.01$; Figure 1B), WNT4 (Log-rank test: $\mathrm{p}=0.004$; Figure 1C) and TCF7 (Log-rank test: $\mathrm{p}<0.01$; Figure 1D).

\section{Immunohistochemistry (IHC)}

Immunohistochemistry for P53, $\beta$-catenin, DKK3, MYC and WISP2 was evaluated in a subset of ACTs (Figure 3). Individual profiles of the IHC for $\beta$-catenin and P53 are summarized in Figure 4. Seventeen out of 24 samples (71\%) presented increased cytoplasmic and/or nuclear $\beta$-catenin accumulation. Nuclear $\beta$-catenin accumulation was found in 3 (13\%) ACTs, none harboring CTNNB1 mutations. In 4 tumors harboring CTNNB1 mutations, $\beta$-catenin cytoplasmic accumulation was found (Figure 4). $\beta$-catenin accumulation was not associated with tumoral stage (Chi-square test: $p=0.8$ ) or poor outcome (Fisher's test: $\mathrm{p}=1.0$ ). CTNNB1 mRNA levels correlated with $\beta$-catenin staining (Spearman's correlation: $\mathrm{r}=0.5 ; \mathrm{p}=0.02$ ). tumors (40\%; Figure 4). Abnormal P53 staining was not associated with the presence of the p.R337H P53 mutation (Fisher's test: $\mathrm{p}=0.6$ ), tumoral stage (Chi-square test: $\mathrm{p}=0.3$ ) or poor outcome (Fisher's test: $\mathrm{p}=1.0$ ). There was no association between abnormal $\beta$-catenin staining and the presence of the 
$22(59 \%)$ of ACTs. MYC immunostaining was absent or low in 15 out of $23(65 \%)$ whereas WISP2 accumulation was found in 19 out of $23(83 \%)$ ACTs.

\section{Discussion}

In this study analyzing a large cohort of Brazilian patients we present evidences that the expression of Wnt-related genes is deregulated in childhood ACTs, although CTNNB1 mutations are infrequent in these tumors. Nevertheless, the presence of CTNNB1 mutations appears to be associated with poor prognosis. Recent data on ACCs in adults demonstrated the activation of the Wnt pathway and its association with more aggressive phenotype (24). The present work is important since data on childhood ACTs were lacking. Only one case report showed evidence of the Wnt/ $\beta$-catenin pathway activation in a 4-months old Thai infant with a cortisol secreting ACC presenting a CTNNB1 deletion (P44_S45del) in the adrenal nodule and also in the liver metastasis (25).

The p.R337H P53 mutation was found in the majority of the childhood patients, in agreement with previous Brazilian studies (3-5). In adult ACTs, the presence of TP53 mutations has been related to poor outcome (23). In the present study, we show that p.R337H P53 mutation is not associated with tumoral stage at diagnosis or poor prognosis in childhood ACTs. Therefore, we hypothesized that additional molecular abnormality in childhood ACTs might influence their outcome. One of these possibilities would be the presence of CTNNB1 mutations. However, we found CTNNB1 mutations in only $6 \%$ of childhood ACTs, all affecting serine residues involved in $\beta$-catenin phosphorylation (19), indicating that $C T N N B 1$ mutations are less frequent in childhood than in adult ACTs. Indeed, a recent study described the presence of CTNNB1 mutations in $36 \%$ of adult ACTs, predominantly in nonsecreting ACTs (22), which are rare in children. Furthermore, in adults, CTNNB1 mutations were reported with similar frequencies in adrenocortical adenomas (ACAs) and carcinomas (ACCs) (20). Due to the uncertainty in classifying childhood ACTs as carcinomas or adenomas using histological criteria, the comparison of this finding is difficult in childhood ACTs (1).

One interesting result in our study is that all CTNNB1 mutations were found in ACTs harboring the p.R337H P53 mutation. This data indicates that in childhood ACTs CTNNB1 and TP53 mutations are not mutually exclusive. Our data in childhood ACTs is different of those found in adult 
252

253

254

255

256

257

258

259

260

261

262

263

264

265

266

267

268

269

270

271

272

ACTs, in which the concomitance of CTNNB1 and TP53 mutations seems to be a rare event (23). In addition, in adults, the presence of either CTNNB1 or TP53 mutations determines two distinct ACCs groups with poor prognosis (23). In our study, in contrast to the lack of association between the p.R337H P53 mutation and outcome, the presence of CTNNB1 mutations was associated with poor prognosis. Indeed, the majority of the patients with ACTs harboring CTNNB1 mutations died (75\%) conversely to only $15 \%$ of the patients without CTNNB1 mutations. Although significant, due to the small sample size of the CTNNB1 mutated group, this data needs to be confirmed in other series. Of note, patients without p.R337H P53 or CTNNB1 mutations presented with stage I disease. These data are in agreement with a previous report demonstrating the presence of CTNNB1 mutation only in the malignant part of a heterogeneous ACT (21).

We found higher CTNNB1 mRNA expression and diffuse cytoplasmic and nuclear $\beta$-catenin accumulation in the few tumors harboring $C T N N B 1$ mutations as well as in the majority of tumors without CTNNB1 mutations. This pattern is different of that observed in adult ACTs (19, 22-24), including our series (data not shown). In adults, $\beta$-catenin nuclear accumulation has been frequently reported in ACTs harboring CTNNB1 mutations $(19,22)$ in contrast to abnormal cytoplasmic staining found in ACTs without CTNNB1 mutations (22). Thus, in adults but not in childhood ACTs, CTNNB1 mutation appears to be a determinant factor in the abnormal $\beta$-catenin nuclear accumulation (22), which indicates an activation of the Wnt/ $\beta$-catenin pathway $(22,26)$. Thus, childhood and adult ACTs might have different mechanisms triggering Wnt/ $\beta$-catenin pathway regulation. To identify other factors that might modulate the Wnt/ $\beta$-catenin pathway in childhood adrenocortical tumorigenesis, we examined the expression of important components of the Wnt canonical pathway including SFRP1, DKK3, WNT4, AXIN1, TCF7, MYC, and WISP2 $(13,15)$.

$D K K 3$, a Wnt signaling inhibitor, is the only $D K K$ family gene expressed at high levels in normal adrenal $(12,15)$. We observed a pronounced DKK3 mRNA underexpression and absent or weak DKK3 immunostaining in most tumor samples. However, underexpression of DKK3 was neither associated with advanced stages of the disease nor with survival. In immortalized cell types, DKK3 acts as a possible tumor suppressor gene (27) and $D K K 3$ reduced expression was shown in human ovarian cancer (28). In lung cancer cells, epigenetic inactivation of $D K K 3$ activates the $\mathrm{Wnt} / \beta$-catenin 
pathway (29). We also observed underexpression of $S F R P 1$, another antagonist of Wnt signaling. It is possible that underexpression of $S F R P 1$ and $D K K 3$ contributes to $\mathrm{Wnt} / \beta$-catenin pathway activation by increasing Wnt ligand availability or Frizzled receptor affinity (13), contributing to the development of ACTs.

We found reduced WNT4 mRNA levels, mainly in ACTs at stages I/II, which was associated with higher overall survival. WNT4 mRNA levels have been consistently detectable in normal fasciculate and glomerulosa zones, with multiple actions on normal steroidogenesis and organogenesis (12) and its deficiency leads to the abnormal development of several organs (14). Thus, WNT4 underexpression could contribute to the development of ACTs.

We observed reduced expression of AXIN1 in ACTs without association with disease stage or survival. AXIN1, a key component of the $\beta$-catenin cytoplasmic degradation complex, is constitutively expressed and is essential for the maintenance of low Wnt signaling activity in the basal state. AXIN1 is a critical determinant in P53-dependent tumor suppression, induces cell death, and reduces cell proliferation in astrocytoma cells (30). In addition, AXIN1 downregulates $\beta$-catenin in lung cancer cells and may also inhibit the proliferation and invasion of these cells (31). Taken together these data suggest that underexpression of $A X I N 1$ might contribute to the increased $\beta$-catenin accumulation observed in childhood ACTs.

TCF/LEF recruits $\beta$-catenin into a transcriptional activation complex, resulting in increased expression of several target genes (32). In the present study we evaluated the expression of TCF7, which was underexpressed, and two Wnt pathway target genes, MYC and WISP2. We observed increased expression of the WISP2 protein in most ACT samples. Previous studies have shown increased expression of WISP2 in macronodular adrenal hyperplasia (33) and in primary pigmented nodular adrenal disease (PPNAD) (34). Thus, the higher expression of WISP2 found in childhood ACTs may result from activation of the Wnt pathway in these tumors.

We could expect hyperexpression of $M Y C$, the other Wnt target gene studied. However, our finding of low MYC expression in childhood ACTs is in agreement with microarray studies showing low MYC expression in adult ACTs. In addition, loss of chromosome 8q24, where MYC is located, 
307

has been shown in ACTs (35). Since in many non adrenal cancers MYC hyperexpression was observed, ACTs might represent a unique class of tumors characterized by low MYC expression (36). Downregulation of $M Y C$ might be a cancer surviving strategy (37). Indeed, we observed more reduced MYC expression in advanced ACT stages.

One putative mechanism underlying deregulation of the Wnt pathway in ACTs could be related to miRNAs. Indeed, it has been shown that childhood ACTs present a set of differentially expressed miRNAs (38). Another mechanism could be the epigenetic silencing of $\mathrm{Wnt} / \beta$-catenin inhibitors, such as DKK and WIF1 (39). The underexpression of DKK3 found in the present study may point out to this later possibility.

One limitation of this study would be the fact of using adult normal adrenals as control. However, qPCR results were confirmed by IHC making this bias less likely. In addition, of note, the P53 p.R337H mutation may define a specific subtype of childhood ACTs and may not reflect the whole spectrum of the disease. Nevertheless, it is important to mention that the expression of all Wnt/ $\beta$-catenin pathway genes analyzed in our study was not different in ACTs with or without the P53 p.R337H mutation.

In summary, CTNNB1 activating mutations are not common in childhood ACTs but appear to be associated with poor prognosis. Nevertheless, most childhood ACTs exhibit accumulation of $\beta$ catenin and its target, WISP2. Interestingly, these tumors exhibit reduced expression of Wnt inhibitor genes, DKK3, SFRP1 and AXIN1. Thus, although our data on Wnt pathway seem complex, the sum of these main results suggests the hypothesis of Wnt pathway activation. Further research is needed to strengthen these findings. Therefore, besides CTNNB1 mutations, other genetic events affecting the Wnt/ $\beta$-catenin pathway may be involved in childhood adrenocortical tumorigenesis. 


\section{REFERENCES}

1. Sandrini R, Ribeiro RC, DeLacerda L 1997 Childhood adrenocortical tumors. J Clin Endocrinol Metab 82:2027-2031

2. Almeida MQ, Latronico AC 2007 The molecular pathogenesis of childhood adrenocortical tumors. Horm Metab Res 39:461-466

3. Ribeiro RC, Michalkiewicz EL, Figueiredo BC, DeLacerda L, Sandrini F, Pianovsky MD, Sampaio G, Sandrini R 2000 Adrenocortical tumors in children. Braz J Med Biol Res 33:12251234

4. Latronico AC, Pinto EM, Domenice S, Fragoso MC, Martin RM, Zerbini MC, Lucon AM, Mendonca BB 2001 An inherited mutation outside the highly conserved DNA-binding domain of the p53 tumor suppressor protein in children and adults with sporadic adrenocortical tumors. J Clin Endocrinol Metab 86:4970-4973

5. Sandrini F, Villani DP, Tucci S, Moreira AC, de Castro M, Elias LL 2005 Inheritance of R337H p53 gene mutation in children with sporadic adrenocortical tumor. Horm Metab Res 37:231235

6. Giordano TJ, Kuick R, Else T, Gauger PG, Vinco M, Bauersfeld J, Sanders D, Thomas DG, Doherty G, Hammer G 2009 Molecular classification and prognostication of adrenocortical tumors by transcriptome profiling. Clin Cancer Res 15:668-676

7. de Reynies A, Assie G, Rickman DS, Tissier F, Groussin L, Rene-Corail F, Dousset B, Bertagna X, Clauser E, Bertherat J 2009 Gene expression profiling reveals a new classification of adrenocortical tumors and identifies molecular predictors of malignancy and survival. J Clin Oncol 27:1108-1115

8. West AN, Neale GA, Pounds S, Figueredo BC, Rodriguez Galindo C, Pianovski MA, Oliveira Filho AG, Malkin D, Lalli E, Ribeiro R, Zambetti GP 2007 Gene expression profiling of childhood adrenocortical tumors. Cancer Res 67:600-608

9. Pianovski MA, Cavalli LR, Figueiredo BC, Santos SC, Doghman M, Ribeiro RC, Oliveira AG, Michalkiewicz E, Rodrigues GA, Zambetti G, Haddad BR, Lalli E 2006 SF-1 overexpression in childhood adrenocortical tumours. Eur J Cancer 42:1040-1043

10. Figueiredo BC, Cavalli LR, Pianovski MA, Lalli E, Sandrini R, Ribeiro RC, Zambetti G, DeLacerda L, Rodrigues GA, Haddad BR 2005 Amplification of the steroidogenic factor 1 gene in childhood adrenocortical tumors. J Clin Endocrinol Metab 90:615-619

11. Almeida MQ, Fragoso MC, Lotfi CF, Santos MG, Nishi MY, Costa MH, Lerario AM, Maciel CC, Mattos GE, Jorge AA, Mendonca BB, Latronico AC 2008 Expression of insulin-like growth factor-II and its receptor in pediatric and adult adrenocortical tumors. J Clin Endocrinol Metab 93:3524-3531

12. Suwa T, Chen M, Hawks CL, Hornsby PJ 2003 Zonal expression of dickkopf-3 and components of the Wnt signalling pathways in the human adrenal cortex. J Endocrinol 178:149-158

13. Chen X, Yang J, Evans PM, Liu C 2008 Wnt signaling: the good and the bad. Acta Biochim Biophys Sin (Shanghai) 40:577-594

14. Heikkila M, Peltoketo H, Leppaluoto J, Ilves M, Vuolteenaho O, Vainio S 2002 Wnt-4 deficiency alters mouse adrenal cortex function, reducing aldosterone production. Endocrinology 143:4358-4365

15. El Wakil A, Lalli E 2011 The Wnt/beta-catenin pathway in adrenocortical development and cancer. Mol Cell Endocrinol 332:32-37

16. Mao B, Niehrs C 2003 Kremen2 modulates Dickkopf2 activity during Wnt/LRP6 signaling. Gene 302:179-183

17. Lavergne E, Hendaoui I, Coulouarn C, Ribault C, Leseur J, Eliat PA, Mebarki S, Corlu A, Clement B, Musso $\mathbf{O}$ Blocking Wnt signaling by SFRP-like molecules inhibits in vivo cell proliferation and tumor growth in cells carrying active beta-catenin. Oncogene 30:423-433 
18. Stratakis CA, Boikos SA 2007 Genetics of adrenal tumors associated with Cushing's syndrome: a new classification for bilateral adrenocortical hyperplasias. Nat Clin Pract Endocrinol Metab 3:748-757

19. Tadjine M, Lampron A, Ouadi L, Bourdeau I 2008 Frequent mutations of beta-catenin gene in sporadic secreting adrenocortical adenomas. Clin Endocrinol (Oxf) 68:264-270

20. Tissier F, Cavard C, Groussin L, Perlemoine K, Fumey G, Hagnere AM, Rene-Corail F, Jullian E, Gicquel C, Bertagna X, Vacher-Lavenu MC, Perret C, Bertherat J 2005 Mutations of betacatenin in adrenocortical tumors: activation of the Wnt signaling pathway is a frequent event in both benign and malignant adrenocortical tumors. Cancer Res 65:7622-7627

21. Gaujoux S, Tissier F, Groussin L, Libe R, Ragazzon B, Launay P, Audebourg A, Dousset B, Bertagna X, Bertherat J $2008 \mathrm{Wnt} /$ beta-catenin and 3',5'-cyclic adenosine 5'monophosphate/protein kinase A signaling pathways alterations and somatic beta-catenin gene mutations in the progression of adrenocortical tumors. J Clin Endocrinol Metab 93:4135-4140

22. Bonnet S, Gaujoux S, Launay P, Baudry C, Chokri I, Ragazzon B, Libe R, Rene-Corail F, Audebourg A, Vacher-Lavenu MC, Groussin L, Bertagna X, Dousset B, Bertherat J, Tissier F $2010 \mathrm{Wnt} /\{$ beta\}-Catenin Pathway Activation in Adrenocortical Adenomas Is Frequently due to Somatic CTNNB1-Activating Mutations, Which Are Associated with Larger and Nonsecreting Tumors: A Study in Cortisol-Secreting and -Nonsecreting Tumors. J Clin Endocrinol Metab

23. Ragazzon B, Libe R, Gaujoux S, Assie G, Fratticci A, Launay P, Clauser E, Bertagna X, Tissier F, de Reynies A, Bertherat J 2010 Transcriptome analysis reveals that p53 and \{beta\}-catenin alterations occur in a group of aggressive adrenocortical cancers. Cancer Res 70:8276-8281

24. Gaujoux S, Grabar S, Fassnacht M, Ragazzon B, Launay P, Libe R, Chokri I, Audebourg A, Royer B, Sbiera S, Vacher-Lavenu MC, Dousset B, Bertagna X, Allolio B, Bertherat J, Tissier F 2010 \{beta\}-catenin activation is associated with specific clinical and pathological characteristics and a poor outcome in adrenocortical carcinoma. Clin Cancer Res

25. Pusantisampan T, Sangkhathat S, Kayasut K, Kanngurn S, Jaruratanasirikul S, Chotsampancharoen $\mathbf{T}$, Kritsaneepaiboon $\mathbf{S}$ Cushing's syndrome in an infant secondary to malignant adrenocortical tumors with somatic mutation of beta-catenin. Pediatr Dev Pathol $13: 238-242$

26. Berthon A, Sahut-Barnola I, Lambert-Langlais S, de Joussineau C, Damon-Soubeyrand C, Louiset E, Taketo MM, Tissier F, Bertherat J, Lefrancois-Martinez AM, Martinez A, Val P Constitutive beta-catenin activation induces adrenal hyperplasia and promotes adrenal cancer development. Hum Mol Genet 19:1561-1576

27. Tsuji T, Miyazaki M, Sakaguchi M, Inoue Y, Namba M 2000 A REIC gene shows downregulation in human immortalized cells and human tumor-derived cell lines. Biochem Biophys Res Commun 268:20-24

28. You A, Fokas E, Wang LF, He H, Kleb B, Niederacher D, Engenhart-Cabillic R, An HX 2010 Expression of the Wnt antagonist DKK3 is frequently suppressed in sporadic epithelial ovarian cancer. J Cancer Res Clin Oncol

29. Yue W, Sun Q, Dacic S, Landreneau RJ, Siegfried JM, Yu J, Zhang L 2008 Downregulation of Dkk3 activates beta-catenin/TCF-4 signaling in lung cancer. Carcinogenesis 29:84-92

30. Zhang LY, Ye J, Zhang F, Li FF, Li H, Gu Y, Liu F, Chen GS, Li Q 2009 Axin induces cell death and reduces cell proliferation in astrocytoma by activating the p53 pathway. Int J Oncol 35:25-32

31. Yang LH, Xu HT, Han Y, Li QC, Liu Y, Zhao Y, Yang ZQ, Dong QZ, Miao Y, Dai SD, Wang EH 2010 Axin downregulates TCF-4 transcription via beta-catenin, but not p53, and inhibits the proliferation and invasion of lung cancer cells. Mol Cancer 9:25

32. Ciznadija D, Tothill R, Waterman ML, Zhao L, Huynh D, Yu RM, Ernst M, Ishii S, Mantamadiotis T, Gonda TJ, Ramsay RG, Malaterre J 2009 Intestinal adenoma formation 
and MYC activation are regulated by cooperation between MYB and Wnt signaling. Cell Death Differ 16:1530-1538

33. Bourdeau I, Antonini SR, Lacroix A, Kirschner LS, Matyakhina L, Lorang D, Libutti SK, Stratakis CA 2004 Gene array analysis of macronodular adrenal hyperplasia confirms clinical heterogeneity and identifies several candidate genes as molecular mediators. Oncogene 23:1575-1585

34. Iliopoulos D, Bimpaki El, Nesterova M, Stratakis CA 2009 MicroRNA signature of primary pigmented nodular adrenocortical disease: clinical correlations and regulation of Wnt signaling. Cancer Res 69:3278-3282

35. Szabo PM, Tamasi V, Molnar V, Andrasfalvy M, Tombol Z, Farkas R, Kovesdi K, Patocs A, Toth M, Szalai C, Falus A, Racz K, Igaz P 2010 Meta-analysis of adrenocortical tumour genomics data: novel pathogenic pathways revealed. Oncogene 29:3163-3172

36. Szabo PM, Racz $\mathbf{K}$, Igaz $\mathbf{P}$ Underexpression of C-myc in Adrenocortical Cancer: A Major Pathogenic Event? Horm Metab Res

37. Okuyama H, Endo H, Akashika T, Kato K, Inoue M 2010 Downregulation of c-MYC protein levels contributes to cancer cell survival under dual deficiency of oxygen and glucose. Cancer Res 70:10213-10223

38. Doghman M, El Wakil A, Cardinaud B, Thomas E, Wang J, Zhao W, Peralta-Del Valle MH, Figueiredo BC, Zambetti GP, Lalli E 2010 Regulation of insulin-like growth factor-mammalian target of rapamycin signaling by microRNA in childhood adrenocortical tumors. Cancer Res 70:4666-4675

39. Gehrke I, Gandhirajan RK, Kreuzer KA 2009 Targeting the WNT/beta-catenin/TCF/LEF1 axis in solid and haematological cancers: Multiplicity of therapeutic options. Eur J Cancer 45:2759-2767 
Figure 1. A, Kaplan-Meier plot of overall survival according to disease stage at the time of diagnosis of pediatric patients with adrenocortical tumor. B-D, Kaplan-Meier plot shows the overall survival in pediatric patients with adrenocortical tumors according to the level of expression of Wnt-related genes: SFRP1 (B), WNT4 (C) and TCF7 (D).

Figure 2. Expression of Wnt/ $\beta$-catenin pathway genes in childhood adrenocortical tumors (ACT). CTNNB1 (G) for ACT in comparison to normal adrenal glands. All results are normalized to the housekeeping genes $\beta$-actin, TBP, and GUSB and are expressed as fold change in relation to the expression observed in normal adrenal glands.

Figure 3. Immunohistochemical (IHC) staining for Wnt-related genes and P53 in childhood adrenocortical tumors and normal adjacent tissue. The nuclear and/or cytoplasmic labeling was developed with NovoRed (red) and counterstained with Harri's Hematoxylin (blue). $\beta$-catenin: nuclear (A; arrows - patient 59 ) and diffuse cytoplasmic staining (B - patient 23). P53: nuclear (D; arrows patient 55) and strong cytoplasmic staining ( $\mathrm{E}$ - patient 22). DKK3: weak ( $\mathrm{G}$ - patient 59) and strong

$475(\mathrm{H}-$ patient 37) cytoplasmic staining. Focal expression of MYC (J; arrow - patient 23) and diffuse 476 expression of WISP2 (K - patient 23). C, F, I, and L represent normal adjacent adrenal cortex. All 477 slides are shown in magnification $\times 400$. 
Figure 1
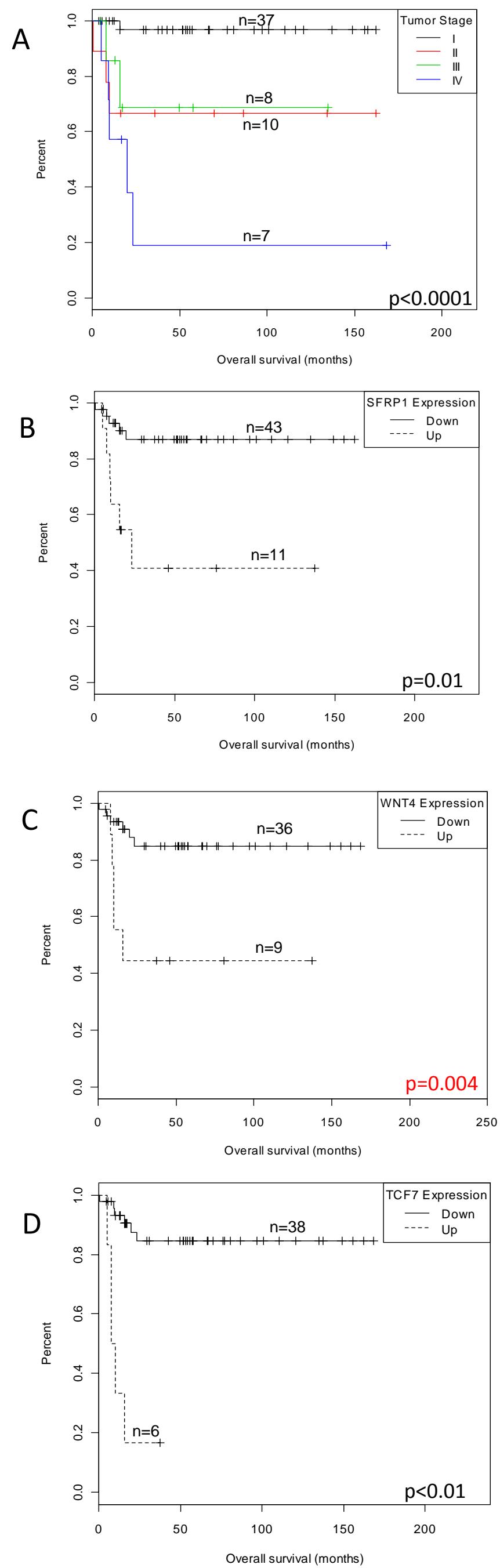
Figure 2

A

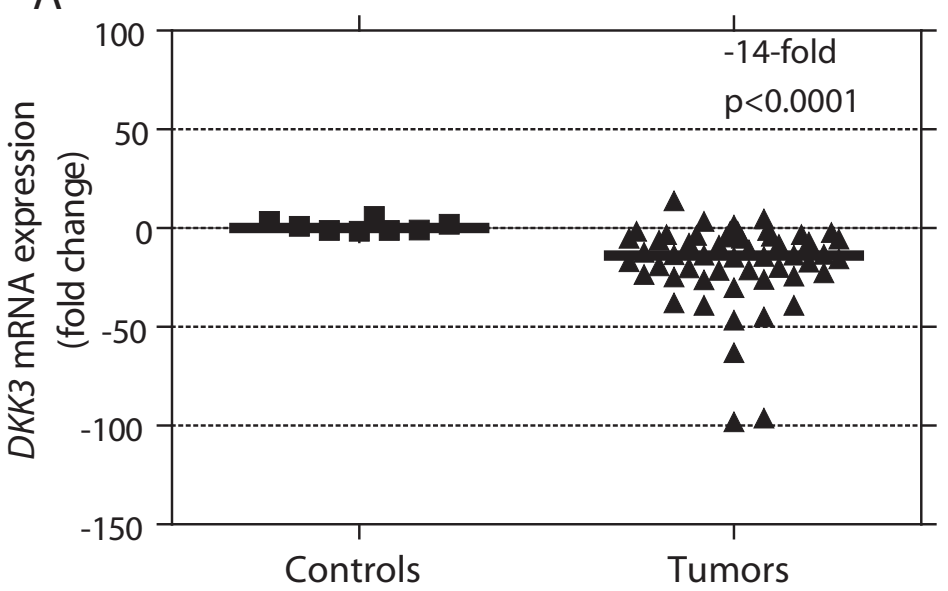

C

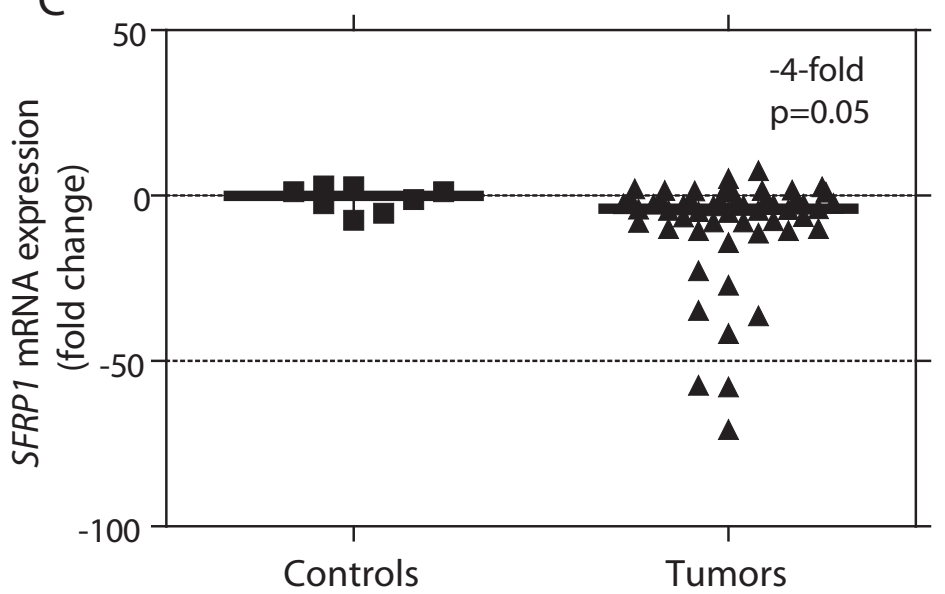

E

वे

\%

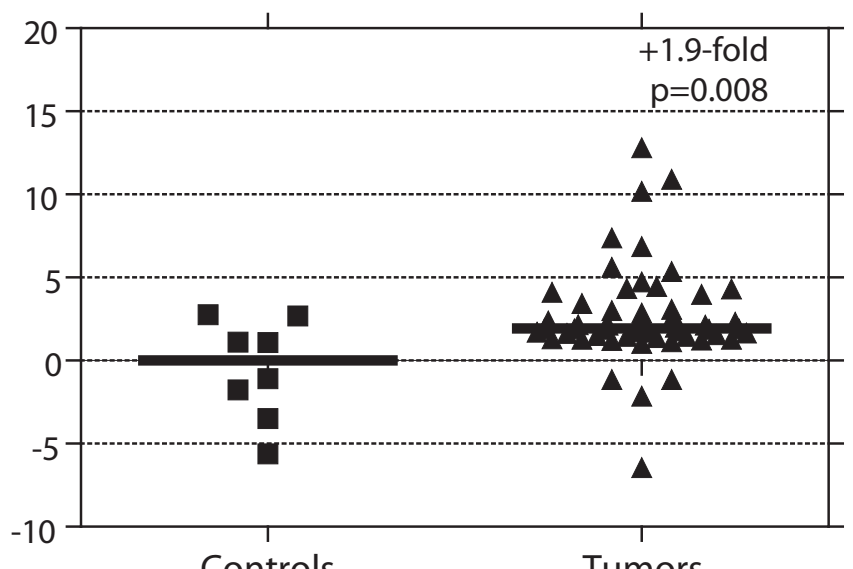

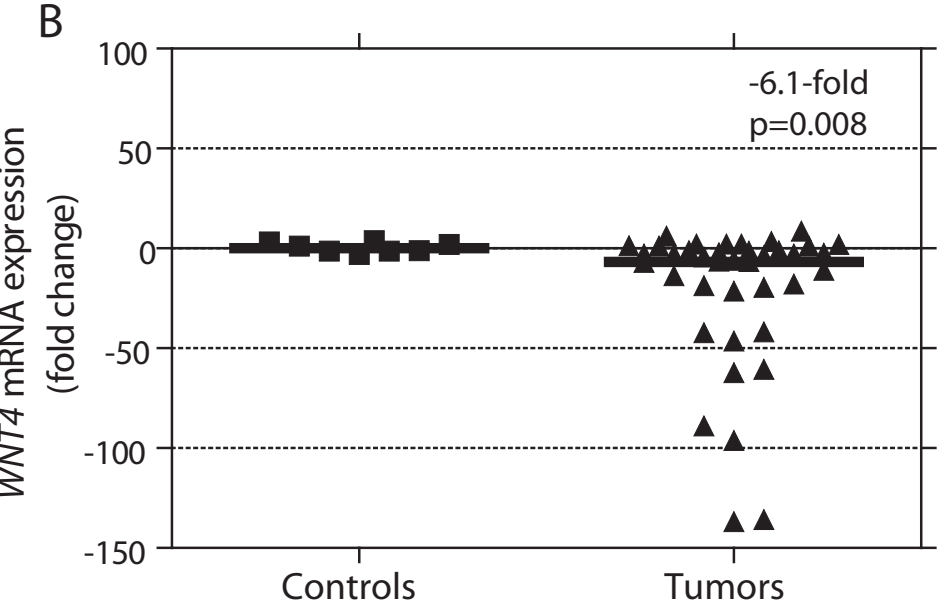

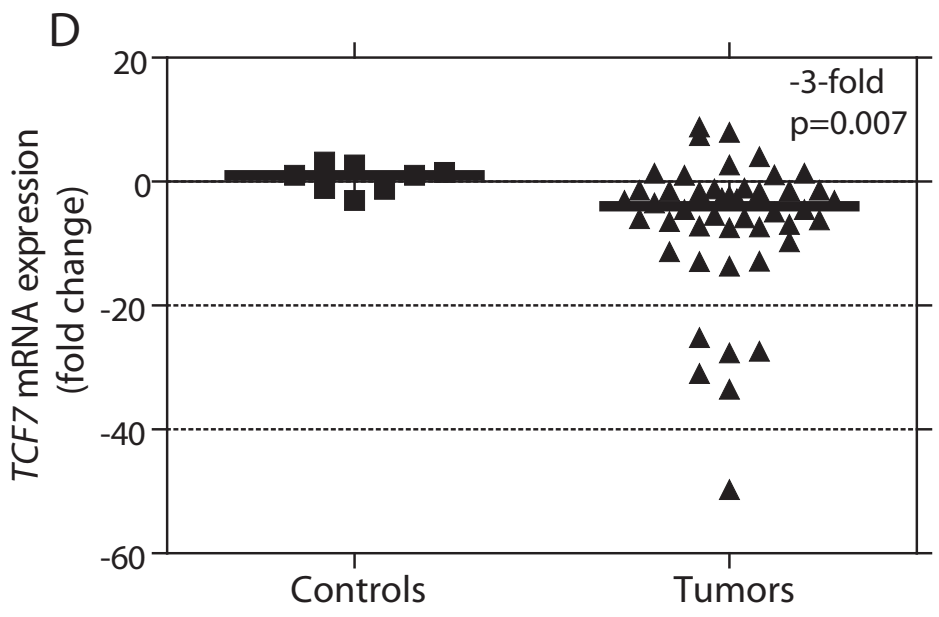

F

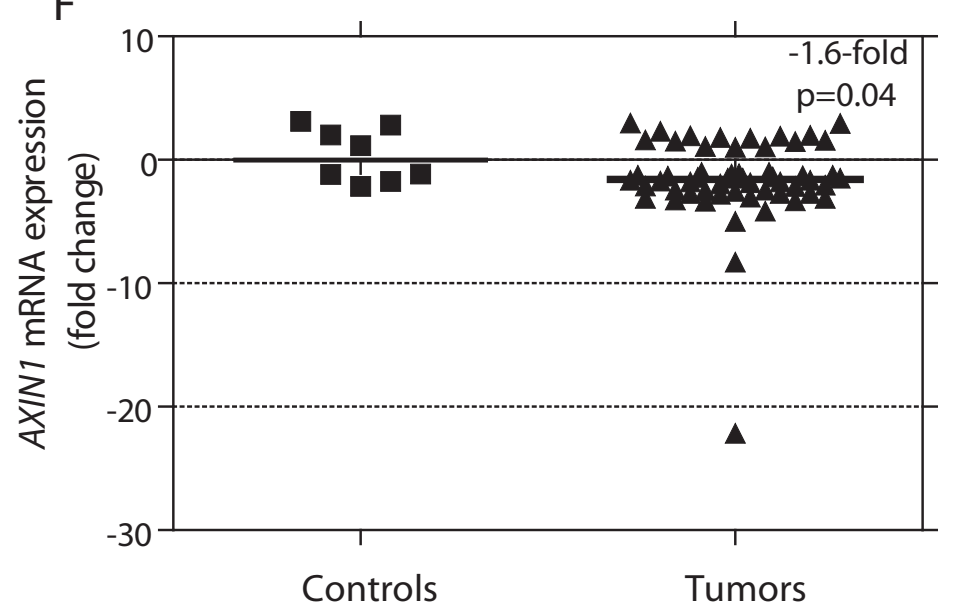

Controls

Tumors 
Figure 3
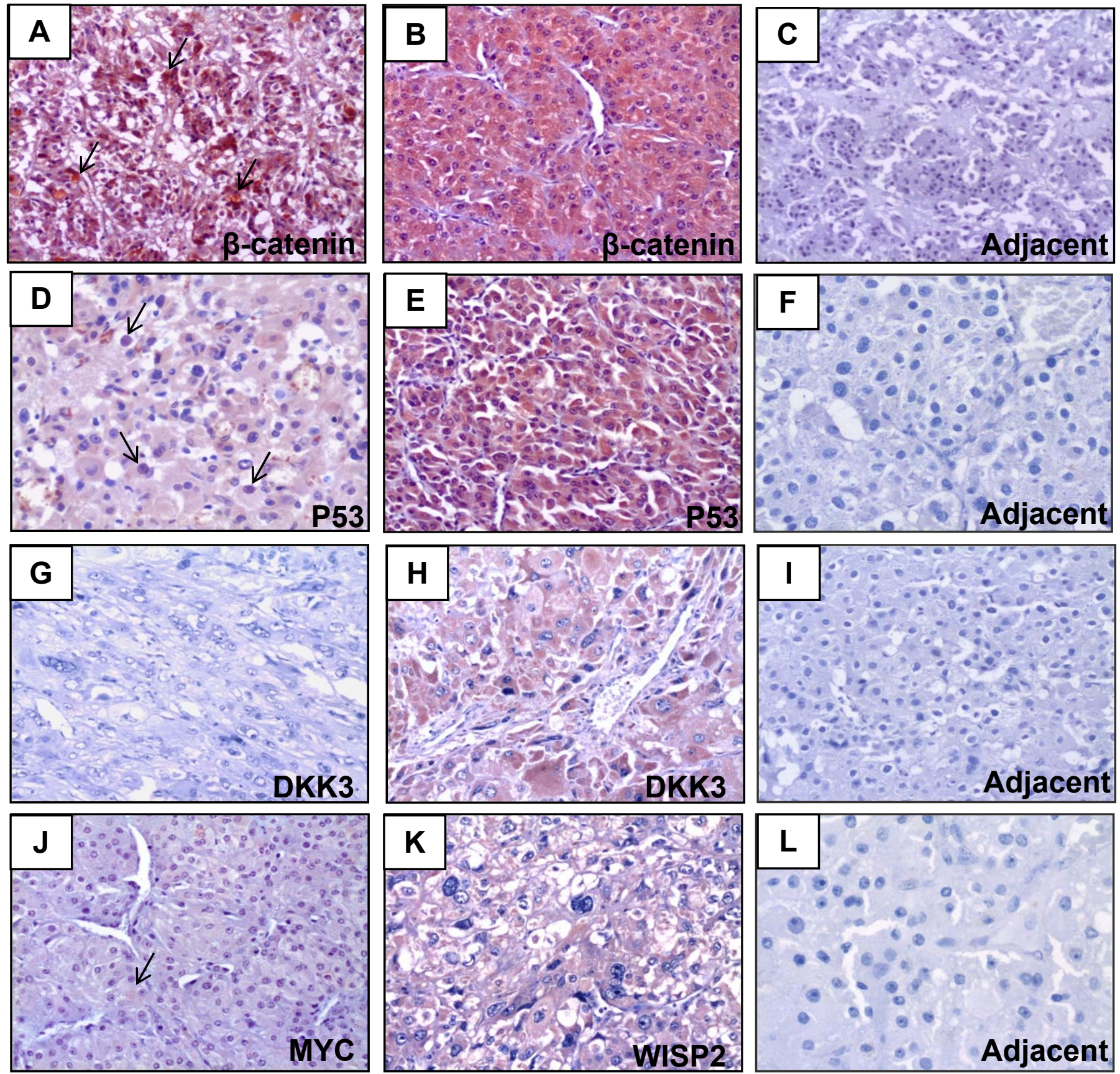
Figure 4. Tumor stage and outcome in a subset of childhood ACTs $(\mathrm{n}=25)$ according to CTNNB1/ $\beta$-catenin and TP53/P53 abnormalities.

\begin{tabular}{|c|c|c|c|c|c|c|c|c|c|c|c|c|c|c|c|c|c|c|c|c|c|c|c|c|c|}
\hline Tumor ID & 22 & 1 & 8 & 25 & 27 & 16 & 13 & 9 & 21 & 37 & 20 & 33* & 23* & $18^{\mathrm{a}}$ & $29^{b}$ & 43 & 47 & $51^{\mathrm{c}}$ & 53 & 55 & $57^{\mathrm{d}}$ & 59* & 61 & 62 & 58 \\
\hline Diseasestage & I & I & I & I & I & I & I & I & I & I & I & I & I & I & I & II & II & III & III & III & IV & IV & IV & IV & IV \\
\hline Death & & & & & & & & & & & & & LF & & & & & & & & & LF & & & \\
\hline$\beta$-cateninIHC & & & & & & & & & & & NA & & & & & & & & & & & & & & \\
\hline $\begin{array}{c}C T N N B 1 M u t \\
\text { ation }\end{array}$ & & & & & & & & & & & & & & & & & & & & & & & & & \\
\hline P53 IHC & & & & & & & & & & & & & & & & & & & & & & & & & \\
\hline TP53Mutation & & & & & & & & & & & & & & & & & & & & & & & & & \\
\hline
\end{tabular}

Tumor ID as presented in Table 1. Presence of death, TP53 and CTNNB1 mutation (black rectangles); LF:lost to follow up 15.8and 16.8 months after surgery, respectively.NA: not available. CTNNB1 mutations: ${ }^{\mathrm{a}}$ p.S45F; ${ }^{\mathrm{b}}$ p.S33F; ${ }^{\mathrm{c}}$ p.S37P; ${ }^{\mathrm{d}}$ p.S45P.*: nuclear $\beta$-catenin accumulation.

P53 and $\beta$-catenin immunohistochemistry (IHC). Negative: white; +: light gray; ++: dark gray, and +++: black.

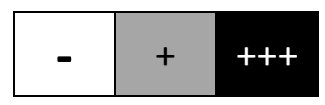


Table 1. Clinical, pathological, molecular features and outcome in childhood ACTs.

\begin{tabular}{|c|c|c|c|c|c|c|c|c|c|c|}
\hline ID & Sex & $\begin{array}{c}\begin{array}{c}\text { Age } \\
\text { (months) }\end{array} \\
\end{array}$ & $\begin{array}{c}\text { Clinical } \\
\text { presentation }\end{array}$ & $\begin{array}{c}\text { Tumor } \\
\text { stage }\end{array}$ & $\begin{array}{c}\text { Recorrence/ } \\
\text { Metastasis }\end{array}$ & Treatment & $\begin{array}{c}\text { p.R337H } \\
\text { P53 }\end{array}$ & $\begin{array}{l}\beta \text {-catenin } \\
\text { mutation }\end{array}$ & $\begin{array}{c}\text { Overall } \\
\text { survival }\end{array}$ & Death \\
\hline 1 & $\mathrm{~F}$ & 5 & $\mathrm{M}$ & I & No & $\mathrm{S}$ & Yes & No & 162.2 & No \\
\hline 2 & $\mathrm{~F}$ & 5 & $\mathrm{M}^{*}$ & I & No & S & Yes & No & 53.2 & No \\
\hline 3 & M & 5 & $\mathrm{~V}$ & I & No & $\mathrm{S}$ & Yes & No & 76.9 & No \\
\hline 4 & M & 9 & M & I & No & S & Yes & No & 46 & No \\
\hline 5 & $\mathrm{~F}$ & 10 & $\mathrm{M}^{*}$ & I & No & S & Yes & No & 4.5 & No \\
\hline 6 & $\mathrm{~F}$ & 10 & $\mathrm{~V}$ & I & No & S & Yes & No & 57.3 & No \\
\hline 7 & $\mathrm{~F}$ & 10 & V & I & No & $\mathrm{S}$ & Yes & No & 51.7 & No \\
\hline 8 & M & 11 & V & I & No & $\mathrm{S}$ & Yes & No & 157 & No \\
\hline 9 & M & 11 & M & I & No & $\mathrm{S}$ & No & No & 148.9 & No \\
\hline 10 & $\mathrm{~F}$ & 12 & V & I & No & S & Yes & No & 66.9 & No \\
\hline 11 & $\mathrm{~F}$ & 12 & V & I & No & S & Yes & No & 29.3 & No \\
\hline 12 & $\mathrm{~F}$ & 13 & V & I & No & S & Yes & No & 54.2 & No \\
\hline 13 & $\mathrm{~F}$ & 16 & M & I & No & $\mathrm{S}$ & Yes & No & 120.9 & No \\
\hline 14 & $\mathrm{~F}$ & 16 & V & I & No & SC & Yes & No & 3.4 & No \\
\hline 15 & $\mathrm{~F}$ & 16 & V & I & No & $\mathrm{S}$ & Yes & No & 30.6 & No \\
\hline 16 & $\mathrm{~F}$ & 17 & M & I & No & S & Yes & No & 11.7 & No \\
\hline 17 & $\mathrm{~F}$ & 17 & V & I & No & $\mathrm{S}$ & Yes & No & 116.2 & No \\
\hline 18 & $\mathrm{~F}$ & 17 & V & I & No & $\mathrm{S}$ & Yes & p.S45F & 37.5 & No \\
\hline 19 & $\mathrm{~F}$ & 18 & V & I & Yes & $\mathrm{S}$ & Yes & No & 97.0 & No \\
\hline 20 & M & 20 & M & I & Yes & SC & Yes & No & 155.9 & No \\
\hline 21 & $\mathrm{~F}$ & 20 & M & I & No & $\mathrm{S}$ & Yes & No & 12.5 & No \\
\hline 22 & $\mathrm{~F}$ & 22 & $\mathrm{~V}$ & I & No & S & Yes & No & 55.5 & No \\
\hline 23 & $\mathrm{~F}$ & 22 & $\mathrm{M}^{*}$ & I & No & $\mathrm{S}$ & Yes & No & 15.8 & LF \\
\hline 24 & $\mathrm{~F}$ & 22 & M & I & No & S & Yes & No & 7.7 & No \\
\hline 25 & $\mathrm{~F}$ & 23 & M & I & No & $\mathrm{S}$ & Yes & No & 51.6 & No \\
\hline 26 & $\mathrm{~F}$ & 25 & V & I & No & S & Yes & No & 42.6 & No \\
\hline 27 & $\mathrm{~F}$ & 28 & V & I & No & S & No & No & 39.8 & No \\
\hline 28 & $\mathrm{~F}$ & 29 & V & I & No & S & Yes & No & 51.4 & No \\
\hline 29 & $\mathrm{~F}$ & 29 & V & I & Yes & S & Yes & p.S33F & 15.7 & Yes \\
\hline 30 & $\mathrm{~F}$ & 33 & V & I & No & S & Yes & No & 5.6 & No \\
\hline 31 & M & 34 & M & I & No & $\mathrm{S}$ & Yes & No & 101 & No \\
\hline 32 & M & 36 & M & I & Yes & SC & Yes & No & 66.5 & No \\
\hline 33 & $\mathrm{~F}$ & 36 & M & I & No & $\mathrm{S}$ & Yes & No & 92.4 & No \\
\hline 34 & $\mathrm{~F}$ & 38 & M & I & No & S & Yes & No & 9.8 & No \\
\hline 35 & $\mathrm{~F}$ & 44 & V & I & No & S & Yes & No & 110.4 & No \\
\hline 36 & $\mathrm{~F}$ & 73 & M & I & No & S & No & No & 137.3 & No \\
\hline 37 & $\mathrm{~F}$ & 145 & M & I & No & S & No & No & 80.6 & No \\
\hline 38 & M & 12 & V & II & No & S & Yes & No & 16.0 & No \\
\hline 39 & $\mathrm{~F}$ & 13 & V & II & No & S & No & No & 86.5 & No \\
\hline 40 & $\mathrm{~F}$ & 16 & $\mathrm{~V}^{* *}$ & II & No & S & Yes & No & 0.4 & Yes \\
\hline 41 & $\mathrm{~F}$ & 17 & V & II & No & $\mathrm{S}$ & Yes & No & 69.8 & No \\
\hline 42 & M & 27 & $\mathrm{M}^{*}$ & II & No & S & Yes & No & 162.2 & No \\
\hline 43 & M & 72 & M & II & Yes & SC & Yes & No & 7.7 & Yes \\
\hline 44 & $\mathrm{~F}$ & 92 & V & II & No & $\mathrm{S}$ & Yes & No & 35.7 & No \\
\hline 45 & $\mathrm{~F}$ & 108 & M & II & No & $\mathrm{S}$ & Yes & No & 9.9 & Yes \\
\hline 46 & $\mathrm{~F}$ & 187 & V & II & No & $\mathrm{S}$ & No & No & 75.8 & No \\
\hline 47 & $\mathrm{~F}$ & 137 & $\mathrm{C}^{*}$ & II & Yes & SC & No & No & 134.5 & No \\
\hline 48 & $\mathrm{~F}$ & 13 & V & III & No & $\mathrm{S}$ & Yes & No & 13 & No \\
\hline 49 & $\mathrm{~F}$ & 16 & $\mathrm{~V}^{* *}$ & III & No & S & Yes & No & 17 & No \\
\hline 50 & F & 19 & $\mathrm{~V}$ & III & No & S & Yes & No & 49.6 & No \\
\hline 51 & $\mathrm{~F}$ & 19 & $\mathrm{~V}^{* *}$ & III & No & S & Yes & p.S37P & 7.6 & Yes \\
\hline 52 & F & 20 & $\mathrm{M}$ & III & No & SC & Yes & No & 4.5 & LF \\
\hline 53 & $\mathrm{~F}$ & 29 & V & III & No & SC & Yes & No & 134.8 & No \\
\hline 54 & M & 52 & V & III & No & $\mathrm{S}$ & Yes & No & 57.6 & No \\
\hline 55 & $\mathrm{~F}$ & 66 & M & III & Yes & SC & Yes & No & 15.5 & Yes \\
\hline 56 & M & 13 & $\mathrm{~V}^{* *}$ & IV & No & $\mathrm{S}$ & Yes & No & 168.4 & No \\
\hline 57 & M & 33 & $\mathrm{~V}$ & IV & Yes & SC & Yes & p.S45P & 4.9 & Yes \\
\hline 58 & $\mathrm{~F}$ & 96 & $\mathrm{M}^{*}$ & IV & Yes & $\mathrm{S}$ & Yes & No & 23.3 & Yes \\
\hline 59 & $\mathrm{~F}$ & 84 & $\mathrm{~V}$ & IV & Yes & SC & Yes & No & 16.8 & LF \\
\hline 60 & $\mathrm{~F}$ & 94 & $\mathrm{M}^{* *}$ & IV & Yes & $\mathrm{S}$ & Yes & No & 19.9 & Yes \\
\hline 61 & $\mathrm{~F}$ & 180 & M & IV & Yes & SC & Yes & No & 9.8 & Yes \\
\hline 62 & M & 185 & C & IV & Yes & SC & Yes & No & 9 & Yes \\
\hline
\end{tabular}

Abbreviations: F, female; M, male; S, surgical ressection only; SC, surgical ressection plus chemotherapy/mitotane; LF, lost to follow up. Age and overall survival time are expressed in months. V, Virilizing tumor; C, Cushing's syndrome; M, Mixed Virilizing plus Cushing's syndrome; M*, Virilizing plus Subclinical Cushing; C*, Subclinical Cushing, **, Hypertension. 